\title{
SITUATION ANALYSIS
}

\author{
OF
}

\section{AFGHAN CHILDREN AND WOMEN}

UNICEF

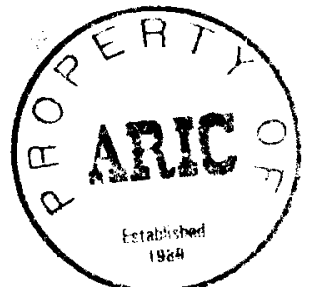




\section{TABLE OF CONTENTS}

Page

Map of Afghanistan

Abbreviations

Afghanistan: Land, People, Economy

Preface

Chapter 1 1978-1991 Civil Strife, Dislocation, and Prospects for the Future

Chapter 2 Governance Issues

Chapter 3 The Economic Backdrop

Chapter 4 Population and Its Implications

Chapter 5 Health Situation of Afghan Children and Women

Chapter 6 Nutritional Situation

Chapter 7 Food Security

Chapter 8 Educating Children and Women

Chapter 9 Children and Women in Especially Difficult Circumstances

Chapter 10 Problems, Constraints and Opportunities

\section{ANNEXES}

Annex I Access to Basic Education

Annex II Maps

Annex III Tables and Charts

Annex IV NGOs Operating Cross-Border From Afghanistan

Annex V Notes on Sources of Population Information

Bibliography 


\section{ABBREVIATIONS}

\begin{tabular}{ll} 
ACBAR & Agency Coordinating Body for Afghan Relief \\
ADS & Afghan Demographic Survey \\
AIG & Afghan Interim Government \\
BHS & Basic Health Services \\
BHU & Basic Health Unit \\
CDC & Centers for Disease Control \\
CMC & Coordination of Medical Committees (Peshawar) \\
CSO & Central Statistics Office \\
DDC & Diarrhoeal Disease Control \\
ECA & Educational Centre of the Alliance \\
EPI & Expanded Programme of Immunization \\
DAI & Development Alternatives, Inc. \\
FAO & Food and Agriculture Organization \\
HABITAT & United Nations Centre for Human Settlement \\
ICRC & International Committee of the Red Cross \\
IRC & International Rescue Committee \\
LHV & Lady Health Visitor \\
MOPH & Ministry of Public Health \\
MSF & Medicin san Frontieres \\
MSH & Management Sciences for Health \\
NWFP & North West Frontier Province \\
NGO & Non-Governmental Organization \\
OPS & Office of Project Services (UNDP) \\
ORS & Oral Rehydration Solution \\
ORT & Oral Rehydration Therapy \\
PHI & Public Health Institute (MOPH, Afghanistan) \\
SCA & Swedish Committee for Afghanistan \\
TBA & Traditional Birth Attendant \\
UNDP & United Nations Development Programme \\
UNFPA & United Nations Fund for Population Activities \\
UNHCR & United Nations High Commission for Refugees \\
UNICEF & United Nations Children's Fund \\
UNIDATA & A project of UNDP/OPS and UNOCA \\
UNOCA & Office of the Coordinator for UN Humanitarian and Economic Assistance \\
& Programmes Relating to Afghanistan \\
UNRISD & United Nations Research Institute for Social Development \\
USAID & United States Agency for International Development \\
WFP & World Food Program \\
WHO & World Health Organization \\
& \\
\hline
\end{tabular}




\section{AFGHANISTAN}

LAND - Afghanistan is a small, landlocked nation bordered by Iran in the west, Pakistan in the south and east, the USSR in the north and China on a small section of the Wakhan corridor in the northeast. Geography has isolated Afghanistan from economic and social changes occurring in the rest of the world and shapes internal climate, economy and communications. The Hindu Kush mountains dominate its 653,000 square kilometers. The severe continental climate brings hot dry summers and cold winters. Precipitation, ranging from $3.2 \mathrm{~cm}$. in the deserts to over $58 \mathrm{~cm}$. in the mountains comes mostly in the winter and as snow in the higher altitudes, feeding the country's five major river systems which provide water for irrigation. The nearest seaport is Karachi, 1600 kilometers from Kabul (L. Dupree, 1978).

PEOPLE - The total number of Afghans is estimated at 17.4 million; 12.9 are inside the country and approximately 4.5 million are refugees in Pakistan and Iran. An estimated 1-1.5 million people have been killed in the ongoing civil war, which also leaves behind large numbers of disabled, orphans and widows. Infant mortality rates are among the highest in the world, estimated at 169 per 1000 overall. It is thought to be higher in some rural areas but lower in Kabul and in Pakistan refugee areas. Fertility rates are high (6.9) and thought to have increased among the refugee population. Literacy rates are low; only $1 \%$ for rural women in the 1970s and not significantly different in the 1990s. The overall literacy rate is estimated at $24 \%$ and is higher among both men and women in Kabul and other urban areas.

ECONOMY - Afghanistan is a least developed country. The per capita GDP was estimated at US\$180 in 1978/79. Current estimates of per capita GDP range between US\$69 and 200. GDP is estimated as having decreased at a rate of 1 to $4 \%$ between 1978 and the present. Agriculture is the principal sector, in 1989/90 producing an estimated 46\% of GDP. War has destroyed or damaged much of Afghanistan's infrastructure and productive capacity, including irrigation systems, roads, schools, health facilities and housing. The country's limited forests are being consumed at a rate ten times their capacity for regeneration. 


\section{PREFACE}

Afghanistan is one of the few developing countries where the child survival and development innovations of the past decade have had little impact. Thirteen years of civil strife have devastated the economy and capacity for development, and have weakened the social compact. Thirteen years ago the indicators of the situation of Afghan women and children were among the worst in the world. Today, little has changed. Thirteen years of destruction, massive movements of people as internal and external refugees, the trauma of war, and the struggle for physical survival have affected every Afghan. The country has lost much of its skilled human resources. The nature of urban life has diverged further from rural practice. Women in cities have altered status had have led to assume additional responsibilities. Rural Afghans, whether in traditional rural homes or as refugees in Pakistan and Iran, have been exposed to new experiences, contacts with Afghans had foreigners from outside their gawm or tribe, and to new ideas. Children everywhere know the meaning of war. They have been thrust from isolation into global relations. International radio reaches where it was never heard before. Afghanistan will never be the same.

The Situation Analysis has been prepared as Afghanistan is still at war, but perhaps poised on the brink of a peace process. It is the circumstances of prolonged war and continuing uncertainty that make this analysis different from other. Normally UNICEF will collaborate with colleagues in Government and with universities and research institutions to bring together data on the situation of children and women. In Afghanistan this is not yet possible. There is little reliable data. National institutions for data collection are fragmented and disabled by lack of funding and of access to information. Security limits new attempts to gather data.

Sound data may not exist, but the needs of Afghan children and women go on. We must carry on with the information that is available. This situation was first prepared as a desk study in late 1989. It has been expanded by consultant visits and interviews in Kabul and Peshawar in late 1991. Available information on Afghanistan is sometimes anecdotal, fragmentary, methodologically weak and even conflicting; this analysis attempts therefore, to recognize where the information is weak and to draw attention to generalizations supported by several sets of information. Therefore it should be read as a first step and not the final work in developing baseline data on children and women. It will be successful if the questions and issues it raises spark discussion and action, leading UNICEF and the larger UN system to creative and successful strategies for facilitating a sustainable rehabilitation and development in Afghanistan. The prospect for Afghanistan and for its future capital - its children is both bright and bleak. From the bleak perspective, Afghanistan has a destroyed infrastructure, a contracted economy, civil fragmentation and a plethora of powerful weapons around the country. The structural factors that underpin the poor situation of children and women remain. These include:

pervasive poverty at the household and national level;

weak resource base;

Ongoing tensions between central and local power; between modernizing and traditional outlooks;

Limitation on the participation of women; and

A geography and topography that work to isolate communities. 


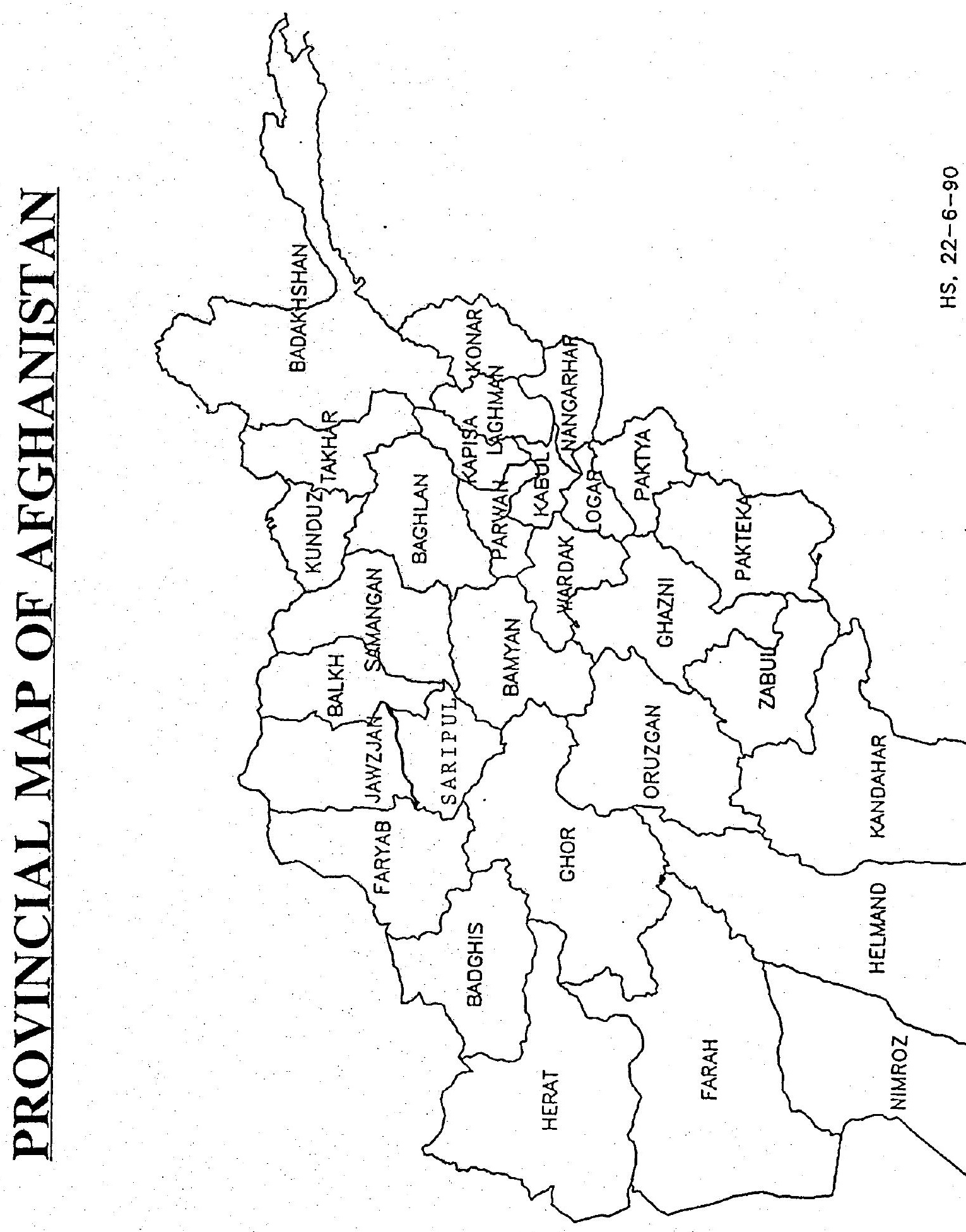


On the bright side, there are opportunities for community based approaches that can produce sustainable improvements in the situation of children and women. And out of the crucible of political conflict over education for girls and women may be opportunities to build a common recognition of the relationship between basic education for Afghan girls and women and the health and potential of children, the community and the country.

The challenge for UNICEF, and indeed the international community, is how to maximize the opportunities and minimize the constraints. As Afghanistan moves from emergency to rehabilitation and eventually development, UNICEF can help Afghans establish the patterns which will guarantee that by the year 2000 , base indicators on the situation of children and women are no longer cause for dismay.

In looking to the future, it is useful to know as much as possible about the present, and to understand the past that impinges on the future. Chapter 1 of this Situation Analysis provides a brief overview of the recent history of Afghanistan and of the social, political and military life, destruction of rural and some urban areas, and the dislocation, internally and abroad, of more than a quarter of the population. chapter 2 explores governance issues in structures and of the social contract, and discusses them in the context of culture and history. Reliable date on the economy and demography of Afghanistan are limited. Chapter 3 reviews what is known the economic environment and its prospects, within which parameters health and education and its prospects, within which parameters health and education services must be funded. Chapter 4 reports on available demographic data, the population estimates being used by the UN system for planning purposes, and some of the implication of these numbers for the situation of children and women.

Chapters 5, 6, 7 and 8 focus more specifically on the situation of children and women in the areas of health, nutritional status, food security and education. Chapter 9 identifies categories of children and women who face especially difficult circumstances. Chapter 10 is both a reprise and a look to the future. It summarizes the key problems or issues in the situation of children and women and the enduring constraints to change. It closes by highlighting opportunities for action.

The situation analysis was prepared by Susan Holcombe, a UNICEF consultant whom I thank and felicitate for a job well done under difficult circumstances. Her work has relied on a wealth of studies, mission reports and analyses as well as interviews with Government officials in Kabul, United Nations and NGO staff in Peshawar, Kabul and New York. She also had substantial discussions with many Afghans in several locations.

Ekrem Birerdinc UNICEF Representative Afghanistan 


\section{CHAPTER 1 \\ 1978-1991 - CIVIL STRIFE, DISLOCATION AND \\ PROSPECTS FOR THE FUTURE}

\subsection{INTRODUCTION}

The upheaval of the past thirteen years is of a scale and scope unprecedented in Afghan history. Perhaps $9 \%$ of the population has been killed, and an unestimated number disabled (cf. Sliwinski 1989). Three to five (or more) million mines have been planted in the countryside. Bombing has destroyed homes and livelihood, driving families into exile. More than a third of the population has been uprooted as internal and external refugees. Accurate measures of GDP are not possible, but the destruction of the country's agricultural base has left both the Government in Kabul and the refugee population heavily dependent on direct outside aid for subsistence and survival. A new generation has been born in exile, never seeing its homeland. At the same time the older generation still experiences the trauma and emotional shock of the war.

The situation leading up to the Saur Revolution in 1978 and the consequent breakdown of national order are the background of the current situation of children and women, as well as factors exacerbating the age old tensions between central and local authority and modernizing and traditional impulses in Afghanistan.

\subsection{PRE-1978 AFGHANISTAN}

What has been written about King Zahir and President Daoud, whose governments preceded the Saur Revolution of 27 April 1978, generally focuses on internal and external political and military issues and the impact of Cold War rivalries. There is little analysis of social policies and practices. While power interests were and remain a reality in national stability, health, education and other social policies and practices contribute to the perceived legitimacy of government at whatever level. In the 1970s health and education development in Afghanistan was a low priority.

King Zahir was ousted by Mohammed Daoud in a 1973 coup. The failure of Government to meet basic needs created the conditions for a coup. Ten years (1963-1973) of an experiment with parliamentary democracy had bogged down; political inaction paralyzed Government. A drought in 1971-72 had reduced wheat and other crop production by an estimated $20 \%$, while livestock numbers fell by as much as $40 \%$. Food aid arrived but inefficiencies and corruption prevented its reaching all intended beneficiaries. Up to 500,000 people may have died in the resulting famine. In 1972, the World Bank noted "The past fifteen years have been frustrating and disappointing... A relatively large volume of aid sustained high levels of investment to little visible purpose in terms of higher standards of living for the vast majority of the population." 
The coup that brought Daoud to the Presidency in 1973 was supported by leftists interested in social change. Development policies which followed, however, continued to focus on investment in industry, particularly on the development of heavy industries based on minerals and other resources. On the eve of the 1978 Revolution little had changed in the situation of children and women in Afghanistan. The World Bank noted in 1978 "In few countries is the health situation as serious as in Afghanistan. Disease and illness are rampant, and the infant mortality rate is one of the highest in the world." Literacy rates in Afghanistan remained low (11-12\%), with only an estimated $1 \%$ of rural women literate. Nearly $70 \%$ of all schools lacked proper buildings (Seven Year Plan), and urban schools often operated on double shifts.

\subsection{FROM REVOLUTION TO REBELLION}

The revolution of April 27, 1978 was complete in two days, with fighting largely limited to opposing factions of the military. Within days the new Government issued its Basic Lines of Revolutionary Duties of Government of Democratic Afghanistan, calling for basic social reforms in Afghan society. These reform programmes included: equitable distribution of land; abolition of usurious land-related debt and of bride prices; and a massive literacy campaign; especially for women.

Implementation of the reforms, the conflict of ideology with tradition, the use of coercive state power and the violent divisions between the Khalqi and Parchami factions of the ruling Peoples' Democratic Party of Afghanistan (PDPA) precipitated and fed a rebellion, and the counterrebellion destruction, which have devastated the country.

Whatever the justice of the reforms intended by the Peoples' Democratic Republic of Afghanistan in 1978, justice was largely lost in the implementation of reforms. Though Government could redistribute land and abolish usurious debt, it could not create overnight a new credit structure in the rural areas. Once-landless peasants might now receive land but they had no landlord to give them seeds, fertilizer or tools required to continue the agricultural cycle. Abolition of bride price, while attractive to urban youth, threatened an institution still important in rural areas and one that gave women some security in a male dominated world. Forcible education for women struck at the heart of deeply held beliefs about women. Hasty and mismanaged reform was a midwife to the Afghan war.

\subsection{PRINCIPAL EVENTS OF THE WAR}

Armed rebellion grew slowly. By March of 1979, for example, hostilities in Konar Province made UN operations no longer viable. In May of 1979 a major uprising threatened government control of Herat and was put down at a heavy cost of human life (estimated at 5-25,000). Population flight, to urban centres and abroad, began as early as 1978 .

Elimination of the Parchami faction from Government did not end tension within the ruling Khalqi group. In September of 1979, President Taraki was replaced by Hafizullah Amin following an incident which cost Taraki his life. The growing insurrection and the inability of 
the Amin Government to control it doomed Amin's tenure. By December of 1979 Soviet troops intervened in Afghanistan to play a more active role in quelling the revolt and assuring the stability of the PDPA Government. Hafizullah Amin was killed and Babrak Karmal, head of the Parchami faction, returned from abroad to take control of Government. The Soviet intervention not only assured the capacity of the PDPA Government to survive but it also introduced a new level of technology or capacity for destruction.

The outside introduction of massive high technology raised the stakes in the conflict. The preponderance of capacity to destroy rested with the Kabul Government. Bombs, jet aircraft, mines including anti-personnel devices, and helicopter gunships were among the instruments available. Over time and with the support of United States, Arab, Chinese and other donors, the mujahidin (literally, holy warriors) also acquired high technology. For the purposes of this analysis, however, what is important is the destructive capacity available to all parties, permitting a level of devastation quite new to the Afghan experience.

In 1985 and 1986, the first signs of change appeared. Mikhail Gorbachev rose to leadership in the Soviet Union in 1985 with an apparent commitment to withdraw from Afghanistan. In 1986, Babrak Karmal stepped down as Afghan leader. Mohammed Najibullah, who had been serving as Secretary of the Central Committee of the ruling Peoples' Democratic Party of Afghanistan (PDPA) became General Secretary in May and President later that year. Najibullah had been known as the first and longtime head of KHAD, the intelligence service set up by President Karmal immediately following the arrival of Soviet troops. Najibullah also came from a well-connected Pashtun family of the Ghilzai tribe. In a speech in December 1986 Najibullah spoke of the inevitability of Soviet withdrawal. Part of the government strategy under Najibullah was the announcement of a cease-fire in January 1987, and the launching of a policy of National Reconciliation. The cease fire did not last, but the reconciliation policy offered amnesty to some opponents of the regime, invited refugees to return, began a process of building links with tribal leaders and of shedding the symbolic appurtenances of an ideological regime. Over time significant changes occurred. Measures to encourage the private sector were introduced. The red flag of the PDPA government was abandoned for the traditional red, green and black flag of Afghanistan. The PDPA was renamed the Watan or motherland party. Non-party people were brought into government. And Islamic religious practice came to play a public role in the actions of government leadership.

\subsection{POLITICAL NEGOTIATIONS}

Negotiations on ending the conflict in Afghanistan had been going on during the 1980s under the auspices of the Secretary General of the United Nations. In April of 1988, Afghanistan and Pakistan signed a treaty (the Accords) for which the United States and the Soviet Union were guarantors. The Accords provided for the withdrawal of all Soviet troops by 15 February of 1989 , with half of the 100,300 troops to be withdrawn by August of 1988 . The Soviet Union and the United States exchanged secret letters that were said to deal with issues of symmetry in equipping and arming the combatants. Though withdrawal of Soviet troops was completed by February of 1989, the Accords have not enabled a political settlement acceptable to a critical 
mass of Afghans. Nor have they produced an end to the fighting which continues between the Government and the mujahidin, and among the resistance commanders. Arms, equipment and other support continued to flow to both sides.

The Accords also increased pressure on the Afghan political parties in Pakistan and Iran to come together and form an alternative government. The seven Sunni parties were able to form an Afghan Interim Government (AIG) based in Peshawar but the AIG has not been effective in coordinating policy and action. With the intervention of the Iranian Government most of the Shi'a parties have joined in an Alliance of Eight. The lack of unity among the parties complicates negotiations. The parties and their military commanders on the inside have not been able to achieve major military advances. Most notably they failed in an attempt to take Jalalabad (March-April 1989) and Gardez (October 1991).

In September of 1991, the two superpowers agreed to a cessation of arms supply to both sides by 1 January 1992. Efforts on the political front continue, still under the auspices of the Secretary General of the UN. The search is under way for a formula for an interim government that will enable a process of reconciliation.

\subsection{CONSEQUENCES OF WAR}

If Afghanistan was poor prior to 1978, the impact of warfare has made it more so. The consequences have differential impacts by region of the country and extend to the following areas:

- Human resources, through loss of life or emigration and through failure to provide basic education and literacy;

- Economic capacity, particularly for agricultural production;

- Infrastructure, especially transport, schools, health facilities;

- Social cohesion, commitment to a civil society.

Plotting the physical geography of war impact is inexact. Sliwinski suggests that destruction was greatest in the central northern border provinces, and in the Pakistan border provinces. Rebellion and war since 1978 have produced 1 to 1.5 million dead on both sides and substantial numbers of children and adults disabled. Perhaps as many as $20 \%$ of Afghan women have been widowed and at least half a million children orphaned.

As many as seven million Afghans have been uprooted from their homes. More than a quarter live as refugees outside the country. Perhaps $50 \%$ of Afghanistan's villages have been destroyed. An estimated $25 \%$ of paved roads and $33 \%$ of secondary roads plus 300 bridges have been damaged or destroyed. Basic services have broken down.

More serious, the elements of social cohesion, which enable a people to work together for national development, have deteriorated in Afghanistan. Ideology has polarized national dialogue. Education is perceived as a vehicle of foreign propaganda rather than an ingredient 
of national development. The role of Government has become suspect among large segments of the population. Leadership is fragmented. The instruments of state power have been weakened, and competing bureaucracies have emerged in Kabul, in rural areas and among refugee parties. 


\section{CHAPTER 2 \\ GOVERNANCE ISSUES}

\subsection{OVERVIEW}

Governance is a term increasingly used to refer to the government and administration functions in a society. For Afghanistan it seems more useful than the singular word government; governance implies a pluralism in the government functions and by whom and how they are exercised. A central feature of governance in Afghan society is the fragmentation of authority, power and responsibility among the Kabul Government, military commanders, shura (local council), militia and mujahidin political party leadership.

This chapter reviews basic governance issues in the context of improving services for Afghan children and women. It describes the current Kabul Government, the centres of autonomous government authority and responsibility that have emerged in rural areas and the refugee political parties. It identifies key enduring structural or underlying factors that continue to shape the environment for governance in Afghanistan and to determine the limits of change for children and women.

\subsection{GOVERNING A FRAGMENTED STATE}

Histories of the Afghan conflict chronicle the spontaneous eruption of resistance to the PDPA Government, the growth of the roles of resistance political parties, particularly those based in Peshawar, as conduits of weapons and support for the resistance. Over time military commanders expanded their areas of control and along with local shura began performing some of the functions of government in those areas. By 1991, many observers estimate that the Kabul Government controls only $20 \%$ of the land area and $35 \%$ of the population inside Afghanistan.

The diffusion of power and of government responsibilities has obvious implications for the capacity to set common objectives for child health and development policies and programmes and to implement activities. The chapters which follow will describe the breakdown of national administration of social services and the evolution of a divided system of Kabul Government services on the one hand and of locality based, cross-border supported health and education services on the other. The aim of this particular section is to describe the capacity for governance in the Kabul government and in the resistance held areas. Information on governance issues comes from government documents, interviews with UNICEF, UNDP, UNOCA and others as well as various publications (Urban, Roy, L. Dupree).

GEOGRAPHY OF CONTROL
The Kabul Government, generally speaking, has control of the principal cities of Afghanistan, including most provincial capitals. It controls some rural areas surrounding the cities, including part of the main irrigated land in the north. Access to the major cities is maintained by road or by air. 
The Government generally maintains access through the Salang Pass north to Hairatan on the Soviet border, a principal entry point for critical imports. Eighmy has estimated that 4.3 million people live in areas under government control.

Most other areas of the country are controlled by the resistance. Power is exercised by the military commander and sometimes the shura. This leadership is locally based, in most cases limited to a specific valley or area. There are a few cases where military commanders have expanded control to a regional level. Ahmad Shah Massoud has established a zone of control in most of Badakhshan and Takhar and much of the northeastern mountains to Panjshir and enabled the development of a civil authority in the Shura-i-Nazar (Council of the North). Mullah Rassoul Ackunzada in Helmand has been expanding his area of control to a major part of the province. The Hesbi Wadat Alliance in the Hazarajat has created a zone of relative peace. Elsewhere in the country authority is fragmented among smaller commanders. The fragmentation is sometimes compounded by divisiveness and fighting among commanders of different political parties and with militia.

Potentially a third set of power centres in the country is the militia. Initiated and armed by the Government the militia were to help defend Kabul Government-held cities and roads and serve a destabilizing role among the resistance commanders. In some cases, individual militia groups operate autonomously like bandit groups, pursuing economic or tribal interests. In the Herat area there is fighting among different militia, sometimes because of rivalry over control of smuggling routes. Militia activities in the north have threatened the security of the road west from Mazar-i-Sharif.

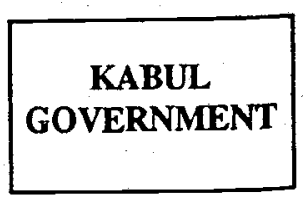

The current form of the Kabul Government reflects changes that have occurred since Mohammed Najibullah became General Secretary of the ruling People's Democratic Party of Afghanistan (PDPA) in 1986. Najibullah, recognizing the possibility of eventual withdrawal of Soviet troops, set in motion a number of political actions intended to broaden the base of the government. Steps included an increased consultations with Moslem clergy, tribal leaders, farmers, party officials and other groups in the country. Najibullah created a National Reconciliation Commission, offered amnesty to those who had opposed the revolution and invited refugees to return to the country, setting up a ministry to facilitate their return. Government began actively to encourage private sector economic activity.

In 1987 Najibullah also pushed successfully for constitutional changes that provided for a presidency with a fixed term of seven years and that allowed greater non-PDPA participation in government. In addition to the Nationa! Assembly, a second legislative chamber, the Council of Nationalities, was set up to give representation to national minorities. Najibullah called a Loya Jirgah (meeting of traditional leaders) in Kabul to approve the constitutional changes. He became President, and the Democratic Republic was renamed the Republic of Afghanistan. The PDPA was renamed the Watan or Motherland Party. Local elections were attempted in 1987, but voting was difficult in much of rural Afghanistan. 
While the leadership of government has undergone considerable change in the past twenty years, the bureaucratic machinery has retained similar structures and modes of operation. The structure of ministries remains similar and administrative practice is still oriented to centralizing and control functions rather than to development change. Management practice is not aimed at achievement of performance goals but to the survival of the institutions.

GOVERNANCE DN RESISTANCE AREAS
It is difficult to generalize about government in resistance areas because of the varieties of experience and of scale and the dynamic political environment. In a simplified model, the key figure in every local area is the military commander. His sphere of control may not extend beyond his village or valley or he may control a larger area with subcommanders reporting to him. Each commander will lead a group of mujahidin fighters and is nearly always aligned with one of the political parties based in Pakistan or Iran, from where he will receive support for the resistance effort. The commanders have emerged out of the resistance and the imperative to organize the jihad or war against the Government in Kabul. Along with military needs, there was 2 requirement for civil government in resistance areas. In some areas local shura or councils evolved to take on civil functions of settling local disputes and ultimately of providing local services. The most elaborate of these civil governments is probably the Shura-i-Nazar, the Council of the North in the area controlled by the Commander Ahmad Shah Massoud. The Shura has autonomous responsibility for health and education functions. Shura elsewhere also exhibit the trappings of government. In the Hazarajat, for example, the shura occupies the old government administrative offices and collects taxes. In other cases, shura are a temporary phenomena that come into existence to deal with particular problems at the village level. The traditional functions of malik and arbab are still maintained. The malik serves as spokesman to the outside world while the arbab oversees water distribution for irrigation. Both are usually chosen by village men.

Behind the mosaic of power centres in resistance-held Afghanistan are two other realities with longer-term implications for programmes for children and women. First, anthropologists and sociologists who have traveled and lived in resistance-held areas believe that considerable social change has been occurring in political and social relations at the local level. This change is most notable in the role of the khan or the traditional landowner who may also have headed a clan or tribe. In many cases an amir may have emerged to replace a khan who fled. Landless before, the amir would take over the landlord's property and also responsibilities to clients and sharecroppers. The amir might play an intermediary role with local commanders. In non-tribai areas, the khan is no longer a political factor. In tribal areas, khans are thought to have lost power. Religious leadership (mawlawi) has gained political influence.

The second implication relates to the style of leadership in each of these power centres. Most of the commanders and other leaders have an individualistic and centralized style of management that limits the scope of enterprise, whether military or civil, that they can undertake. All decisions are made by the commander; action is held up for his decisions. Only Massoud in the north-east has developed a decentralized approach allowing the delegation of responsibility and authority that enable a larger organization. 
MinIIA

insecurity.

RESIST ANCE

PARTIES

Though created and armed by the Kabul Government with the purpose of extending government control over a section of road or a remote post, the militia often play an independent role perhaps serving their own tribal agenda. The role of the militia complicates rehabilitation and development efforts in rural areas, and adds to

The primary Afghan resistance political parties are based in Pakistan and Iran. The parties play two critical functions. First they are the voices of the resistance to the outside world, both in terms of generating moral, material and financial support for the resistance and also as negotiators of a prospective settlement. Secondly, they are the source of funds and materials for the military commanders inside. For this reason, military commanders inside are linked to political parties on the outside.

The seven principal Sunni parties are based in Pakistan. Several of the parties were in Pakistan before the 1978 revolution fighting for an Islamic republic in Afghanistan (Jamiat Islami and Hizbe-Islami of Gulbaddin Hekmatyar). Hizbe-Islami of Yunis Khalis favors a theocratic republic and the Islamic Unity of Afghan Mujahidin is a Sunni Wahabi group favoring an Islamic republic. The National Islamic Front of Afghanistan, the Islamic Revolution Movement and the National Liberation Front are conservative parties favoring a pre-revolutionary, Pashtunbased government. With the exception of Jamiat Islami, which is mainly Tajik-based, the other parties are mainly Pashtun-based. Jamiat Islami includes other Dari-speaking groups and has made an effort in the 1980s to increase its influence in Pashtun areas. These seven parties, under pressure from bilateral supporters, formed the Afghan Interim Government (AIG) in 1988 with fourteen ministries. The AIG continues to exist but experiences considerable disunity.

The Shi'a political parties have been plagued by rivalries. They represent largely the Hazara population based in the centre of the country. In 1987 they formed the Alliance of Eight including the Islamic Movement, The Word, Revolutionary Guard Corps, Party of God and four other small parties, but not the original resistance group in the Hazarajat, the Council of the Union. Iran has given financial support to the Shi'a groups. Observers note two impacts of the war on Shi'a and Hazara groups. The first is that independence, isolation from the central government and participation in the war have developed pride and self-confidence among a people traditionally regarded as inferior in Afghanistan. Secondly, young well-educated mullahs returning to Afghanistan from training at Qom and elsewhere have brought with them ideas of the importance of organization and of social development. Observers report the opening of schools and libraries in the Hazarajat under their leadership, including facilities open to women.

\subsection{STRUCTURAL CONSTRAINTS}

Whether political negotiations resolve the conflict in Afghanistan and mend the fractured political community, there are enduring political and cultural constraints on the capacity of any government or governments to alter the situation of children and women. In Afghanistan there are first age-old tensions between modernizing and traditional forces, and centralizing and 
Mahmud Beg Tarzi, leading intellectual and modernist of early twentieth century Afghanistan, noted "Amanullah has built a beautiful monument without a foundation. Take out one brick and it will tumble down." And later he said of Amanullah, "If only he had waited for two years and built up the army as Ataturk suggested, what might he have done?" (L. Dupree 1973).

Tarzi is perhaps the most outstanding of Afghan intellectuals who sought to modernize Afghanistan and who is thought to have had pivotal influence on Amanullah's reforms. Tarzi spoke out against European imperialism but also against the resistance of Muslim religious leaders to change and learning from western ideas. "If Islam is worthwhile, it is worthy of challenge," Tarzi said, recalling that Islam carried "the torch of learning" in the Dark Age of Europe (Dupree 1973). During the twentieth century, the power of the religious establishment, while it ebbed and flowed, also remained a factor. It took strength from tribal leaders in opposition to central authority and from dissidents and conservatives in the rural family.

These same forces continue to operate today, with some alteration in roles. The leadership of the 1978 Revolutionary Government borrowed modernist ideas from western thought (particularly the Soviet Union). When implemented, this radical agenda ignited or intensified the resistance of religious and tribal leaders opposed to radical reform and the interference of the central Government. The parallels with reform and rebellion in the time of the Amanullah Government are instructive but they do not explain what is different about the situation today.

First, the resistance to the Kabul Government cannot be neatly characterized as the rebellion of religious and traditional leaders against both modern reforms and central government authority. While the mujahidin party leadership is religious, it is not simply traditional in outlook. Several of the party leaders are Islamists rather than traditional. The Islamists seek central government power so that they can create an Islamic state apparatus in Afghanistan.

Second, the role of tribal leadership has changed. Except in border areas of Pakistan, traditional leadership is in flux. Many khans, as noted, have fled the country and been replaced by a new class of rural leadership. Few of the leadership in the royal family, the Durrani Mohammedzais, remain inside the country. The military commanders, few of whom come from traditional power structures and some of whom are Islamists, have emerged as a new leadership class.

Third, the persistence of conflict has allowed development of separate Afghan bureaucracies with divergent political ideologies. The Kabul bureaucracy should be characterized not as communist but as secular and westernized and as having integrated large numbers of middle class women into the public sphere. The mujahidin bureaucracies, inside the country and in Peshawar, are Islamic or conservative in outlook and male in orientation.

Fourth, reform and rebellion have altered power relationships among and within the ethnic groups. For the moment the Ghilzais have replaced the Durranis as the dominant Pashtuns. The Hazaras, the Tajiks and other ethnic groups have emerged in new positions of power as important resistance fighters. 
Fifth, the experience of dislocation and refugee flight exposed increasing numbers of Afghans to modernizing influences either in cities or in refugee camps where they may have access to modern health services, radio and television for the first time. It is not clear whether those exposed to these influences will return unchanged to rural life. The experiences of war and displacement may alter permanently the alliances and power relationships in the continuing tensions between modernizing and traditional forces, and between local and central authority.

GOVERNANCE \& WOMEN
The 1978 revolution has polarized the symbolism if not the reality of women's roles in Afghan society. On the one side, the Kabul Government's reforms for women were for many Afghans tainted by their association with foreign or unIslamic ideas. The position of fundamentalist and Islamist parties in exile is more extreme than that of the pre-1978 society. Afghan women appear to be left little alternative between these two symbolic models.

In traditional Afghan society women are valued for their reproductive roles, particularly for producing the sons who carry on the family line and assure the family's status. To assure the descent and the honor or status of the family, the honor of the woman is critical. To protect that honor, the Afghan woman is shielded from contact with any outside male through seclusion, veiling and carefully prescribed gender behaviors. Opposition to education for females is rooted in the need to protect women from outside contact. In general, women have accepted their gender role in society and have seen children and the family as a desirable focus. In return, women gained from their status some measure of economic and physical security and often a high respect from men. (Boesen 1989; and N. Dupree 1989).

Power in Afghan society is traditionally hald by male heads of household. There is a clear separation between the public and private spheres of life, in both of which the male head or patriarch is the power holder. In the public sphere, power is shared among males, depending on their class, economic level and other stratification (Moghadam 1989). Women, together with the children for whom they carry the primary responsibility, bear the greatest burden of morbidity and mortality; yet women exercise no power in the public sphere where decisions are made on the use of public or community resources that affect the health and welfare of children. While women traditionally participate in agricultural, handicraft and other production, they nearly universally lack control over the means of production as well as the benefits from it.

The Revolutionary Government that came to power in 1978 verbalized a political commitment to equality for women and initiated programmes aimed at bringing women into the public sphere through literacy training and mass mobilization programmes. Many observers believe that the resistance to government programmes for women, along with the refugee and war experiences, have intensified the symbolic value of women's honor to the Afghan identity, thus making the physical and psychological seclusion of women more rigid among refugees and more harsh than it had been previously. The intensification of fundamentalist views on women has been expressed as harassment and even violence against women refugees participating in income generating and education activities. (Boesen 1989 and N. Dupree 1989). 
The polarization of official attitudes on women between the Kabul Government and the parties in Peshawar is not the whole reality. NGOs working with cross-border programmes see a widening gap between party leadership in Peshawar and the leadership inside the country on the participation of women in education and development programmes. The sensitivity of the gender issue will remain a programme constraint.

BUREAUCRACY \& THE FUTURE
Without analyzing the capacity of the Afghanistan government bureaucracy, it is possible to point to several factors which will have long-term impact on its ability to implement programmes for children and women.

During thirteen years of conflict Afghanistan has lost considerable skilled manpower in all sectors. Some are dead; others have migrated to Europe and North America and are not expected to return in large numbers. The flight of trained Afghans has harmed the standard of tertiary education operated by the Kabul Government. A generation of refugees and rural Afghans have lost access to secondary and higher education. There is a shortage of trained manpower and of the capacity for training.

Among the existing pool of trained Afghans there are problems of integration of skilled manpower into a national system should a political settlement evolve. The problem is complicated by the different levels and types of training of doctors, middle-level health workers, community-level health workers and of teachers, as well as by the differentials in pay scale among the government and the various cross-border health and education programmes.

Finally, the bureaucratic culture in Afghanistan is likely to remain an impediment to successful achievement of programme goals. In an assessment of the administrative structure of Afghanistan in 1978 the World Bank noted that public administration in Afghanistan was oriented toward maintaining law and order and was not significantly directed to development needs. There is not much evidence since then of a change in bureaucratic orientation. What this means in practical terms is a bureaucratic focus on accountability for books distributed or vaccines used, rather than a concern with increasing the number of children who successfully complete first grade the first time around or with increasing the number of children and women completely immunized.

LEGACY

OFWAR

The psychological impact of war on the future generation is difficult to measure. For some children the burden of war is disability, the memories of the killing of parents or family, or the terror of bombing and battle. For some children it has been extended by exposure to school curricula and materials that glorify war and demonize the enemy. The socialization of a generation of children under conditions of war and bitter hatred make difficult the process of reconciliation. And reconciliation is threatened not only by attitudes, but by the large supply of weapons left among the population. 


\section{SEARCHING FOR TRUTH}

The economy of Afghanistan defies accurate description. The numbers argue with what the eye sees. The numbers, such as they are, suggest an economy nearly bankrupt. Growth is negative; agricultural production is a fraction of pre-war output; domestic expenditure, perhaps $80 \%$ of it for war, gallops ahead of declining revenue; trade imbalance grows; government tax policies, controls, subsidies and expansion of money supply distort prices and feed inflation; and infrastructure and human resource capacity deteriorate.

The eye absorbs a mixed picture. There are no scenes of famine or mass starvation. There is indeed poverty, but there has always been poverty in Afghanistan. There are beggars but they are few compared to neighboring countries. And there is also conspicuous consumption and the effort of the urban middle class to maintain their standard. UN missions speak of poverty and food shortages in rural areas, and of poor households turning to grass or linseed oil cake for a survival diet. Survey teams report on the destruction of traditional cash income opportunities in rural areas. Others, in Konar, Nangarhar and other border provinces, refer to new income opportunities where farmers disassemble wrecked tanks or collect rocket fragments for sale to scrap merchants in Pakistan. Observers note instances of a new class of nural elite. Landlords, often military commanders, exact a higher share from their sharecroppers than the pre-wat norm or militia generate revenue from posts along roads and smuggling routes. Other observers see ownen-occupiers farming relatively evenly distributed land, and local commanders and shura attempting to create conditions conducive to economic productivity.

In Kabul's Old City residents may direct you to the home of someone poorer than they, perhaps a widow out on the street begging while her five children and dying father-in-law stay at home in a tiny room without heat or food. Not far away in Shar-i-Nau, the New City shopkeepers flog Mercedes, Toyotas and other luxury cars. Construction of commercial space in the same area has stalled for thirteen years while nearby the occasional lixury house rises. A careful eye notes deferred maintenance, increased stress on basic services, and occasional pockmarks on walls, standing testament to past rocket fragments. The markets have local and imported food, but purchase of a handful of groceries would quickly exhaust a civil servant's monthly salary. At 11:00 in the morning hordes of people may crowd around a government petrol station awaiting sale of a pittance of diesel oil. Petrol isn't available there at the subsidized prices of Afs 40 per liter, but it can be found in the black market for perhaps $\$ 4.00$ per gallon. Anything, it seems can be found in the market-for a price. Come afternoon, it may be difficult to find a civil servant at his or her desk as many search after alternative sources of income. But the middle class keeps the appearance of middle class fashion. Frequent afternoon weddings with fancy dress and videotaping belie the image of Kabul as a war-torn city.

If the numbers don't tell the whole story of the economy of Afghanistan, the visual images give many stories What are the real resources of Afghanistan? and what is the capacity for rehabilitation and recovery?

Why are these questions important in an assessment of the situation of children and women? The state of the economy of Afghanistan, or anywhere else, sets the parameters of possibility and determines the government ane community resource base for health and education services. Purchasing power at the household level is the outside limit of family capacity to buy health and education services. 


\section{CHAPTER 3 \\ THE ECONOMIC BACKDROP}

\subsection{FINDING ECONOMIC INFORMATION}

In most parts of the world it is possible to estimate the capacities of the national and household economies, and to assess the effects of income distribution among households. In most countries there are national income statistics, national budgets, data on exports and imports, indebtedness, inflation rates, employment patterns, and on income distribution, often allowing identification of trends over time. In Afghanistan, little of this information is available.

Economic assessment in Afghanistan confounds standard approaches. Where elsewhere you can begin with assumptions of a distinct and national economy, in Afghanistan you find a collection of distinct but overlapping and porous economies:

- There is the economy of the Government that controls roughly $20 \%$ of the land area of the country. There are national statistics and indicators published for this economy but war, lack of access, and security and political concerns leave these numbers flawed.

- There is the private sector in Kabul and other government-controlled cities that includes most money and credit activities, trade and private industrial production. Only part of this economic activity is reflected in official statistics and we can only guess at what part.

- There are the economies of rural Afghanistan, where much of the production remains and where local authorities, commanders and shura, raise revenues, incur expenditures, exploit resources and, whether by intent or defautt, create economic policies influencing production. There is virtually no information on these economies.

- There are other economic actors, the Afghan, Pakistani and other traders in Pakistan and elsewhere who trade directly across bonder with non-government and government areas, or who participate in opium trade and in smuggling.

- Then multilateral, bilateral and non-governmental agencies provide development assistance and cash, some of which goes directly into the hands of individuals and commanders throughout rural Afghanistan. From some bilaterals there is also military aid and cash, some of which ends up inside the country. 
The evidence of these economies and economic influences is not systematic and often only anecdotal.

The economic capacity of the various authorities holding political and civil responsibility in Afghanistan, and of the local communities and households, is important to planning for children. How do we measure that economic capacity in the absence of any of the standard information? This analysis will examine and try to integrate:

- the key economic indicators for Afghanistan as reported by Government and as augmented by several key studies (UNDP 1990, Robert R. Nathan Associates 1989, UNIDATA);

- sectoral issues critical to economic capacity for child health and development investments;

evidence on what is known about parallel economies, including opium poppy production and smuggling;

evidence on the capacities of the household economy.

The analysis needs to be done against a backdrop of Afghanistan's economic potential, and the level of development reached in the pre-war period. The economic capacity is intertwined with the decentralized and fragmented political capacity of Afghanistan. This section builds on the assessment of governance in the previous chapter. The objective is to identify the key economic factors tikely to influence national, community and household economic capacity to support and sustain improvements in the situation of children and women.

Finally, there needs to be a word of caution. Numbers are used in the discussion which follows to describe the economy of Afghanistan. Most numbers are only estimates, a fact which is readily acknowledged by the sources making the estimates, some of whom explain their assumptions in detail. Whatever their weaknesses, these numbers are the only ones available. Sometimes they are corroborated by other estimates independently derived, and sometimes they are supported by qualitative evidence. The point is, however, that all numbers must be used with caution. At best they may identify some problems and trends which need further research.

\subsection{ATTEMPTING GENERALIZATIONS ABOUT THE AFGHAN ECONOMY}

Assessing the relationship between the capacity of the economy and the potential for improving the situation of children and women in Afghanistan is like walking on quicksand. The information available permits a few tentative generalizations and raises some questions: 
In the short run, perhaps through to mid 1992, the Government may be able to obtain enough food and petroleum products to keep its economy running. Without replacement of the commodity assistance from the Soviet Union, the Kabul Government economy risks collapse. Economic breakdown threatens the survival of urban populations.

The destruction of thirteen years of war leave Afghanistan less able to invest in rehabilitation and development of a collapsed economy.

At the same time the private sector and the parallel economies, legal and illegal, have demonstrated resilience and capacity to generate earnings.

Whatever the strength of the private sector and the parallel economies, there is little evidence that surplus income generated is redistributed to poorest Afghans or invested in health or human resource development.

The resilience of the private sector and of parallel economies may be purchased at the cost of long-term economic development. Short-term exploitation of resources may jeopardize the long-term potential of forest or semi-precious stones. Smuggling and opium poppy production earn present high returns that may not be sustainable in the long-term.

The fragmentation of the governance structure is demonstrated by the autonomous economies of military commanders or shura who may collect taxes or revenues or receive aid directly from bilateral or other outside interests. Integrating these local economies into a new national whole will be difficult if integration is not to destroy the capacity for local initiative and responsibility.

Information available raises questions about the capacity of the economy(ies) to absorb the 4.5 million or more refugees in Pakistan and Iran should they return. The potential for land tenure disputes and clashes is not fully understood. There is considerable question as to whether there is sufficient arable land now uncultivated to absorb returnees.

Women are an invisible and unvalued factor in the economy. They are the principal producers in the handicraft sector, which constitutes more than half the industrial sector. They perform a wide range of production functions in the agricultural sector. No systematic data has ever been collected on women's economic roles. No analysis has been done on the links between women's economic roles and child health and development.

The demise of the cold war and the reduction of bilateral perceptions of Afghanistan as a strategic prize reduce the prospects of Afghanistan receiving substantially increased external assistance in the future. At the same time, the United Nations system is likely to continue to play the key role in shaping the framework for external assistance. 


\subsection{GEOGRAPHY: BACKDROP TO ECONOMIC ACTIVITY}

Long one of the world's poorest countries, Afghanistan's economic situation and prospects are limited by the harshness of climate and a rugged topography and landlocked location that reinforce the isolation of villages and ethnic groups and inhibit the development of an adequate transportation network. Many of its mineral resources are not economically exploitable. There is little industrial development. Agriculture is the basic economic activity.

Afghanistan can be divided into four geographic zones: the northern plains, the central mountains, eastern and south-eastern mountains and foothills and the southern and western lowlands. The northern plains, bordered on the north by the Amu Darya (Oxus River), are relatively low in elevation (365 meters) and have cold winters with snow and freezing temperatures, and hot summers $(40 \mathrm{C})$. Annual rainfall is around $25 \mathrm{~cm}$ per year. The central mountains include the Pamir and the Hindu Kush, with peaks ranging from 4000 to 5800 meters feet and valleys at 27000 meters. The eastern region encompasses numerous productive valleys at 1200 to 2000 meters, many of which are highly productive. The largest river valleys are the Kabul and the Konar. The lower elevations have a milder climate. The two remaining hardwood forests of the country are located in this region (Konar and Paktya). The south western area is lower ( 300 to 900 meters and hotter (reaching $45+C$ in the summer) and contains two major river valleys, the Helmand and the Harirud. These rivers support large irrigation networks. A dam at Kajakai on the Helmand regulates river flow and has provided hydroelectric power.

The climate is arid and semi-arid with rainfall ranging between 2.3 and 58 centimeters. In all areas the scarce rainfall comes mostly in the fall and winter, often in the form of snow on the mountains. Spring melt feeds the rivers in the valleys of the country and provides water for the irrigation necessary for the most productive agriculture. An estimated $12-13 \%$ of the total land surface is arable, of which only about a half was cultivated in normal pre-war years. Of the land cultivated, about two thirds was irrigated in pre-war years. Irrigated land accounted for the greatest part of production.

Geography also helps explains the occurrence of natural disasters in Afghanistan. The north-east is susceptible to earthquake, as in 1991 when a shock of 6.5 on the Richter scale cost lives and damage to housing. Despite a generally dry climate, flooding is a periodic hazard. In 1991, flood waters damaged crops and buildings in the south-west.

\subsection{KEY ECONOMIC INDICATORS}

Key economic indicators are the usual measures of a national economy. Given the fragmentation of the economies in Afghanistan, the official statistics are at best inadequate and have been adjusted by Government, the United Nations and other institutions over the years to reflect realities in areas outside government control. The key indicators from several sources all reflect the deterioration of the Afghan economy since 1978. 
All estimates of Gross Domestic Product (GDP) suggest stagnation and contraction in the Afghan economy since 1978/79.'

Contraction of domestic product is the direct result of the war and the loss of physical and productive assets and of human resources. The sharpest decline is thought to have been in the agricultural sector.

\section{TABLE 1 ESTIMATES OF GROSS DOMESTIC PRODUCT}

(billions of Afghanis in constant 1978 prices)

\begin{tabular}{lcccc} 
& $1978 / 79$ & $1986 / 87$ & $1989 / 90$ & $1990 / 91$ \\
\cline { 2 - 4 } & 142.9 & - & 118.5 & 114.8 \\
Ministry of Statistics & 117.2 & 105.9 & 103.5 & - \\
UNDP & 113.7 & 80.9 & - & - \\
Nathan Assoc. & 1 & &
\end{tabular}

Sources: $\quad$ Republic of Afghanistan Statistical Yearbook 1991; UNDP Programme for Rehabilitation and Development 1991; Robert R. Nathan Associates, Afghan MacroEconomic Database Development, 1990.

UNDP (DCR 1989) estimates a per capita income in 1989 of US\$185, using the official conversion rate of US $\$ 1=$ Afs 50.6. UNDP indicates that if the free market conversion rate in 1989 (US\$ $1=$ Afs 546) and 1989 prices are used, then 1989 per capita income is approximately US\$ 69. The World Bank estimated that the per capita income in Afghanistan in $1976 / 77$ was US $\$ 180$. In the Afghan setting estimates of per capita income may be misleading and fail to communicate much about household purchasing power.

Overall, the role of the private sector in the economy is more significant than that of the public sector. In an analysis of GDP in 1989, UNDP (DCR 1989) estimated that $81.6 \%$ of GDP was produced in the private sector. This share was highest in agriculture $(99 \%)$, and lowest, but still substantial in industry and construction (55.9\% and $25 \%$ respectively).

Table 2 below shows estimates of gross domestic product by sector and suggests the deterioration which has occurred. In particular it shows the decline in agricultural production both in absolute terms and as a portion of total production between 1978/79 and 1989/90. Agricultural production was $53 \%$ of total in 1978/79, and fell to an estimated $46 \%$ in 1989/90. Government services grew rapidly during the same period.

'The Afghan year runs from March to March. 
TABLE 2: GROSS DOMESTIC PRODUCT BY SECTOR

(Afs. million at constant $1978 / 79$ prices)

1. Agriculture, Livestock, \& Forestry

61

2. Mining, Industry \& Energy

14,400

3. Construction

$$
4,300
$$

$$
3,500
$$

9,700

$$
1,700
$$

95,500

9,275

4,775

4,500

$1986 / 87$

$1989 / 90$

Share \%

4. Transport \& Communications

47,350

47,700

$1989 / 90 \mathrm{GD}$

5. Trade \& Distribution

$$
14,651
$$

14,100

46.1

6. Others

4,800
2,900
9,100
1,700

3,500

7. Total Production

80,501

2,700

8. Service

[Private (5\% of 7)

[Public

9. Housing

5,730

$$
13,165
$$

4,025

9,140

8,300

1.4

10. Total NDP at factor cost

110,505

4,830

1,500

75.4

11. Depreciation

6,700

98,496

78,100

15.1

12. Total GDP at factor cost

117,207

7,400

5,467

5.3

4.5

4,680

98,080

105,896

103,547

100.0

\section{Source: $\quad$ UNDP 1990}

Except for 1989/90, UNDP has adjusted most figures from data taken from the Ministry of Statistics in orde the depressed economic situation. UNDP has estimated service sector figures. Figures for 1989/90, howe taken directly from official data. They are therefore inconsistent with the 1986/87 estimates, and unde seriousness of the economic decline that has taken place in Afghanistan. 
CROP PRODUCTION

Agriculture has been and remains the primary economic sector. As noted above, agriculture has contributed around half the total domestic economic production. It is the source of livelihood for most people. Wheat is the principal cereal crop. Though estimates vary, cereal production has declined since 1978. The nutrition chapter below discusses in greater detail the food supply situation in terms of staple wheat production and imports. In 1978 the World Bank spoke positively about Afghanistan's capacity to mobilize its agricultural resources to feed its people and to expand exports. Though Afghanistan was receiving food aid throughout the 1970s (roughly $100-120,000$ metric tons per year), it was producing enough wheat for domestic needs outside the urban areas. In 1974, agricultural exports were twice the value of non-agricultural exports. Since 1978, however, all evidence shows a decline in most cereal, fruit and vegetable and industrial crops (see Table 3). The impact of declining food production is discussed in Chapter 7. The decline of industrial crop production has constrained industrial processing.

\section{TABLE 3: COMPARATIVE ESTIMATES \\ PRODUCTION OF SELECTED PRINCIPAL CROPS}

(thousands of metric tons)

$1978 / 79 \quad 1986 / 87$

Govt RRNA Govt RRNA
$1989 / 90$

Govt RRNA
Food Grains

Wheat

Corn
28132639

$\begin{array}{ll}780 & 732\end{array}$
$1925 \quad 1238$

$567 \quad 365$
2200

610

Fruits \& Vegetables

Fruits

Vegetables

$\begin{array}{ll}824 & 733 \\ 766 & 719\end{array}$

na

428

740

na 437

890

Industrial Crops

Cotton
Sugar beets
Sugar cane
Oil seeds

132

$73 \quad 68$

$64 \quad 60$

$35 \quad 33$
$47 \quad 34$

24

$75 \quad 34$

$45 \quad 20$
35

3.5

78

45

Sources: UNDP 1990, taken from Ministry of Statistics; Robert R. Nathan Associates 1990. 
By the late 1980s war had markedly reduced agricultural production. More than a quarter of the agricultural labor force was lost to the war or has fled, abandoning land. Fighting destroyed farm infrastructure and implements. Oxen that served as basic farm power were killed or sold. The collapse of effective national government reduced availability of improved seeds, fertilizer, and of credit for farming inputs., and the loss of oxen and farm implements. The result was a reduction of the area under cultivation, of productivity and of output. Government estimates that in 1989/90 only 3 million of a normal 4 million hectares were cultivated, 43,000 hectares of fruit trees and 3000 minor irrigation systems damaged and 3 million units of farm implements lost or destroyed.

Particularly following the signing of the Accords, reduced warfare in increasing portions of rural Afghanistan have created the conditions for improving crop production. The Swedish Committee estimates that crop production may have increased from 53\% of pre-war production in 1988 to perhaps $60 \%$ in 1990 despite sunnpest and locust infestations. Improvements could be linked to increased aid agency cross-border efforts to provide improved seed, fertilizer and support to irrigation rehabilitation and oxen for farm power.

Women have traditionally performed specific functions in agricultural production, depending on the location, ethnic group and class of the household. Traditional tasks were weeding, transplanting rice, planting vegetables and harvesting. Tasks involving modern technology were reserved for men. Food processing was exclusively a women's task (cf Planning and Afghan Women, UNICEF and UNIFEM 1989).

War has affected women's roles, including in agriculture. Observers inside Afghanistan have noted women working the fields with their children in locations where many men have been lost (Logar). In areas of Afghanistan regarded as particularly traditional (Nangarhar, Paktya, Pakteka), women have been observed communicating directly with men unknown to them, though with the consent of the males of the woman's household (Christensen 1990). To date there has been no systematic field research on women's functions in agriculture and the relationship to productivity and household capacity to meet the needs of children.

OPIUM

Opium poppy production is not recorded as part of national product but it is a major and increasing part of agricultural production and of domestic and foreign exchange earnings. Poppy production could be said to have benefitted from rehabilitation of agricultural infrastructure. Reported doubling of the Afghani price of dried opium in the past year (1991) would appear to make poppy production a continuing attractive proposition for farmers. UN and USAID sources suggest an increase in production from 250 metric tons in 1977 to 750 metric tons in 1988 and 800 tons in 1991. Production was reported highest in Helmand, Nangrahar, Badakhshan and Uruzgan but also present in lesser amounts in Kandahar and Konar. Opium poppy production is a traditional crop in Afghanistan. It always represented a significant though unofficial proportion (some say as much as a sixth) of foreign exchange earnings in the 1970s. Domestic opium use was formerly limited to low levels in a small number of poor rural areas (Badakhshan) as a way of dulling the pains of cold and hunger during long winters. There is reportedly increased heroin production in the region (Pakistan) and increased heroin addiction among young people in both Afghanistan and Pakistan. 
Who benefits from opium poppy production is only partly clear. Poppies are reportedly grown in varying amounts as a cash crop by subsistence farmers and as a commercial crop on a larger scale in some irrigation schemes, notably in the Helmand. While the subsistence household does not get the benefit of the street price in first-world cities or of the middle man's profits, poppy production is a profitable and sometimes a survival strategy for the small farmer. Production is likely to continue so long as demand remains high in the west.

Pre-war evidence of how subsistence farmers used profits from poppy production is anecdotal. Decisions on use of profits were made by the male head of household and appear to have been invested in consumer goods like radios or motorcycles and not in improved health or education. What happens to profits from larger scale production and the earnings of the middlemen is less clear. Anecdotal evidence links these opium earnings to support for the resistance (armaments), bank accounts in the Gulf and elsewhere, and conspicuous consumption in Peshawar, Quetta and Kabul:

A contractor for the United Nations International Drug Control Programme, as part of an opium poppy production survey in Nangrahar Province, calculated the hypothetical advantages of poppy production at the household level. Assuming a family of two adults and five children farming three jerib of land in the Shinwar Valley, the contractor calculated a total annual cost of (Pakistan) Rs. 1890 for clothing and Rs. 6768 for food and energy costs except wheat (total $=$ Rs. 8658). Wheat if purchased for the family would cost Rs. 2044 annually. If the family plants the entire three jeribs in wheat, expected yield would be $1134 \mathrm{~kg}$. After subtracting the $1022 \mathrm{~kg}$ needed to feed the family, $112 \mathrm{~kg}$ would be left for sale. This would bring about Rs. 224 in the market, far short of the Rs. 8658 required for estimated clothing, energy and other food items. Without cash or in kind income, the subsistence farmer cannot survive. If the entire three jeribs were planted in poppy, the yield would be $54 \mathrm{kgs}$. of opium resin, netting about Rs. 13,878 on the market. The cost of $1022 \mathrm{Kg}$ to meet family wheat requirements would be Rs. 2,555, which if added to the Rs. 8658 needed for clothing, energy and other food would bring total household costs to Rs. 11,213. This would leave the household with a 'profit' of Rs. 2665. While one might quibble with aspects of this hypothetical analysis, profit advantages of poppy production remain and small farmers continue to produce it.

\section{LIVESTOCK}

Livestock has traditionally been a major part of agricultural production, the basis of the nomad economy and an indicator of wealth. Afghanistan's livestock suffered major reduction in size and quality since 1978 due to sales

to finance emigration or living costs; losses resulting from bombardment, mines or shooting by the army; and decline in animal health services with increase in animal diseases. Government estimates that $60 \%$ of the cattle and $40 \%$ of sheep and goats were lost or destroyed, leaving an estimated 1.5 million cattle and 12 million sheep and goats in 1990. 
Swedish Committee surveys in rural Afghanistan (1990) confirm a large loss of livestock and, in particular, the decline of karakul sheep that had been an important foreign exchange earner before the war. With the reduction of hostilities in lecent years trends in livestock numbers have reversed, particularly in response to the growing need for farm power for crop production. The Swedish Committee notes an increase in oxen ownership between 1987 and 1989 in two thirds of the provinces. Numbers of cattle have not grown at the same rate as oxen, but the distribution of ownership is equitable with only $16 \%$ of families surveyed owning no cattle and almost half the households owning two or more cattle. Sheep and goats showed the greatest increase in the 1987-89 period. SCA found that in 20 of 29 provinces more than $70 \%$ of families owned sheep and goats: Little is known about numbers and distribution of chickens. Poultry are normally a productive activity of women. Veterinary services were meager in the pre-war period and almost non-existent in rural areas in the early years of the war. More recently cross-border and cross-line activities have begun primary veterinary activities, some of which have included attempts to involve women in improved animal husbandry skills and in traditional poultry activities.

Respondents to the 1988 and 1989 Swedi.sh Committee surveys cited farm power as the second biggest problem of farmers, after water shortages. Between 1988 and 1989, the hiring of tractors by farmers rose from 19 to $31 \%$ of farmers. In Zabul, Paktya, Pakteka, Kandahar, Helmand and Ghazni, the majority of farmers were found by the surveys to have no oxen and to hire tractors. This may reflect the scacity of oxen, or an ample supply of cash to purchase or hire tractors.

FORESTS

In the pre-war period, natural forest was thought to cover 2 million hectares, representing about 30 million cubic meters of wood. Even in that period forest reserves were being depleted because of wholesale cutting and wastage. In recent years ruthless felling of the forests in Konar and Paktya feeds an exploitative crossborder trade with Pakistan, leaving behind denuded hillsides but little cash in the hands of Afghans. Reports from Konar tell of trucks daily plying the mountain passes to Pakistan. The trucks are loaded with 100 beams of hardwood perhaps 300 centimeters in length for which the trader paid Rs. 50 per log and for which he can expect Rs. 900 per log in Pakistan. Ultimate destination of some of the hardwoods is the Middle East.

These hardwoods are not a key input to housing construction. Traditionally Afghan farmers have grown poplar trees along irrigation canals, rivers and streams. Poplar provides ridge poles, lintels and other items for traditional housing construction as well as fuel, furniture and baskets. Its production is important to the farmer for domestic use and cash generation.

INDUSTRY MINING ENERGY
Handicrafts, not factory production, dominate the industrial sector. This reflects the rural character of the nation but does not always make visible the role that women play in rural non-farm production. UNDP (1990) estimates that handicraft producticn contributes $6.5 \%$ of GDP and $85 \%$ of manufactured exports. Handicrafts are thought to engage more than 200,000 laborers, the majority of whom are women working in their homes but marketing through 
a male intermediary. An estimated $65 \%$ of handicraft production is carpets. Though handicrafts are important as a source of income and employment, good information is not available on the quantity and quality of production or the distribution of benefits from eamings. There is evidence of a deterioration in quality because of shortages of raw materials and because the need for income induces faster, but lower quality, production. Factory production generally has declined since the pre-war period. Only wheat flour, bakery products, shoes and chemical fertilizer show increases. Official data indicate, however, that fertilizer production declined in $1989 / 90$ from 1980s levels. For most sub-sectors, the declines appear to reflect disruptions of war, uncertain business climate, interruptions of raw materials and energy supply and loss of skilled manpower.

Recent government policy has reversed the traditional bias of preceding Governments to public sector production at the expense of the private sector. Since 1987, the Government has actively encouraged private investment and established a Central Office for Development and Promotion of Private Investment. It also reinvigorated an autonomous Chamber of Commerce. Lack of financing and the uncertain climate for anything but short-term investment limit the impact of changed government policy on private sector production.

Afghanistan has inadequately surveyed but potentially valuable mineral resources in iron and copper. Gas is the principal resource presently exploited. Gas production reportedly peaked at 2.8 billion cubic meters in 1984-85 and decreased to 1 billion cubic meters in 1988-89. Recently production was stopped because of technical and security problems. Production has primarily been exported to the USSR, accounting for 47\% of export earnings in 1986-87 and for $29 \%$ of government revenue. Gas is also used to produce urea and a limited amount of electric power. Coal deposits are estimated at 400 million tons. Production in 1989 was estimated at 135,000 tons, down $8 \%$ from the previous year and $42 \%$ from 1978. Mines in Samangan, Bamyan and Herat are currently not producing because of the war situation. Coal is used for domestic consumption and the public sector industries at Jangalak in Kabul.

Energy constraints cripple economic activity, create stress on the environment and work hardships on households. As noted, coal and gas are inefficiently exploited. They do not yet reach their potential for domestic and commercial use. Electricity production declined $13 \%$ between 1986/87 and 1989/90. Output is skewed toward urban areas --- only 6\% of the people have access to electricity and half of them are in Kabul. Electrical service in Kabul is erratic and rationed for priority institutions. This reflects war damage to hydroelectric installations and to transmission lines (the Kajakai Dam, largest in the country, is out of service). For power generation, transportation and limited domestic heating, Afghanistan relies on diesel fuel imported from the Soviet Union and, more recently, Iran. Transport of petroleum is costly and subject to security risks. Shortage of energy puts pressure on Afghanistan's limited forests to meet domestic requirements. 
TABLE 4: ESTIMATED INDUSTRIAL, MINING AND ENERGY PRODUCTION

Mining and Ouarrying

Natural Gas

Coal

Salt

Food Processing

Wheat Flour

Bakery Products.

Sugar

Veg. Oils

Textile \& Leather Goods

Ginned Cotton

Cotton Textiles

Rayon Textiles

Woolen Textiles

Shoes (Leather)

Chemical Products

Fertilizer

Th. Tons

105

105

Other

Cement

Electricity

Mn. Cu. Mtr.

Th. Tons

Th. Tons

$1978 / 79$

$1989 \% 90$

Th. Tons

97

Th. Tons

20.4

Th. Tons

10.8

10.3

220

127

28.5

Th. Tons

Th. Tons

41.5

Mn. Mtr.

88.5

165

60

0

Mn. Mtrs.

23

24

Mn. Mtrs.

0.4

304

0.16

518

1.9

000 Pairs

126

845

68

Mn. KwH

1052

Source:

UNDP 1990 and Ministry of Central Statistics.

TRANSPORT

AND

COMMUNICATIONS
Inadequate transport and communications networks have always hampered commerce and industry but also the efforts of the central Government to manage national health and education systems. Roads are the main means of transport. There are $2,700 \mathrm{~km}$. of paved roads, primarily the larger part of the highway circling the centre of the country with spurs to the Soviet, Iranian and Pakistani borders. Additionally there are $4,300 \mathrm{~km}$. of gravel roads and about 10,000 of dirt roads. There have been few new additions to the road network since 1978. One major exception is a rail and road bridge over the Amu Darya at Hairaton. There has been considerable deterioration of the network as a result of war damage and neglect. UN missions in non-government-controlled areas report on the nearly impassable conditions in some areas, and more generally of the ingenuity of Afghans in keeping routes and vehicles usable. Military commanders, militia and the Afghan army control different sections of the road systems, some extracting tolls to permit passage. Remarkably commerce continues. 
That the number of trucks on the road is not significantly different in 1990 than in $1978(22,140$ to 23,600 ) reflects government rather than private sector expenditure to replace trucks destroyed or exported to Pakistan. The number of buses decreased from 12,290 to 9,800 and cars and taxis increased from 30,600 to 33,872 . Road freight is estimated to have declined from 1,943 to 1,080 million tons per kilometer. These estimates exclude the considerable traffic in areas outside government control.

HOUSING

The Government housing sector has been oriented toward planned urban construction in multi-family units mainly in Kabul. Since the 1960s a Master Plan for Kabul envisaged replacement of the old city with pre-fabricated apartment buildings. During the 1980s, construction of pre-fabricated housing in Kabul produced about 1200-1800 units per year, enough to alter the skyline of some neighborhoods but insufficient to meet the needs of in-migrants during that period. The private sector or individual construction has met that demand, building smaller units in a traditional mode.

During the war urban housing in towns other than Kabul has been destroyed. Moreover, as much as one third of rural housing may have been destroyed or severely damaged. Rehabilitation of housing and resettlement will strain limited supplies of building materials. There are differing views on strategies for managing housing reconstruction and supplies. The Danish Committee for Aid to Afghan Refugees operating cross-border in Konar province has set up production of pre-cast concrete beams for roof construction and lintels for windows. DACAAR found that the cost of pre-cast elements in Konar was lower than that of timber. Habitat, working cross-line north of Kabul found that timber (poplar) beams and lintels were lower cost and that Habitat support to housing stimulated traditional production and trade in poplar. Habitat has also seen autonomous revival of brick kiln production in areas where it operates.

\subsection{PUBLIC FINANCE}

Government policy and practice throughout the 1980s have pushed the national economy out of balance. The requirements of war have militated expenditures that may have amounted to as much as $80 \%$ of the government total (UNDP, DCR, 1989). Revenues have not kept pace with expenditures. Development expenditures have been drastically reduced. The gap between exports and imports continues to grow. Money supply and exchange rate practices, price controls and subsidies contribute to inflation and severe price distortions.

\section{REVENUE AND EXPENDITURE} in 1988 amounted to only one half of 1978 revenues.

Government capacity to raise revenues has eroded significantly during the war. While Government revenues in nominal terms increased between 1978/79 and 1986 (16.5 billion to 42 billion Afghanis), they have been declining since 1986 (UNDP DCR 1989). Half the nominal increase in the 1978-1986 period is due to earnings from gas exported to the Soviet Union. If gas is excluded, the government revenues from other sources 
Aside from revenues from gas exports, import duties are a major revenue source. Income and corporate taxes, limited to a small segment of the economy, are the only direct taxes collected. Thus a major and continuing public finance issue in Afghanistan is the capacity of Government to raise and broaden its revenue base. The World Bank in 1978 noted the extremely small size $(<7 \%)$ of the Afghan tax to GNP ratio, relating it to the small size of the monetized sector and the role of smuggling as a major economic sector beyond the reach of tax collection. Even if not easily calculable, the tax ratio remains low today (See Robert R. Nathan Associates 1990). The reasons remain the same: a non-monetized sector, smuggling and illegal revenues beyond the reach of tax collection. What is different today is the emergence of decentralized and locally-based revenue collection 'systems' of local commanders and shura in areas not controlled by the Kabul Government. Evidence on this revenue collection is anecdotal. Key forms of tax are apparently shares of crop production and road tolls.

Government recurrent expenditure in nominal terms increased from 12.5 billion Afghanis in 1978 to 160 billion Afghanis in 1988. Expenditure increases are due to military expenditures, subsidies to consumer items, and government wages and salaries. UNDP (DCR 1989) estimates that military expenditures may account for as much as $80 \%$ of expenditures. It is not at all clear that available budget figures fully reflect military and security expenditures.

Recent economic pressures on Government are reflected in the decrease of the development budget to Afs. 9 billion in 1989 from Afs 21 billion in 1988 and Afs 14 billion in 1978 (nominal terms) (UNDP DRC 1989). The Government budget is increasingly a deficit operation financed by the Central Bank through a rapid increase in money supply. This contributes to rapid inflation and depreciation of the Afghani.

A Robert R. Nathan Associates analysis of the period 1978/79 to $1986 / 87$ concludes that an average annual revenue increase rate of $14 \%$ during that period fell far short of the average annual increase in expenditures of $23 \%$. With an average annual inflation rate of $14 \%$, revenues in real terms actually remained constant while expenditures steadily increased.

\begin{tabular}{|c|}
\hline MONEY \\
AND \\
CREDIT \\
\hline
\end{tabular}

Key issues here revolve around the expansion of money supply since 1978, the limited role of the government-owned commercial and specialized banks and the continuing major role of the money bazaar. Money supply has grown at a rate nearly equivalent to the inflation rate. Money supply expansion reflects the growing deficit spending of Government and results. from borrowing by Government from the banking system.

The government commercial banks and the specialized banks (Agricultural Development Bank, Industrial Development Bank, Mortgage and Construction Bank) have little impact on the private sector. Even in the pre-war period, the outreach of these specialized banks was limited. The Agricultural Bank in 1978 was estimated to reach only $7 \%$ of farmers. The money bazaar, long an institution in the Old City, continues to supply basic financial services, including money changing (see below), financing of external trade, and credit. These private market interest rates for loans have been estimated at around $27 \%$ compounded annually. The private 
money dealers operate freely and openly, without government interference. There is no official or 'trade association' monitoring or regulation, and therefore it is difficult to estimate the volume and range of transactions by the money market. Afghan traders in 1991 indicate that credit financing is primarily for short-term trading transactions and not for longer-term, development investment.

EXCHANGE

RATE

POLICIES

Multiple official exchange rates exist side by side with the money bazaar market rate. The official rate applies only to limited transactions including certain aid transactions and some exports. Private sector and some public sector export transactions are handled through the money bazaar at the market rate. Throughout the 1980 s to the present the government exchange rate has remained at Afs. 50.6 to US $\$ 1.00$. The market rate has risen from Afs $38=$ US $\$ 1.00$ in 1978 to over Afs $1000=\$ 1.00$ (1991). The depreciation of the Afghani has not been at a steady rate. The rate of exchange fell by nearly four-fold between 1978/79 and 1986/87 (from Afs 38 to Afs 148 per US\$ 1.00) and eleven-fold between 1978/79 and 1989 (from Afs 38 to Afs 414 per US\$ 1.00). In 1989 there was a sharper drop, perhaps reflecting the political uncertainty at the time of the Soviet troop withdrawal. Again in 1991, there has been a further, rapid deterioration to the present level (Afs $1100=$ US $\$ 1.00$ October 1991).

INELATION

Inflation had the effect of tripling prices between 1978/79 and 1986/87. Since then, the rate of inflation accelerated rapidly in 1989 and again in 1991, fueled in major part by growing government budget deficits and political uncertainty. The impact of price inflation when incomes have not been rising at the same rate, is somewhat mitigated by government subsidies on food and through free food entitlements for many classes of government employees. For poor families lacking entitlement and access to parallel incomes, the impact has been harsh.

Because of subsidies and price controls as well as the political situation, price statistics in Afghanistan are deficient. Data has been collected regularly on prices of basic items in Kabul and the UNIDATA publication of Kabul prices reflects price trends by category (Table 5).

Government has tried to control prices or mitigate their impact through several measures. Recently, for example, they have encouraged private sector food imports in order to increase supplies. The key tool for influencing prices and their impact has been through free and subsidized food distribution through a system of entitlements or food coupons. UNDP reports that 450,000 food coupons were distributed in 1989. ICRC estimated 225,000 coupon holders in Kabul. For those households entitled to coupons---most classes of government employees and army widows---the access to basic food coupons that represent has been an important means of survival. Chapter 7 describes the coupon system and government subsidy of bakeries in relation to food security. The subsidies have been possible because of availability of commodity aid from the USSR. With the contraction of Soviet aid, Government capacity to subsidize basic foods is also shrinking. Distribution of food rations was five months behind schedule in October 1991. Employees outside the public sector do not in general have the coupon entitlement. This group includes day laborers, who may earn (late 1991) Afs. 1500 per day and the less skilled 
or educated migrants from outside Kabul. Other international food aid (WFP) is not directed toward the government distribution system, but toward food for work in support of rehabilitation.

In government controlled areas, energy prices are also subsidized, distorting pricing for other commodities. Electric power is sold below cost to domestic consumers and closer to cost to industrial users. The price of petrol has been subsidized but is now no longer effectively available to the private sector at the subsidized price of Afs 40 per liter, or US\$ .04 at the market price. The black market price of $\$ 4.00$ or more per gallon more closely reflects reality.

There has been price inflation and volatility outside areas of government control. The consequence at the household level is considerable variation in purchasing power by location. The Agricultural Sector Support Project (DAI) funded by USAID in Peshawar has been tracking prices of agricultural commodities in Afghanistan by province. Their 'informal price index' for December 1989 to December 1990 shows a 78\% increase in prices of wheat, mutton, beef, oxen, urea and phosphatic fertilizer. Price rises were least for consumer items $(49 \%)$ and highest for production input items $(106 \%)$. These findings show high variation in price by province. The highest average wheat price was in Faryab Province at Afs 1228 per seer while the lowest average price was Afs 654 per seer in Konar. Price levels reflect natural conditions (pest infestation in Faryab), easier access to production inputs (Konar) or other factors which operate locally.

\begin{tabular}{|c|c|c|c|c|}
\hline $\mathbf{T A B}$ & $\begin{array}{l}\text { 5: CONSE } \\
\text { Consumer } \\
197 \\
\text { (1) }\end{array}$ & $\begin{array}{l}\text { RICEIN } \\
\text { lex in Kab } \\
1990 / 91 \\
=100)\end{array}$ & $\begin{array}{l}\text { KABU } \\
y\end{array}$ & \\
\hline & $1978 / 79$ & $1988 / 89$ & $1989 / 90$ & $1990 / 91 *$ \\
\hline Food Stuffs \& Tobacco & 100 & 434.2 & 923.0 & 1179.7 \\
\hline Cereal & 100 & 341.0 & 1139.9 & 1300.6 \\
\hline Meat & 100 & 6819 & 1126.5 & 1466.8 \\
\hline Dairy Products & 100 & 508.4 & 1026.5 & 1457.9 \\
\hline Oil and Fats & 100 & 470.0 & 819.8 & 858.4 \\
\hline Vegetables & 100 & 598.0 & 1301.1 & 1576.8 \\
\hline Fruit & 100 & 452.6 & 893.5 & 969.9 \\
\hline Other Food Stuff & 100 & 294.3 & 739.5 & 1098.2 \\
\hline Cigarettes \& Tobacco & 100 & 519.7 & 952.8 & 1141.5 \\
\hline Non-Food Items & 100 & 370.0 & 493.0 & 987.0 \\
\hline Source: UNIDATA 1991 & & & & \\
\hline
\end{tabular}


FOREIGN

TRADE

The value of Afghanistan's exports, as officially reported, has decreased steadily from 1978 while the value of imports has doubled (Table 6). The trade gap has been growing at the same time as commodity and project assistance has been declining. While the bilateral trade account in the 1970s showed a deficit, there was an exchange surplus because of official aid, tourism earnings and remittances from workers abroad. In the 1980s. these factors fail to offset the trade imbalance and revenue from the export sector has declined.

Cotton, a traditional export, has declined because of security conditions and because of government pricing policies. Tourism receipts are negligible. The principal trading partner of Afghanistan during the 1980s has been the Soviet Union.

A considerable but unmeasured portion of Afghanistan's foreign commerce is unrecorded. A Robert R. Nathan Associates study estimated that official trade data underestimated the volume of trade between Afghanistan and Pakistan by a factor of eight. Official export data is compiled on the basis of information from border posts, which may be unmanned or out of government control, and from $\mathrm{Da}$ Afghanistan Bank and public and private traders themselves. Imports, particularly those through the private sector, are not systematically recorded.

This unrecorded commerce includes substantial exports of opium (see above), unrecorded remittances from abroad, and revenues from smuggling. Afghanistan, with import duties lower $(25 \%)$ than those of Pakistan (125\%), is ideally sited as a staging area for smuggled goods over the historically porous border with its neighbor to the east. Electronic goods from Japan and consumer goods (from cigarettes to toiletries) are imported overland, chiefly through the Soviet Union and relayed overland to the iarge market in Pakistan, and by direct air connection to Eastern Europe. Afghan traders, who may have bases in New York and London, manage a transit trade for whatever consumer goods and commodities offer promise of a profit. There is also unrecorded movement of consumer goods and livestock across the Iran border. Vestiges of this trade can be seen in the shops of Kabul which are well stocked with luxury foods, electronics and other consumer goods. Other unrecorded trade includes hardwoods, precious and semi-precious stones such as lapis lazuli and emeralds. Production of these stones was strictly controlled in the pre-war period. Conflict and the absence of central control have allowed their exploitation.

Who benefits from this unrecorded commerce? It appears that both Government and the resistance do. Some of the earnings from unofficial activity undoubtedly pay for some of the unofficial imports to the country. Other earnings are transferred out of the country. There is no system for tracking this commerce and there is no systematic way of tapping, or taxing, these earnings for development. 
DEVELOPMENT ASSISTANCE

Aid flows throughout the 1980s have been bifurcated. Contributions from the Soviet Union and socialist bloc countries have gone to the Kabul Government. Development assistance from the Western bloc and Saudi Arabia has gone to cross-border development activities. Following the withdrawal of Soviet troops and the changes in the Soviet Union and Eastern Europe, aid flows from that direction appear to be declining. Increased assistance through the United Nations has partially filled the gap in the interim. With the reduction of USSR support and the end of cold war conditions that fostered high aid levels in the past, prospects are not bright for increased levels of aid to Afghanistan.

There is differing information on development assistance and debt from several sources. One, UNDP, reports (DCR 1989) that external assistance actually disbursed in Afghanistan in 1989 was $4 \%$ higher than in 1988 . The total reported as disbursed in 1989 was US\$152.5 million. The share of total bilateral (mostly Soviet Union) fell in 1989, while that from the United Nations rose 6.7 times. USSR assistance in 1989 was $\$ 94$ million or $62 \%$ of the total. NGOs accounted for $\$ 7.5$ million or $4.9 \%$ of 1989 assistance. Some information on NGO cross-border funds are given in Annex IV. Little is known about development assistance from Saudi Arabia and other Arab governments. The increases in UN assistance in 1989 and also 1990, were due to food and relief assistance provided by UNHCR, the initiation of UNOCA assistance and an increase in UNICEF and UNDP assistance.

Two thirds ( $\$ 100.1$ ) of 1989 assistance was in the form of grants; the remaining $\$ 52.5$ million came as concessional loans, primarily from the USSR. The total Afghan debt in 1989 was US\$ 4.5 billion. The debt service ratio has remained low because of repeated re-scheduling of the debt to the USSR. Debt servicing in 1989 was US\$ 23 million.

Human resource development has been the highest priority of assistance to the Kabul Government and for cross-border activities. The UNDP (Kabul) Development Cooperation Report for 1989 indicates that $35 \%$ of total assistance went for human resource development. The largest part of this was $\$ 40$ million for training of 7800 Afghan students in the Soviet Union. A similar number of students were to be trained in 1990 . Humanitarian, health and transport were the remaining top priorities for development assistance to the Kabul Government. NGOs implementing cross-border activities have invested heavily in training of basic health workers, primary teachers, and several categories of agricultural extension workers. A unified assessment of the numbers and skills of these workers does not exist.

\subsection{ECONOMIC ISSUES AND THE SITUATION OF CHILDREN AND WOMEN}

Creating the conditions for sustainable improvement in the situation of children and women requires a cessation of war, the rebuilding of a civil polity and macro-economic reform and reconstruction. There are several sectoral economic issues with the potential for opportunity or, if not properly managed, harm. 


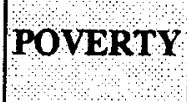

Poverty is a key feature of the Afghanistan economic situation. Government capacity to fund health and education services has eroded. The number of households below the poverty line probably exceeds the pre-war survey estimates of $20-40 \%$.

The meaning of Afghanistan's poverty on a macro-economic level has been reviewed above. Government revenues have been falling recently as expenditures, primarily for the war effort, have been rising. Government capacity to raise revenue was never strong. The money which visibly exists in the country may come largely from smuggling, opium, of cross-border payments of salaries to mujahidin fighters, teachers, health and agricultural workers and others, or of payments to military commanders. In the short run this money puts resources into rural areas. It may have a multiplier effect in reviving rural demand and supply. There is not much evidence that it is being invested in children. In the long term money from these sources is either not sustainable or it does not represent a viable source of government tax revenue.

\section{POVERTY IN THE OLD CITY}

While conducting fieldwork in the old section of Kabul, a poor housewife said make sure you go to the poorest homes in our neighborhood. Go to widows' homes-those are the ones who need help the most..

"A young man led us down narrow pathways to just such a household-a desperately poor little compound containing six young children, all wearing used clothing, and an old man who was crippled, the man made paper kites for an income. He invited us into a mass of mud. The mother of the children was out begging in the city bazaar. Her husband had been killed in a battle in Khost. . .

Pamela Hunte

UNICEF Consultant 1991

On the household level poverty weighs directly on children and women. There is no data today on income distribution or on percentages of Afghans living below the poverty level. Surveys in the late 1960's found $20-40 \%$ of Afghans living below the poverty line; in Kabul $6 \%$ of Afghans received more than $50 \%$ of the income; in rural areas there was a better distribution. Even without data on poverty, present evidence suggests an increase in numbers of people living in poverty. The declines in agricultural and industrial production,, the destruction of infrastruction, the deterioration of health and education services, the loss of human resources and continuing insecurity create the conditions for impoverishment of increasing numbers of people.

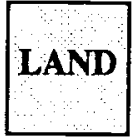

Land reform in 1978 sparked resistance and rebellion against the new Kabul Government, and led to population upheavals. In 1991 the issue remains. Do land and land tenure questions have the potential of again becoming an issue as growing numbers of the 4.5 million Afghan refugees in Iran and Pakistan return to their traditional villages to take up where they left off years before? 
Land issues are volatile in many countries. Distribution may be inequitable, and contribute to inefficiencies in production. In Afghanistan these distributional questions have long existed, but deep respect for ownership rights and traditional village social and economic relationships made the 1978 PDPA Government attempt at land reform a politically costly effort. The World Bank in 1978 reported that farm ownership and tenure patterns---large landholdings farmed by sharecroppers and tenants as well as small fragmented holdings---served as a disincentive to investment in farm improvements that would increase yields. A 1973 UNICEF study of village life described the nature of this maldistribution of land at the village level. In one of the study villages, $52 \%$ of the households owned only $13 \%$ of the land. In 1978, the post-revolution Central Statistics Office noted that $5 \%$ of the households owned $45 \%$ of agricultural land and that there were 666,000 landless peasants who worked for landlords under tenancy arrangements that might have allowed them to retain one sixth to one eighth of their produce. Traditional water rights or distribution systems favored landowners at the head of canals and discouraged community improvements and efficient use of water resources. Traditional debt systems (gerau) also worked to keep poor farmers impoverished.

\section{THE POVERTY LEVEL - 1970S STYLE}

"The village of Ri-Jang lies about 20 kilometers south of the large city of Mazar-i-Sharif in northern Afghanistan. It comprises 224 inhabitants living in 42 households. Its existence centres around agriculture, which is at the mercy of the rains... In a typical year over 65 percent of total income is from dry-farmed wheat, about 23 percent from livestock, 2 percent from irrigated gardens, and the remainder from casual labor. But income and wealth in Ri-Jang are distributed very unequally: the wealthiest 8 families own $78 \%$ of the goats and sheep, 65 percent of the land and earn almost 65 percent of the total income; while the poorest 22 families own less than 5 percent of total goats and sheep, only 13 percent of the land and earn only 15 percent of total income. Although only 3 families own no land at all, all of the poorest 22 families cannot make enough to subsist from their own land. Hence more than half of the wheat they produce is from sharecropped land. They are also forced to supplement their incomes by hiring out their labor, and by carrying snow in the summer and bushes in the winter down to Mazar-iSharif on the donkeys most of them own. Almost half their income comes from these sources. Health in Ri-Jang is poor: 38 of $\mathbf{4 2}$ households drink heavily polluted water.. 4 households eat meat less than once a week.... Only 20 people in Ri-Jang are literate, including only 1 woman."

- From the CINAM study of

Afghan villages, UNICEF 1973.

The attempted land reform of the PDPA Government failed but the patterns of land ownership in rural Afghanistan have nonetheless changed. Civil war resulted in the dislocation of at least 4.5 million external refugees and perhaps 2 million internal refugees. With the movement of people out of rural areas, the ratio of people to cultivable land decreased. What was the place of these refugees in the old land tenure structure? And who now controls the land and water? Without a farm census the answers to these questions are conjectural. 
In 1987 the SCA Agricultural Survey found that owner-occupiers had fallen by $31 \%$ between 1978 and 1987 and that the number of sharecroppers had increased in that period. The 1988 and 1989 Agricultural Surveys of SCA found that about $78 \%$ of farmers were owner-occupiers. implying "a substantial recovery in the proportion of owner-occupiers". It is difficult to draw conclusions from these SCA percentages. They could imply either a return of owner-occupiers and displacement of sharecroppers or a situation where sharecroppers have re-defined themselves as owner-occupiers.

Other sources suggest that, at least in some areas, it was the landlords and owner-occupiers who fled, either to avoid conflict or to avoid living under the PDPA Government. In Konar, from where $53 \%$ of the population is estimated to have left as refugees (UNIDATA), cross-border teams from DACAAR suggest that refugees fled the fertile river valleys and that unrelated groups moved down from the hills to take over the farmland. Evidence from other areas suggests that those who fled may have been from a minority ethnic group feeling insecurity from their majority neighbors in an uncertain time. As part of his strategy to unite Afghanistan in the late 19th century, Amir Abdur Rahman Khan forcibly moved Pashtun groups to settle in north of the Hindu Kush. Descendants of these settlers are thought to be well represented among refugees from northern provinces. International staff working cross-border and cross-line also report on the role of some military commanders as a new class of landlords who take as much as two thirds of the crop from sharecroppers in order to finance war efforts. With only fragmentary information on land tenure and the claims of returning refugees, it is not possible to estimate the potential for conflict over land tenure in the future.

It is true that Afghans have traditional procedures for resolving land disputes. Disagreements may be referred to a local, respected gazi or judge. In areas where disputes are between different ethnic groups or clans, where the traditional social contract has eroded and where the use of guns is common, the potential for conflict is increased. There are also provinces where significantly higher portions of the rural population have fled as refugees.

A related issue is the availability of agricultural land in relation to the numbers of refugees who will return to farming. Farmers currently inside identify a labor shortage as one of their constraints. Before the war there was underemployment of labor in agriculture. The potential population of rural Afghanistan, should sizeable numbers of refugees return from Iran and Pakistan to farms are substantially greater than the pre-war farming population. At the same time, damage to irrigation infrastructure and the lack of distribution systems and credit for inputs makes existing land less productive than its potential. And today, the best farming land is being used. The return of refugees will bring into cultivation increasingly marginal land, speeding process of degradation. The significance of all this is that rural land is probably not sufficient to sustain the returning refugees. The implications for children and women are threats to nutrition and the lack of resources for health and education. 
CASH INCOME

The evidence that comes in from expanding UN and NGO work in rural areas points to the importance of cash income opportunities in rural areas to enable rural households and communities to obtain non-food necessities, and to invest in health and education. Cash is presently available in rural areas but it comes from sources that are not likely to be sustainable in the future. Payments to mujahidin fighters and commanders and salaries paid cross-border to health, education and agriculture workers may shrink as strategic and donor interest in Afghanistan declines. Pressures to reduce opium poppy production may increase. Three areas of opportunity for expanding rural production and income can be identified:

There are traditional cottage industries in rural Afghanistan where production and marketing has been held down or depressed because of the prevailing insecurity. Key industries are carpets and silk production, areas where women producers dominate. Brick, pottery and glass production, raisin processing and cultivation of quick growing timber for construction are among other village level enterprises with potential for increased domestic and international markets. Meat, dairy and vegetable production for local and urban markets are other areas where Afghans have the basic skills, but where support may be needed to create, re-establish and expand markets. Poultry production is a traditional function of women in many areas.

Strengthening and expansion of household garden production has potential for increasing valuable household food resources, and of generating income from surplus. Some UNICEF and other nutrition survey teams in rural Afghanistan noted the absence of household production among families with poorly nourished children. Practice varies among classes and throughout the country. The absence of gardens may reflect lack of the most basic resources for planting. Household gardens are a potential entry point for working with women and working on nutrition and education in other life skills.

- New areas of production, related to food processing and packaging and daily use articles may have potential for domestic and international markets.

Capital may be the basic factor missing that would enable poor rural and urban people to initiate or expand traditional cottage industries as a measure of security and transport facility is restored. UN missions and NGOs report that villages in the Hazarajat and women silk producers in Herat have asked about credit. Government credit institutions never reached adequately into rural areas and credit was not in any case available to women. Traditional money-lending in Afghanistan, as elsewhere, was often exploitative and did not enable poorest borrowers to sustain and expand independent production.

In an economy that is predominantly agricultural, cottage industry opportunities have a direct relationship to the extent and nature of poverty and to the empowerment of families most at risk. 
REACHING WOMEN

Disasters like the civil war in Afghanistan wreak havoc. They may rupture traditional patterns of living. This disruption is costly to the social fabric; it also creates opportunities for Afghans to alter traditional cultural, economic and political behaviors that are no longer functional and that indeed are harmful to family, community, and nation.

The traditional isolation of women from information and from the benefits of their own production may no longer make sense in terms of the conditions facing Afghanistan today. The ways in which this isolation can be broken needs to be designed by Afghans themselves.

Reaching women is a politically sensitive issue in Afghanistan. It is the issue that helped spark the resistance to the new government in 1978. It is the issue that aroused opposition, threats and violence in Pakistan against some projects serving refugee women. Recognizing the sensitivity of the issue should be a starting point, not a finishing point. Outsiders may argue that the question of reaching women should be put aside until the critical needs of rehabilitation and resettlement are solved. Waiting misses the opportunities created by social flux. Waiting allows new patterns of operation---which continue to exclude women---to be established.

Pamela Hune

UNICEF Consultant, 1991
We entered a small two-story compound where a wedding was taking place. Afier meeting the guests and having tea, the mother of the groom said, So look around-there are at least four widows right here among our people!' These women asked if we had any employment for them. One said, 1 'll do anything-I have two babies to support. And, if you want, I can find five or six other widows who will be willing to start work immediately." 


\section{CHAPTER 4 \\ POPULATION AND ITS IMPLICATIONS}

\subsection{DEMOGRAPHIC OVERVIEW}

There is little reliable data on the demographic characteristics of Afghanistan. The absence of reliable baseline data is a practical constraint on planning and monitoring relief, rehabilitation and development programmes for children and women. The best available estimates of key demographic indicators suggest an unusual profile that has both immediate and longer-term implications for the situation of children and women:

- Afghanistan is one of few countries of the world showing a decline in population inside the country. From an estimated total population (including 800,000 nomads) of $13,851,358$ in 1979 (CSO), the internal population has dropped to $12,870,529$ in 1990 (UNIDATA; UNICEF).

- Afghanistan has experienced massive population shifts since the late 1970s. More than one third of the Afghan population has been uprooted. An estimated 4,569,282 are refugees in Pakistan and Iran. There are an estimated 1.5 to 2.0 million internal refugees.

- This brings the total population of Afghans, internal plus refugees in Pakistan and Iran, to $17,419,811$.

Estimates of the number of nomads range from 700,000 to 2.5 million. The estimate presently used by Government and most international agencies is 1.5 million nomads.

Estimates of war casualties range from 800,000 to 1.5 million people. The number of widows, orphans and disabled has not been reliably estimated but it far exceeds the capacity of the Afghan family system to absorb them.

The total fertility rates estimated for Afghans are among the highest in the world (6.8 UNFPA 1991) and reach significantly higher levels in the refugee camps.

In summary, estimates suggest a sharp population decline inside Afghanistan in the years immediately following 1979; a gradual growth of the remaining internal population from 1979 on so that the 1979 levels will be reached in the early 1990s even without the return of refugee population; massive internal and external dislocation of population; a particular paucity of data on the nomad population; and the potential for explosive population growth.

The demography of Afghanistan has long been a subject for debate. It remains a controversial subject. The assumptions on which estimates are made will always be open to discussion. For this reason the demographic data needs to be used with caution. For population totals nationally, 
by province and district, UNICEF relies on estimates developed by UNIDATA with adjustments made by UNICEF. A discussion of the UNIDATA estimation methodology can be found in Afghanistan, Population Estimates By Province, District and Sub-District, UNIDATA, April 1991. A listing of principal sources of population information are included in Annex V.

TABLE 7: COMPARATIVE ESTIMATES OF AFGHAN POPULATION

\begin{tabular}{lccccc} 
& 1979 & 1991 & 1990 & 1990 & 1990 \\
& GOA & GOA & UNHCR/DCA & ADS/EIGHMY & UNIDATA/UNICEF \\
Settled & $13.1 \mathrm{~m}$ & $16.4 \mathrm{~m}$ & $16.2 \mathrm{~m}$ & $15.9 \mathrm{~m}$ & -- \\
Nomads & $0.8 \mathrm{~m}$ & $1.5 \mathrm{~m}$ & -- & $0.9 \mathrm{~m}$ & {$[1.5 \mathrm{~m}]$} \\
\hline TOTAL & $13.9 \mathrm{~m}$ & $17.9 \mathrm{~m}$ & - & $16.9 \mathrm{~m}$ & $17.4 \mathrm{~m}$ \\
Refugees & --- & -- & -- & $4.5 \mathrm{~m}$ & $4.5 \mathrm{~m}$ \\
$\begin{array}{l}\text { Total Pop. } \\
\text { Inside Afg. }\end{array}$ & -- & -- & - & $12.4 \mathrm{~m}$ & $12.9 \mathrm{~m}$ \\
\hline
\end{tabular}

*Differences with totals due to rounding.

Sources: $\quad$ GOA, Ministry of Statistics; UNIDATA, UNICEF, Eighmy.

\subsection{POPULATION TOTALS}

For planning and monitoring purposes UNICEF is using the estimate (1990) of total population of Afghans of 17,419,811. This includes a population inside Afghanistan of 12,870,529, and refugees in Pakistan and Iran estimated at 4,549,282. Included in the total are an estimated 1.5 million nomads, of whom 398,049 are estimated to be refugees. While several different attempts have been made to estimate current Afghan population, there is remarkably little variation among the estimates (Table 7). Differences between the UNIDATA and the Eighmy estimates are almost equivalent to differences in estimates of the nomad population.

Table 8 shows the estimated distribution of population by province of residence or by province of origin (in the case of refugees). The estimates have been made by UNICEF Kabul on the basis of UNIDATA figures that have been adjusted for the presence of nomads, changes in counting of the internally displaced and UNHCR estimates of returned refugees from Pakistan and Iran. Estimates of Afghan population in Table 8 do not make reference to emigrants since 1979 to other countries, a number estimated at 222,298 . 
TABLE 8: ESTIMATED AFGHAN POPULATION 1990 BY PROVINCE OF LOCATION OR PROVINCE OF ORIGIN (FOR REFUGEES), INCLUDING NOMADS

\begin{tabular}{|c|c|c|c|c|}
\hline$\therefore$ & $\begin{array}{l}\text { Adjusted } \\
\text { Inside } \\
\text { Population } \\
\end{array}$ & $\begin{array}{c}\text { Refugee } \\
\text { Population } \\
\text { Pakistan/Iran }\end{array}$ & $\begin{array}{c}\text { Refugee } \\
\text { Population } \\
\text { as \% of Total }\end{array}$ & $\begin{array}{c}\text { Total } \\
\text { Afghan } \\
\text { Population } \\
\end{array}$ \\
\hline Kabul & $1,659,945$ & 350,082 & $17 \%$ & $2,010,027$ \\
\hline Kapisa & 408,142 & 10,003 & $2 \%$ & 418,145 \\
\hline Parwan & 379,988 & $41,930$. & $10 \%$ & 421,918 \\
\hline Wardak & 388,146 & 26,708 & $6 \%$ & 414,814 \\
\hline Logar & 46,909 & 215,737 & $82 \%$ & 262,746 \\
\hline Ghazni & 804,575 & 69,890 & $8 \%$ & 874,465 \\
\hline Paktya & 140,566 & 529,807 & $79 \%$ & 670,373 \\
\hline Nangarhar & 467,540 & 519,957 & $53 \%$ & 987,497 \\
\hline Laghman & 389,923 & 81,555 & $17 \%$ & 471,478 \\
\hline Konar & 184,575 & 210,996 & $53 \%$ & 395,571 \\
\hline Badakhshan & 612,962 & 316 & - & 613,278 \\
\hline Takhar & 625,122 & 18,237 & $3 \%$ & 643,359 \\
\hline Baghlan & 427,388 & 222,763 & $34 \%$ & 650,151 \\
\hline Kunduz & 368,232 & 293,623 & $44 \%$ & 661,855 \\
\hline Samangan & 315,667 & 19,556 & $6 \%$ & 335,223 \\
\hline Balkh & 636,325 & 43,557 & $6 \%$ & 679,882 \\
\hline Jawzjan & 345,275 & 30,133 & $8 \%$ & 375,408 \\
\hline Faryab & 661,015 & 7,090 & $1 \%$ & 668,105 \\
\hline Badghis & 166,803 & 167,100 & $50 \%$ & 333,903 \\
\hline Herat & 373,446 & 487,719 & $57 \%$ & 861,165 \\
\hline Farah & 202,987 & 248,666 & $55 \%$ & 451,653 \\
\hline Nimroz & 179,744 & 89,044 & $33 \%$ & 268,788 \\
\hline Helmand & 517,449 & 263,341 & $34 \%$ & 780,790 \\
\hline Kandahar & 428,278 & 329,634 & $43 \%$ & 757,912 \\
\hline Zabul & 199,437 & 64,557 & $24 \%$ & 263,994 \\
\hline Oruzgan & 541,028 & 40,863 & $7 \%$ & 581,891 \\
\hline Ghor & 444,301 & 15,882 & $3 \%$ & 460,183 \\
\hline Bamyan & 307,066 & 15,613 & $5 \%$ & 322,679 \\
\hline Pakteka & 288,864 & 94,295 & $24 \%$ & 383,159 \\
\hline Saripul & 358,833 & 40,628 & $10 \%$ & 399,461 \\
\hline Total & $* 12,870,529$ & $4,549,282$ & $26 \%$ & $17,419,811$ \\
\hline
\end{tabular}


Eighmy has developed an additional breakdown of population distribution inside Afghanistan according to location in Government controlled and resistance controlled areas. Table 9 shows his estimates indicating that $65 \%$ of the population live in resistance controlled areas. Others estimate that the resistance controls $80 \%$ of the land area.

\section{TABLE 9: ESTIMATE OF POPULATION DISTRIBUTION BY AREA OF GOVERNMENT AND RESISTANCE CONTROL}

Government Control

1. Greater Kabul (4 woleswalis/alaqadaris)

$4,358,990$

$1,787,896$

2. Other Urban Centers

$2,571,094$

Resistance Control

$8,004,235$

Total

$12,363,325$

Source: $\quad$ Eighmy 1990

DENSITY

Highest density of population in Afghanistan is in Kabul and in a band running from the northern provinces south-east to Nangarhar. Map 1 in Annex II shows UNIDATA estimates of population density by province. Provinces in the southwest and Badakhshan are thinly populated. Low population density combined with inadequate transport and infrastructure creates constraints on access and potential for inclusion in rehabilitation and development activities. The UNIDATA estimates of population density include the population currently inside Afghanistan as well as refugees in Pakistan and Iran by province of origin.

\section{DEMOGRAPHIC INDICATORS}

For purposes of planning during the 1990s, UNICEF is using the following key demographic indicators:

$$
\begin{aligned}
& \text { Crude Birth Rate }=49 \\
& \text { Crude Death Rate }=23 \\
& \text { Infant Mortality Rate }=169 / 1000 \\
& \text { Population Growth Rate }=2.6
\end{aligned}
$$

Estimating demographic indicators is difficult not only because of the lack of demographic data as discussed above but also because of dislocation and casualties due to war. The Ministry of Statistics, for example, has used a growth rate of $1.92 \%$. This is lower than the rate estimated for the 1979 Census (2.6\%) and estimates of 2.2 and $2.4 \%$ used by UNHCR and Eighmy. 
UNIDATA has also used a rate of 1.95 in its projections. The lower rates are useful in capturing the impact of war death. Assuming that the level of warfare will reduce and that mortality due to war and to preventable causes will decline, a higher growth rate for future projections seems valid. The rates chosen are consistent with the pre-1978 situation but do not take account of the possibility of a 'baby-boom' phenomenon often seen in post war situations.

UNICEF is also using a higher birth rate than the UNIDATA estimate of 41 per 1000 , as well as a higher death rate than the UNIDATA estimate of 21.5 per 1000 . Given the evidence of high fertility among Afghan women (see below) these indicators may be more useful for future projections, particularly of the child population. Table 10 presents these UNICEF projections. They include UNHCR estimates of gradually increasing number of returning Afghan refugees.
TABLE 10: MID-YEAR IN-COUNTRY POPULATION PROJECTIONS 1991-93

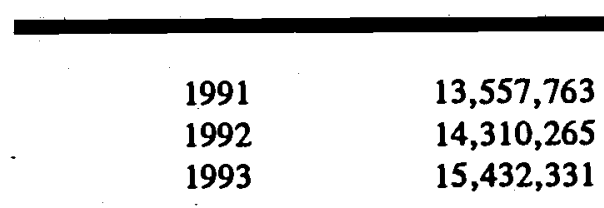

Source: UNICEF

\subsection{IMPACT OF WAR ON THE AFGHAN POPULATION}

CASUALTIES

There are no recent reliable estimates of the number of people killed on account of war. All information suggests a high level of mortality. Sliwinski, projecting from survey work with refugees in Pakistan, suggested that 1.25 million or $9 \%$ of the population had been killed (1987). Eighmy (1990) calculated 795,258 war dead but suggested that the number may exceed 1 million. Other estimates are both higher and lower. What is significant for the future is not only the total number, for which we have no accurate estimate, but the distribution. Using Sliwinski's analysis as indicative of the distribution, it appears that war related deaths are, not surprisingly, highest among men and heaviest in the productive middle years. The difference is 38 war-related deaths per thousand women but 134 per thousand for men. This is reflected in the high number of widows and orphans and in the high dependency ratio.

Sliwinski suggests that $20 \%$ of refugee women have been widowed by war. A 1988 UNICEF Afghan Women's Skill Inventory among refugee women in Pakistan found a similar proportion; $18.6 \%$ of women surveyed identified themselves as widows. There are no reliable estimates of number of orphans but Sliwinski's findings of a $19 \%$ orphan rate among one sample suggests that there are more than half a million and probably more than a million. [For many but nol all Afghan ethnic groups, an orphan is a child who has lost the father].

While male war-related mortality is higher than that of women, female mortality from bombing is estimated at nearly twice that of males. 
INTERNAL DISPLACEMENT

Little is known about internally displaced populations, except that they are large (1.5 to 2 million) and that displacement has taken the form of migration to the several cities perceived as havens or to the more remote interior. Very often households moved because of the intensity of fighting or bombing. There is anecdotal evidence that young urban males may have left cities to avoid conscription.

The urban share of the population is estimated to have increased from $15 \%$ (1979) to $23 \%$ (1989). The Kabul population may have doubled during this period. The 1986 Kabul Census indicated a population of 1.3 million for the then ten districts of Kabul City. This is an increase of $39.7 \%$ from the 1979 Census estimate of 931,000 Kabul residents and represents a growth rate of $5 \%$ a year. Some believe that the 1986 Census under-enumerated the actual population. Other estimates of Kabul population in the mid 1980s range as high as 2 million, though it is not clear whether these include Greater Kabul or are limited to Kabul City. It is believed that there has been some out-migration from Kabul during the late 1980s because of increased rocketing of the city along with more precarious food supplies. Mazar-i-Sharif, relatively protected from the impact of war, has also seen an increase in population.

While it is not possible to estimate accurately the current population of Kabul or Mazar-i-Sharif, the important point is that both Census and anecdotal information point to rapid population growth. The largest portion of migrants to the city appear to be women and children. Other cities, heavily exposed to bombing or warfare---Herat, Kandahar, and Jalalabad---, have lost substantial population.

There is evidence of considerable rural to rural migration, as agriculturalists in vulnerable locations sought security, frequently away from plains areas and into the mountains. Map 2 in Annex II suggests the areas to which displaced people have gone. More needs to be known about land use patterns and expectations of these people for return.

\section{OUTMIGRATION}

Refugee out-migration is one of the most visible aspects of the Afghan demographic profile. Roughly 33\% of the 1979 Afghanistan population, or $26 \%$ of the present Afghan population, have left the country. Based on UNHCR survey work, UNIDATA estimates that there are 3,271,580 refugees in Pakistan and $1,277,700$ in Iran. (UNIDATA 1991 provides a breakdown for refugees in Iran and Pakistan by Province). UNICEF Tehran, however, on the basis of data provided by the Iranian Council of Afghan Refugees, estimates a total of 2.2 million Afghan refugees in Iran. Refugee arrivals in Pakistan peaked between 1978 and 1980 but substantial numbers have continued to arrive each year since. 
FIGURE 1 - Year of Leaving Afghanistan

(Refugees in Pakistan)

Source: Christiansen (UNRISD) 1987.

The long length of the refugee experience for a substantial portion of the population, including children born outside their homeland, has implications for repatriation. Corresponding data is not available for Iran.

The population estimates for Afghan population in Table 8 imply assumptions about the province of origin of refugee population. Generally speaking, refugees in Pakistan are predominantly Pashtun and come in greatest numbers from the border provinces. Refugees in Iran are largely Shi'a, Farsi or Balouchi speakers and come in largest numbers from border provinces and the Hazarajat. 
RETURNING REFUGEES

UNHCR estimates that about 200,000 refugees have returned to Afghanistan in 1990 and that the rate of return will increase with 300,000 returning in 1991. For planning purposes, UNICEF Kabul estimates a return of 500,000 in 1992 and one million in 1993. UNICEF has incorporated these estimates in its projection of population, so that the mid-year population inside Afghanistan in 1993 is expected to reach 15,432,331 (Table 10).

\subsection{POPULATION CHARACTERISTICS}

NOMADS

The dearth of knowledge about the nomad population is reflected in the continued use of a static population estimate of 1.5 million over the 1979-1991 period. Nomads (kochis) had a traditional pattern of summer grazing in the mountains and winter in the warmer lowlands, including in Pakistan and Iran. It is not clear to what extent migration patterns have been interrupted or the nomads, many of whom are Durrani or Ghilzai Pashtuns, incorporated to some extent in refugee numbers. There are also reports of sedentary groups turning to a nomadic pattern for security reasons.

ETHNIC AND

LANGUAGE DISTRIBUTION

Afghanistan has an enormous variety of ethnic and language groups (L. Dupree 1978). The Pashtuns, speaking Pashtu, in the south and east represent the largest single group. In 1978 Dupree estimated their number at 6.5 million. Tajiks, speaking Dari, are the second largest group; according to Dupree's estimate they numbered 3.5 million in 1978. They are concentrated in the north-east but are found in urban areas and elsewhere. The 1986 Kabul Census indicated that $24 \%$ of Kabul population was Pashtun and $57.5 \%$ Tajik. Other major ethnic groups include the Uzbek, Hazaras, Farsiwan, Turkoman, Balouchi, Brahui, Nuristani and Kirghiz. Maps 3 and 4 in Annex II show the distribution of ethnic and language groups. There is overlap among the groups in many areas. Dari and Pashtu are the dominant languages. For those whose mother tongue is not Dari or Pashtu, the second language is likely to be Dari. Ethnicity is an important issue with respect to attitudes about education and involvement of girls.

\subsection{AGE STRUCTURE}

Data is not available on a national scale for after 1979. For planning purposes, UNICEF is using age distribution patterns from the UN Stable Population Tables, the South Asian Model, assuming a population growth rate of 2.6 and life expectancies of 42 (female) and 41 (male). For the population inside Afghanistan, these assumptions produce the estimated age structure shown in Annex III. They imply a population 14 and under of 5.5 million or about $42.7 \%$. In 1975 CSO estimated that $43.2 \%$ of the population was 14 and under; in 1979 the Census estimated the 14 and under population at $44 \%$ of the total.

Anecdotal and other evidence give meaning to the age structure and suggest considerable variation by location. The Kabul 1986 Census reported finding 280,000 children of school age population for grades 1 to 5 . This corresponds roughly to the age group 5 to 9 . It represents 
$21 \%$ of total population. If these figures reflect reality, they suggest that a very high proportion of the Kabul population are children. Fragmentary evidence from cross-border medical teams indicate that in areas affected by migration the numbers of children and on progress report declined. Even in Ghazni, one EPI (Expanded Programme of Immution as against the pre-war noted that children under five represented national ratio of $18.4 \%$. In Iran among refugees, aninces where most refugees reside (UNICEF $55 \%$ of the Afghan population in the eastern pre 1 million Tehran 1990). Iranian authorities estimated that out of representing $20 \%$ of the total Afghan children and women of child-bearing age, each grears to be true; women and children predominate refugee population. In Pakistan the reverse appearable on age structure. UNRISD survey data in the refugee camps. Estimates are not under 15 among the population. This is re-enforced confirms a growing percentage of childrenels among refugee women.

by reports of vastly increased ferion in Afghan Population

\section{GENDER ISSUES IN
POPULATION STRUCTURE}

Striking gender distinctions in the Afghan demographic profile have implications for programming. Primary indicators of the status of women include sex ratios and life expectancy. Sex ratios indicate the number of males per 100 females. Normally the number of females in the population exceeds that of males. In South Asia the low status of women and lack of access to health and women and lack of access to reval, in the past showing a
education services is reflected in a reversal of
the normal pattern. Afghanistan has been a special case of this reversal in th even greater imbalance than its neighbors. Estimates for 1990, however, show a drop in differential between males and females. This drop probably reflects the heavier war-relate mortality among men. It is possible that pre-war estimates
women, given the cultural constraints on counting women.

Life expectancy rates in 1979 also reflected the lowered health and education status of wom The change indicated in the 1990 estimates in Table

4.6 FERTILITY AND POTENTIAL FOR POPULATION GROWTH

Hidden behind the recent decrease in population inside Afghanistan lies potential for population growth. The 1979 Census indicated a total fertility rate for the country of 7.08 , urban women bearing an average of 5.8 children and rural women an average of 7.3. fertility rate was exceeded by no other in Asia and few in the world. $2.2 \%$ and $2.6 \%$. in the 1970s, despite high mortality rates, was estima 
apparent negative growth inside Afghanistan during the 1980s should not blind planners to the potential for explosive population growth. Little is known about the current fertility rate. UNFPA estimates it to be 6.8 (1991). Several factors indicate the potential for rapid growth.

TABLE 12: Life Expectancy at Birth in the Afghan Population

\begin{tabular}{cccc}
\multicolumn{2}{c}{1979} & \multicolumn{2}{c}{1990} \\
Male & Female & Male & Female \\
41.6 & 39.9 & 41.0 & 42.0
\end{tabular}

First the population will be expanded by the return of a potential 4.5 million refugees in the next decade should a peaceful solution to conflict emerge. Second, the fertility rate of refugees in Pakistan is thought to be very high. Small-scale surveys in refugee camps and across the border in rural areas suggest that the fertility rate may be increasing in the short run. A survey in camps between Hangu and Thal in Pakistan suggested a possible total marital fertility rate of 13.6 live births during child bearing years. Third, peace may make possible considerable reduction in high rates of mortality, due to both war-related causes and preventable diseases. Finally, the possibility of a baby boom in the wake of peace is as real in Afghanistan as it has been in other countries.

\subsection{THE DEMOGRAPHIC PROFILE AND PLANNING FOR CHILDREN AND WOMEN}

The unusual demographic profile of Afghans suggests some of factors which need to be considered in identifying target groups and interventions on behalf of children and women.

- The population decline and the currently low in-country population should not obscure the potential for population explosion through return of refugees and an increase in growth rate because of high fertility and declining mortality rates. A rapidly expanding population complicates and increases the cost of rehabilitation and development efforts.

- Differentials in amount of refugee flight by province may place a heavy burden for absorption patterns on those provinces more heavily depopulated. The problems can be exacerbated not only by the numbers of returnees but also by the potentials for conflict with those who remained behind, particularly over land tenure questions.

- There are considerable unknowns about whether the internally dislocated will return to their place of origin. Dislocated persons who remain in Kabul and other towns may find themselves competing for resources and employment with returning refugees who decide not to return to their home rural areas. The result could be very rapid increase in urban populations with consequent problems of slum development and totally inadequate urban and social services. 
- Though the number and location of widows, orphans and disabled is not well-established whether inside the country or among the refugees, these are groups which will continue to be at risk and will be made more vulnerable through their own population shift or that of others. Identifying these groups needs to be incorporated into action programmes.

- Gender differentials in demographic statistics need to be monitored as part of a longerterm effort to track the capacity of interventions to have an impact on the situation of children and women. 


\section{CHAPTER 5 \\ SITUATION OF AFGHAN CHILDREN AND WOMEN - HEALTH}

\subsection{MORTALITY}

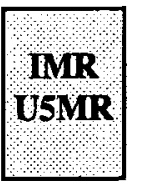

The present infant mortality rate is estimated at 169 per 1000. The under-five mortality rate is 298 per 1000 (UNICEF 1991). These estimated rates are the highest in Asia and are exceeded only in a handful of African countries in especially difficult circumstances. Because there has been only one, incomplete, attempt at a national census in 1979, and other national sample survey estimates are limited to the Afghan Demographic Survey in 1973, national estimates of mortality are hollow figures. They are projections based on best possible assumptions, but they may not illustrate the reality of mortality patterns. Table 13 recapitulates both the national estimates as well as locality specific estimates of infant and child mortality over the past 18 years. These estimates must be treated with varying degrees of caution and they provide only a limited base for generalization. They are the only guide to the distribution of mortality and to trends over time.

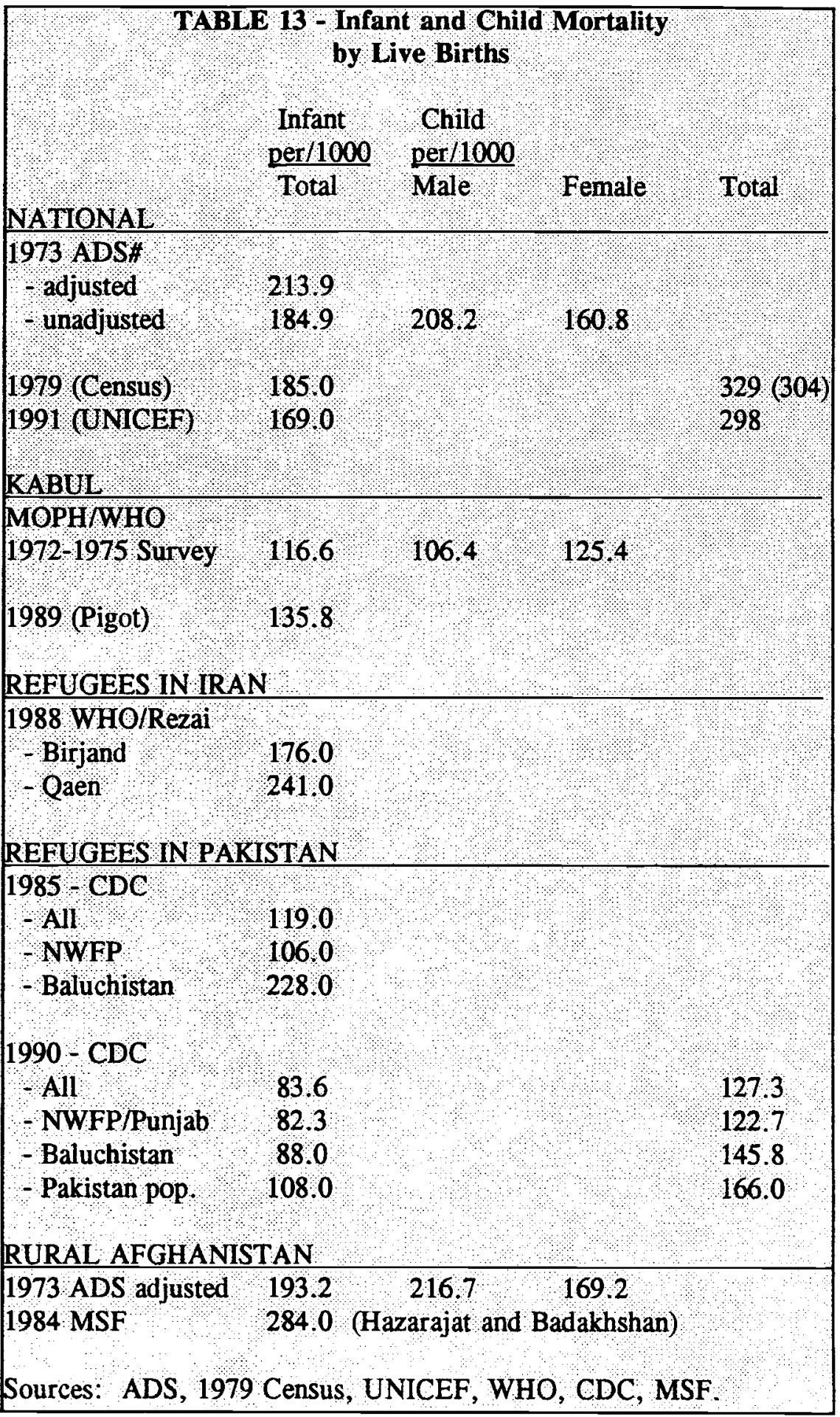


They suggest the following:

Infant mortality continues to be higher in rural than in urban rates and may be higher in 1991 -- at least in provinces that are food deficit and isolated---than prior to the outbreak of fighting.

Urban mortality rates, using Kabul as the indicator, may have increased in the same period, perhaps reflecting the impact of the more than doubling of the Kabul population in the wartime period.

Refugees in Pakistan have experienced a dramatic drop in infant morality. Results of surveys conducted by the Centers for Disease Control (CDC Atlanta) show a drop from an infant mortality rate of 119 per 1000 in 1985 to 86.6 in 1990 . The under-five mortality rate was 127.3 in 1990. This dramatic drop would appear to reflect the positive impact of proximity to the bilateral and NGO aid and Pakistan government services. Indeed, mortality rates are lower in the refugee camps than among the Pakistan population (108 per 1000). The apparent halving of the infant mortality rate within a short period needs to be investigated in terms of Afghan perceptions and their resulting expectations for health care.

Among refugees in Baluchistan infant mortality rates have dropped less rapidly than in NWFP. Refugees in camps in Iran experience high infant mortality; little is known about the Afghans dispersed elsewhere in Iran.

Neonatal mortality is thought to be high. The CDC 1990 survey reported that "if all deaths associated with tetanus symptoms were true tetanus cases, the neonatal tetanus-specific mortality rate would be 13.9 deaths per 1000 in NWFP and 21 per 1000 in Balouchistan." This is a higher rate than that estimated in the 1986 CDC survey. There are reports of high neonatal tetanus inside rural Afghanistan.

The 1972-1975 Ministry of Public Health/WHO Survey of Infant and Early Childhood Mortality in Relation to Fertility Patterns breaks down mortality rates by age group of the mother, by gender of the child and by neighborhood. Their findings pointed to significantly higher mortality rates for female children, for residents of crowded and poor areas and for children of mothers under 20 years of age.

MATERNAL MORTALITY

of 778 per 100,000 live births.

There is little data on maternal mortality rates. The ADS in 1973 estimated a maternal mortality rate of 640 per 100,000 . This is among the highest in the world in the world. Reports from teams working in rural Afghanistan suggest that maternal mortality remains high. Maternal mortality has decreased in Pakistan refugee camps (CDC 1990). A WHO (1988) survey in two camps in Iran found a maternal mortality rate

\subsection{CAUSES OF MORTALITY}

For all groups of the population, the principal causes of mortality are preventable by immunization or by simple, low cost, improved health, hygiene and nutrition practices. 


\section{NEONATAL \& \\ INFANT \\ MORTALITY}

Among neonates, a principal cause of death is tetanus. In 10 refugee camps in NWFP a survey found a neonatal tetanus rate of 13 per 1000 . In two refugee districts surveyed in Iran the neonatal tetanus rates were 64.5 and 155 per 1000 births. The immediate explanations are the lack of access for women of child bearing age to tetanus immunization as well as the unsanitary conditions of delivery for most Afghan women. Sterile instruments for cutting the cord and items like soap and water are frequently absent. Unsanitary delivery is a consequence first of the lack of knowledge of Afghan women themselves and the low status of the birth process and the traditional birth attendant (dai). Second, Afghan women have little access to modern delivery services, not only because of cultural limitation but also because of the absence of such facilities.

A contributing cause of infant mortality may be high incidence of low birth weights, particularly among populations where female health is at risk (see below). Data from Kabul MCH Clinics (Pigot 1989) suggest a rate of low birth weight of $19.4 \%$. UNFPA has been assessing data on rate of low birth weights among deliveries at Malalai Hospital in Kabul where the percentage appears to range between 4 to $5 \%$ in recent years.

UNDER-FIVE MORTALITY

Diarrhoea, acute respiratory infections and measles, particularly when compounded by malnutrition, are most commonly identified as the principal causes of infant and childhood mortality. There is a consistency over time in identification of the same causes of infant and child mortality and in the observations of overlapping causes of mortality, particularly through poor nutrition. Data is limited to statistics of curative facilities or to surveys based on recall. In 1978 a UNICEF consultant provided a summary of data on causes of mortality (see table in Annex III). Though the information is dated, it is presented as a way of underscoring the continuity of causes of infant and child mortality throughout the changes of the past thirteen years.

Data in the 1980s is even less systematic. Nonetheless, formal and informal survey results all confirm diarrhoea, acute respiratory infections and vaccine-preventable diseases (measles), in most cases compounded by malnutrition, as the principal causes of under-five mortality. There are no reliable data on mortality among under fives due to war-related causes.

In a preliminary assessment of health and nutrition of children in Kabul, Mazar-i-Sharif, and Herat for UNICEF in 1989, Pigot identified diarrhoeal diseases and acute respiratory infections as the two major causes of mortality among hospitalized children. He also noted as relevant the prevalence of vaccinepreventable diseases.

RURAL AREAS

attributed equally to acute respiratory infections, tuberculosis, gun shot wounds and unknown causes.

Estimates of causes of under-five mortality in rural Afghanistan are largely anecdotal. A 1990 survey in Wardak province by Management Sciences for Health (MSH) found 19 mortality cases, of which 10 were under five. A third of total deaths were linked to diarrhoea. The remainder of the deaths (all ages) were to acute respiratory infections, tuberculosis, gun shot wounds and unknown causes. 
Mission reports from rural areas note the interaction of poor nutritional status with diarrhoea and acute respiratory infections to cause death; the apparent high incidence of measles leading to infant and child death; and the increasing impact of malaria as a contributing factor to mortality.

\section{REFUGEES}

MATERNAL MORTALITY

The CDC in 1984 and 1985 identified diarrhoea as contributing to $39 \%$ of under five deaths. Measles was a contributor to $24 \%$ of deaths, malaria with fever $21 \%$, neonatal tetanus $9 \%$ and unknown causes $21 \%$. In 1990 the CDC found diarrhoea contributing to $42 \%$ of deaths in NWFP and $57 \%$ on Baluchistan. Acute respiratory infections were associated with $68 \%$ of under-five deaths in NWFP camps and $61 \%$ in Baluchistan.

The 1988 WHO survey in two camps in Iran identified vaccine preventable diseases including neonatal tetanus, diarrhoeal diseases and acute respiratory infections as acute causes of death.

Systematic data on the immediate causes of maternal mortality are scarce. Outside of war-related mortality, the additional burden of mortality among women between the ages from 15 to 44 as opposed to men derives from childbearing experience, poorer nutritional status and less access to health care. Only a small percentage of deliveries are attended by trained health personnel. Pigot reported on hospital-based data in Kabul which identify a high rate of complications of childbirth due to placenta retention, uterine rupture and hemorrhage, plus osteomalacia which leads to delivery complicated by obstructed pelvis. Mortality may also be compounded by anemia, poor nutrition and the general poor health of women (see below).

The lack of prenatal care and screening, the lack of access to trained personnel for delivery, women's own lack of knowledge and food practices, along with the unsanitary conditions of delivery, contribute to the unusually high maternal mortality of Afghan women.

\subsection{MORBIDITY}

An assessment of the causes of morbidity describes the magnitude and range of health problems among Afghan children and women. Not all morbidity may have the severity mentioned above in the discussion of mortality. Morbidity may nonetheless affect the development and capacities of large portions of the child and female population.

INFANT \& CHILD MORBIDITY
A comparison of morbidity data from the 1970s with data available today indicates that morbidity patterns remain similar, with a high proportion of morbidity stemming from preventable causes or causes that could be simply treated. Because of war and political disruption, time has stood still for mos Afghan women and children. For a few, chiefly among refugees in Pakistan time has begun to move rapidly ahead. The technology and potential of child survival interventions ha changed radically in the past decade. Immunization has begun to reach some urban and refugee childrer at levels not imagined before the war. Other children remain isolated from complete immunization anc other simple interventions. Health practices and environmental conditions have not improvec appreciably. Overall morbidity patterns remain constant. 
As noted above diarrhoea, acute respiratory infections, measles and neonatal tetanus complicated by malnutrition are the principal causes of death. Other principal forms of morbidity in the under five population include tuberculosis, malaria, polio, whooping cough, parasites, leishmania, skin infections, eye infections and meningitis (not necessarily in order of magnitude or severity). Some contribute directly to mortality; other morbidity reduces the resistance and the capacity to develop (mentally and emotionally as well as physically) of the under five population.

DIARRHOEAL DISEASES

Diarrhoeal diseases are recognized as the most common cause of morbidity among all groups of Afghans. Analysis of diagnoses among children under five at health institutions in Kabul, rural Afghanistan and in refugee locations indicates that diarrhoea is the most common complaint. Recent data from the Indira Gandhi Institute of Child Health in Kabul for children 0-14 indicate that 35\% of admissions are for diarrhoeal disorders. Data from MCH centers is similar. This corresponds to Feacham's analysis of incidence of diarrhoea in 1979 on the basis of data from the Institute of Child Health and the Institute of Public Health. Feacham also found that $80 \%$ of the children under five seeking treatment for diarrhoea were under the age of two. Similar analysis is not available for the present. Reports from NGOs working cross-border in rural Afghanistan also indicate high incidence of diarrhoeal disease. MSH in 1988 found that diarrhoea and dysentery constituted $32 \%$ of diagnoses by cross-border health workers with three months training. The Coordination of Medical Committees (CMC, Peshawar) has analyzed the data on patient records kept by the health workers of CMC members working crossborder. Their results show that $23.86 \%$ of children were diagnosed with some type of diarrhoea.

Survey estimates of episodes of diarrhoea per child per year vary. In Kabul, the Ministry of Public Health estimated the number of episodes per year at 3.9; UNHCR estimated 4.7 episodes per year per child in Pakistan refugee camps. Many observers believe that these are underestimates of the frequency of diarrhoea. In the WHO survey in two districts in Iran, Rezai found that in the seven days prior to interview, $45 \%$ of children in the sample had diarrhoea (defined as three or more watery stools for more than two consecutive days). The CDC survey in 1985 among Pakistan refugees found diarrhoea and parasitic infections the most common disease among children, reporting a level of 30-50\%.

Diarrhoea has a seasonal pattern. The CMC analysis of patient data found that diarrhoea in rural areas is most common in June and July. Feacham (1978) found a dramatic rise in incidence of diarrhoea in June and a corresponding fall in October.

There are no reliable and comprehensive data on incidence and severity of other types of morbidity among Afghans. The fragments of information show that several diseases have remained acute over the past two decades.

ACUTE RESPIRATORY INFECTIONS
Acute respiratory infections (ARI) are identified as widespread and serious among all groups of Afghans. At the Indira Gandhi Institute of Child Health, 17.\% of admissions for children 0-14 were for acute respiratory infections (Pigot 1989). In the pre-war period, Feacham reported that incidence of upper respiratory infections was $32 \%$ among children $0-5$ at the Institute of Child Health. The Ministry of Public Health and WHO reported incidence of upper respiratory infections among 
children 0-2 in Greater Kabul to be $32 \%$ (1978). Together with infectious and parasitic diseases, respiratory system disorders comprised nearly half (47.65\%) of all clinic visits in rural Afghanistan (CMC 1990).

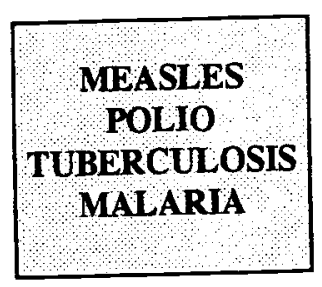

areas.
NGOs operating from Pakistan and UN cross-border and cross-line missions report increases in incidence of measles, polio, whooping cough, malaria and/or tuberculosis. In Kabul, Pigot (1989) noted continuing high incidence rates for vaccine-preventable diseases in children under five, with an incidence rate of $13.5 \%$ for measles and $0.6 \%$ for polio. He also reported an increase of meningococcal meningitis during the spring of 1989 in Kabul and Herat, and an increase in malaria cases in Kabul, perhaps a result of in-migration to Kabul from malaria-endemic

There are numerous anecdotal reports from NGOs and missions on a high incidence of measles and polio in rural Afghanistan. Some observers believe that emerging demand for immunization among rural Afghans stems from the incidence and severity of measles, along with the recognition of the power of the vaccine. Polio is perceived as a serious problem by some Afghans, and less so by others. Handicap International working with Afghans in Quetta finds that poliomyelitis is the second most frequent diagnosis $(12.9 \%)$ among its patients, after traumatic conditions and before amputations. For children under five, polio was the most frequent cause (19\%) of disability, before war related injuries. In Badakhshan and Takhar, however, people less frequently reported polio as a cause of disability to a UN advisor (Kristiansson 1991). Tuberculosis appears to be a common diagnosis (8.7\% in the MSH Wardak survey), but chiefly among the age group six and above. UNHCR also reports a prevalence of tuberculosis three to four times greater among refugees than among the Pakistani population.

Malaria, following a successful control programme in the 1950 s and early $1960 \mathrm{~s}$, became a public health problem again in the 1960s due to the resistance of the vectors to DDT and dieldrin. In the 1970s, the Government was trying new strategies, but an estimated 6 million people lived at risk (Feacham 1978). Today missions in rural areas report an increase in malaria. UNHCR reports high incidence of malaria among refugees in Pakistan and some suggestion that the problem is increasing. The other diseases commonly reported among Afghans over the past two decades suggest exposure to a wide variety and increasing incidence of infection. Leishmaniasis is reported as increasing in Kabul. UN Salaam Missions noted it in Parwan and Jawzjan. Trachoma is reported among children in Kabul (14.5\% among children 5-14 surveyed-Pigot) and among refugees (IRC). Eye infections, conjunctivitis and blindness are also reported. Parasites are a common if not immediately life threatening infection widely noted among Afghan children. Ascaris continues to be a major infection. In 1978 Feacham estimated that up to $80 \%$ of children in some areas were infected. Intestinal parasites are a contributor to malnutrition and to general debility. Scabies and lice have also been reported.

FEMALE MORBIDITY
Analysis of adult morbidity by gender usually focuses on separating conditions related to women in their reproductive function, identifying problems of hemorrhage, infection, toxemia, obstructed labor and induced abortion. 
A Management Sciences for Health analysis of records of health workers inside Afghanistan (1988) indicated the diagnoses of women 15-44 seeking care (7\% of the total patients) (Table 14). A 1990 survey in Wardak Province shows that women interviewed by basic health workers had twice as much morbidity as males in the same age group (16-45). Earlier MSH survey work in three provinces (1977) also revealed higher levels of illness for women than men in all age categories.

Differentiation by gender of causes of morbidity should be a starting point for collection of data and identification of problems. Even anecdotal evidence on the health status of

TABLE 14: Diagnoses of Women (15-44)

Anemia

Dysentery

Injury

Malaria

Bronchitis

Hepatitis

Amebiasis

Source: MSH 1988
$21 \%$

$6 \%$

$5 \%$

$5 \%$

$4 \%$

$4 \%$

$4 \%$ women is more limited than that on children.

\subsection{TRENDS IN MORBIDITY AND MORTALITY}

Recognizing the limitations of the data, tentative generalizations about mortality trends can be made:

- Overall, the Afghan population has not experienced a decline in infant, child and maternal mortality rates at a time when mortality indicators have been falling in other least developed countries.

- Mortality rates have remained the same or risen for populations already at risk and invisible and inaccessible to government or outside assistance; these include:

- $\quad$ infants and women in refugee camps in Iran;

- $\quad$ infants, children and women in rural Afghanistan, especially in but not limited to isolated mountain populations;

- infants, children and women living in difficult circumstances in Kabul and other cities.

The apparent decline in infant and child mortality rates among refugees in Pakistan indicates a potential for health interventions to reduce mortality rates in a short period of time. The Pakistan refugee experience also raises questions of how and whether it is possible to build on those achievements if and when refugees disperse to Afghanistan and no longer remain the concentrated target of substantial foreign assistance.

Causes of mortality appear for the most part to remain constant:

- diarrhoea, acute respiratory infections, measles and malnutrition remain principal causes of mortality;

- neonatal tetanus appears to have increased. 
Generalizations about morbidity are more difficult. However, the following trends appear:

- Overall morbidity, traditionally widespread, may be increasing, particularly for rural populations isolated from health interventions and dislocated groups in Kabul and some other urban areas.

Principal causes of morbidity remain diarrhoea, acute respiratory infections, malnutrition and measles.

Other infectious diseases remain widespread and sometimes severe in impact, including polio, tuberculosis and whooping cough. There is continuing prevalence of parasites, skin infections and eye infections. Tuberculosis, malaria and leishmaniasis appear to be increasing.

While incidence of vaccine-preventable diseases appears to be declining in accessible refugee camps in Pakistan, tuberculosis is reported to be increasing and there is no evidence of decline of diarrhoea, respiratory infections and other less severe infections that are related to hygiene conditions and practices and to overcrowding. The continuing though declining incidence of neonatal tetanus reflects the difficulties of reaching women even in refugee camps.

\subsection{EXPLAINING THE PERSISTENCE OF HIGH MORTALITY AND MORBIDITY}

War and insecurity are the simple explanation for the persistence of high mortality and morbidity. The war has reduced resources for health care and prevention, but to find in war the simple explanation for the current health status of Afghan women and children is to obscure the structural factors that will contribute to continuing high mortality and morbidity long after the conflict has subsided.

On one level, explanation for high mortality and morbidity can be found in the low quality and limited accessibility of basic health services. On another level, there are structural factors that perpetuate poor health services and practices. These include social and cultural attitudes, poverty, lack of management capacity, a low level of education and unhealthy environmental conditions. War and insecurity are but an overlay on top of these two levels of causes of high mortality and morbidity.

HEALTH

FACILITIES \& PERSONNEL
The health infrastructure for Afghans is divided into three parts: the urban and limited rural areas controlled by the Government in Kabul; the rural areas controlled by various mujahidin groups; and the refugees. Information on facilities and personnel are scarce and conflicting. Insecurity prevents a comprehensive and independent assessment of what really exists and what health services are delivered. Information from the 1970 s on health facilities provides a starting point for understanding the changes which have occurred since 1978.

Key generalizations that can be drawn from the descriptions below include:

Health facilities and personnel in the 1970s were essentially biased toward urban male adults and curative care. A limited beginning to a national primary health care approach based on community level workers was aborted by the circumstances following 1978. 
- Present government services are limited to Kabul and other urban and surrounding areas. Pigot (1989) estimated that $33 \%$ of children $0-5$ attended $\mathrm{MCH}$ clinics and that the rate of attendance of women was about the same.

- There has been a proliferation of health facilities and personnel supported cross-border, and more recently cross-line, in rural Afghanistan. In sheer numbers, facilities and personnel reported in rural areas exceed pre-war totals by a factor of five or more. Double counting and other factors give a reduced actual total. Bias in service and insecurity limit access of women and children.

- Refugees in Pakistan, and some of those in Iran, have had greater access to better quality health facilities and personnel than Afghans living inside the country.

The urban, curative and adult male orientation of the national health system continues from pre-war to the present. Though the Seven Year Plan (1976-1983) identified infants as the highest priority group, actual expenditures reveal contrary real priorities. In 1977, Management Sciences for Health, working with the Ministry of Public Health, undertook an analysis of health expenditure and demonstrated an expenditure bias toward target groups least at risk (adult males) and toward urban areas. Table 15 shows that infants who suffered $40 \%$ of the mortality received only $6.1 \%$ of health expenditure. Adult males who make up the official work force were the focus of $54 \%$ of expenditure.

During the 1970s efforts to redress formal health system bias toward urban, male, curative care did emerge from MOPH collaboration with outside donors and the advocacy efforts surrounding the global conference on Primary Health Care in 1977. Principal innovations included efforts to expand the number and quality of basic health centers (BHCs), 116 of which were outside of Kabul Province in 1977 (UNICEF 1978).

The BHCs were intended to serve a multi-purpose preventive and curative role with a seven-person staff headed by a doctor and including a female auxiliary nurse/midwife. In fact, however, the Basic Health Centers were able to reach only $6 \%$ of the population in the 1970s. The Government sought to expand coverage by opening health sub-centers staffed by a nurse and a vaccinator. Difficulties of posting staff, particularly females, to rural units and drug supply and management problems contributed to the underutilization of facilities. Whatever the coverage achieved by the BHCs, they were apparently regarded as a respectable place for women to visit. An MSH three-province survey in 1977 found that only $7 \%$ of men interviewed would forbid daughters or wives to attend the BHC. (World Bank 1978).

TABLE 15 - Health Service Expenditure by Target Group - 1977/78 Budget, MOPH

Target Group $\%$ of Total Budget

Infants $0-1$

Children 1-14

Mothers

Labor Force

$61 \%$

$31.5 \%$

$8.5 \%$

$53.9 \%$

Total

$100.0 \%$

Source: MSH, Financial Analysis of Health Programmes, Kabul 1977. 
Recognizing the limits of BHCs, the Government had begun in the late 1970s work on the development of a self-financing Village Health Worker Programme and on training of traditional birth attendants (dais) in simple preventive measures. Though immunization coverage in the 1970s was limited efforts to establish a capacity for EPI were under way. The success of the smallpox campaign in the early 1970s was thought to have left positive attitudes about the benefits of immunization.

Today the responsibility for health policy, strategy and programme is diffused among a variety of power centers. In various ways the Government in Kabul, the Interim Government in Peshawar, the various military commanders, shura, UNICEF and other donors and the NGO community are all actors in the Afghan health policy environment. This has contributed to a proliferation of approaches, some innovations and a need for coordination and harmonization.

The Government in Kabul has articulated a commitment to child and maternal health. The National Child Policy, adopted by the Council of Ministers in 1986, gives priority to special welfare programmes for children, including immunization, curative care, nutrition and special care for disabled and indigent children. In his message to the World Summit for Children in 1990, the President of Afghanistan called children and mothers a special target of efforts to eliminate the damage done by war. Where the Kabul Government has a health infrastructure and support from UNICEF and others, there have been accomplishments. Immunization reaches $60-80 \%$ of children under two in Kabul (see below). Awareness of ORS and ability to prepare it is widespread in Kabul due to communications efforts. These achievements are limited to Kabul and other urban and semi-urban areas and the structure of government health services remains biased to male, curative and urban rather than preventive and female needs in rural areas.

Resistance, war and budget constraints limit the ability of the Government in Kabul to reverse the urban, male, curative bias of the health system. Little budget data is available to indicate expenditures and trends. Costs of the war along with priority given to treatment of war-injured limit Government's own expenditures to salaries and the most basic maintenance of facilities. Strategies and programmes implemented cross-border are supported by UNICEF and other international donors and a large number of NGOs There are links with the Afghan Interim Government (AIG) particularly through the Alliance Health Committee. On an operational level, the type and amount of cross-border supported health service is determined by the priorities of local commanders and local security conditions. NGOs on cross-border activities as well as UNICEF cross-line missions note an increasing demand from commanders for immunization and other health services. The Coordination of Medical Committees (CMC) and the Agency Coordinating Body for Afghan Relief (ACBAR) serve as coordinating mechanisms for cross-border approaches. ACBAR has worked with member NGOs to develop standardized approaches to training, drug supply and programme objectives and monitoring.

Because there is little comprehensive data on the Afghanistan-wide situation, there may be several useful ways of trying to get at the real access of Afghans to health service. These include looking at the various estimates of health facilities and personnel currently operating; and the status of immunization, diarrhoeal disease control, and maternity care programmes. Immunization, in particular, is an indicator that reflects achievements of a rapid impact programme. 
GOVERNMENT FACILITIES
It is extremely difficult to make firm statements about the quantity and quality of health facilities and personnel in Afghanistan. The existence of facilities cannot be verified in all cases and there is inconsistency among reports on facilities. The Ministry of Public Health reports the following in 1991:

54 hospitals; 5192 beds

83 basic health centers

$44 \mathrm{MCH}$ centers

44 nutrition units

2472 medical doctors

3873 paramedical

UNICEF, on the basis of field missions across line and from other reports estimates (1991) the following:

64 hospitals, of which 14 are in Kabul

179 basic health centers, of which 30 are in Kabul

Kabul Government facilities, as noted, are urban oriented but have a higher utilization rate than was the case pre-war. An estimated $46 \%$ of the Kabul Government hospital beds and $83 \%$ of the MCH clinics are based in Kabul. Many of basic health centres and sub-centres located in rural areas have been damaged or destroyed by war, and many are out of control of the Kabul Government. Within Kabul, statistics suggest that $33 \%$ of children $0-5$ attend $\mathrm{MCH}$ clinic regularly, and the attendance rate for women is estimated to be about the same (Pigot 1989). In the largely urban institutions supported by the Kabul Government, there are severe shortages of drugs and supplies, hampering efforts to provide basic services. Hospitals servicing war injured children are under stress.

During the war medical personnel have moved to Kabul and other cities because of insecurity in rural areas and the increased demand for health services in Kabul because of war casualties. Health staff supported by the Kabul Government may be greater in 1990 than in the pre-war period but its distribution is heavily skewed toward Kabul, and its performance remains weak.

What is notable about Kabul Government health personnel is the increase in number of women health professionals. By the late 1980s there were an estimated 300 female doctors and 3,000 female nurses employed by the Kabul Government. More than $50 \%$ of the medical students enrolled at the medical colleges in Kabul and Nangarhar are women.

\section{$B A R A K I, K A B U L$}

"A few women of the poor neighborhood had assembled on the rooftops and were discussing healih care facilities in the area. 'All of my children are sick with fevers and colds and we have no good treatment around here. The doctors insult us when we go to them. And here in my house 1 don't have any heat to keep my children warm..' The women are distraught with their daily problems of survival and were not able to talk about anything else."

\author{
Pamela Hunte \\ UNICEF Consultant, 1991
}


Pigot suggests that the level of medical personnel in Kabul is currently adequate for the population levels, an abnormal situation resulting from the flight of personnel from the countryside. Other observers note the low productivity of Kabul-based staff and the lack of an orientation toward performance goals (see section on management below). During a process of reconciliation, it remains to be seen whether present urban-based personnel who formerly worked in rural or small urban facilities will return to them, or whether the social environment will encourage newly trained medical personnel to serve in rural areas. Another effort of the Kabul Government has been to involve the community in health education through mass based organizations. Activities of the Women's Organization of Afghanistan, the Women's Council and the Youth Organization include some health education content. Not enough is known about the health education activities of these groups and their effectiveness in influencing health and hygiene practices.

CROSS BORDER HEALTH

Making sense of available health facilities and personnel in rural Afghanistan is difficult. ACBAR notes 291 health centers or clinics supported by their members in rural Afghanistan, plus at least 1400 health posts or sub-clinics that may provide only first aid. There is considerable disagreement about the extent of double counting and the number of disappearing facilities. UN observers who have travelled extensively in rural Afghanistan in both pre-war and present periods suggest that there are indeed more health facilities and personnel in rural areas now than before, but that local insecurity and conflict may narrowly limit real access and, in particular, access of women and their children. On the bright side, one could postulate that the seeds of a fragmented, locally based primary care system have been planted in some areas. This is true especially in the north-east, but also in other areas where military commanders or shura have been able to give priority to social issues. Health care has moved from treatment of war casualties to include curative care and limited preventive activities including an immunization campaign. While children and women remain underserved, it is possible to speculate that today some rural Afghans may have better access to health care than they did in the pre-1978 period. Tomorrow, if the foreign financial and technical support dissipates, Afghans may not be able to afford the rural health system which has sprung up. And tomorrow, Afghans will have the task of reconciling far flung and disparate services into a system which can be sustained by government and community resources.

The first cross-border medical interventions were aimed at war injuries. Foreign medical teams maintain hospitals in Wardak, Bamyan, Ghazni and Parwan. Most facilities, however, are small clinics staffed by two to five medical workers who may have been trained from three to eighteen months. Some clinics may be attached to resistance fighting units, but the vast majority provide primary curative health care. Over time and particularly as security has improved in specific locations, medical care has increasingly gone to meet general health needs of the population remaining in rural areas.

Children and women continue to be underserved by facilities. A $1990 \mathrm{CMC}$ analysis of patient record books found that of the clinic patients, $11 \%$ were children zero to four, $18 \%$ were children 5-14 and $16 \%$ were women age 15 and above. Clinics in villages were found more 
likely to treat women than more isolated mujahiddin posts. An earlier CMC analysis found that the vast majority $(98 \%)$ of patients come to health clinics for non-traumatic medical complaints. An early (1988) MSH analysis of patients treated by the Alliance Health Committee basic health workers found that only $2 \%$ of patients were under aged five and only $7 \%$ of patients were female. Other NGOs have reached a higher proportion of women. International Medical Corps in a 1987 analysis of 22,000 patient encounters found that $28.4 \%$ of patients were women and $25 \%$ were children under the age of nine.

Information on health personnel trained cross-border and cross-line is scattered, and subject to the same problems of double counting and lack of verification as health institutions. It is instructive to look at the variety of training programmes and numbers of health personnel reported by ACBAR members in Pakistan. ACBAR figures suggest the possibility that there are far more trained Afghans working in rural health inside Afghanistan than was ever the case before. Two NGOs alone, MSH and SCA, report training and supporting more than 3000 basic health workers inside Afghanistan. AVICEN and others have trained nearly 100 vaccinator teams for working inside Afghanistan. Several NGOs report conducting dai or TBA training in Konar, Logar and other provinces, while other NGOs report training more than 1350 TBAs and more than 3000 female health workers among the refugees inside Pakistan. Other agencies have provided longer term training to male and female nurses and to doctors with the expectation that they would serve either Afghan refugees or Afghans inside Afghanistan.

REFUGEE HEALTH

Health care may also be more accessible today to most refugees than it was before they fled their homes in rural Afghanistan. In Pakistan, the Afghan Refugee Health Programme (ARHP) seeks to provide $\mathrm{MCH}$, immunization, curative care, basic drugs, disease control and health education through a system of basic health units and sub-units. The BHUs are staffed by a medical officer, a lady health visitor (LHV) and other staff. The health services are run collectively by the Government of Pakistan, UNHCR and NGOs. In North West Frontier Province there are roughly 200 BHUs and sub-units providing a coverage of one unit per 11,000 population. The impact of this coverage is best indicated by infant and child mortality rates among refugees in Pakistan, which are half those estimated for Afghans inside Afghanistan (see above).

In Iran, the refugees have the right to use local facilities. Iran's national primary health care system at the community level provides service through health houses and health centers. To the extent that the influx of refugees puts pressure on the Iranian system the quality, timeliness and quantity of health services is impaired. Afghan refugees in transition camps (mostly in the eastern provinces) receive preventive and curative care from health facilities and pharmacies in the camps.

\section{IMMUNIZATION}

remains low, at $4 \%$.
Immunization is an area where children have significantly improved access to health service. UNICEF estimates an annual coverage rate of $27 \%$ for Afghan children 0-1 living inside the country. This is a substantial increase over the pre-war period. Tetanus coverage for fertile women 
Coverage rates are much higher in the Kabul Government controlled areas than in rural areas. A household survey in 1990 found $63.7 \%$ of children fully immunized (for BCG, DPT, OPV and measles). It is more difficult to determine coverage in rural Afghanistan areas served crossborder. It is estimated that about $5 \%$ of children $0-1$ are reached. Cross-border immunizations did not initially focus on the $0-1$ population. Indeed there were pressures from commanders to vaccinate all children, and sometimes even adult males. During 1991 NGOs began to focus on the $0-2$ age group and are moving toward the UNICEF target group of $0-1$. NGOs report high drop-out rates before complete immunization, reflecting some of the difficulties in achieving targets. In a 1990 survey in Wardak Province, MSH found that two thirds of all children 0-5 had received one or more vaccination and that TB scars were found in $56 \%$ of the children. There was no gender difference.

Coverage rates among refugees in Pakistan are also significantly higher than for rural Afghans. Reports on immunization coverage in $1989 / 90$ for children 12 to 23 months suggest good coverage and better coverage than for Pakistani children (Table 16):

\section{TABLE 16: IMMUNIZATION COVERAGE (\%)}

Afghan Refugees

$\underline{\text { NWFP }}$ Punjab $\quad$ Balouchistan $\quad \underline{\text { Pakistan }}$

Children 12-23 mo.

$\begin{array}{lllll}\text { BCG } & 89 & 96 & 75 & 77 \\ \text { DPT } & 68 & 89 & 71 & 64 \\ \text { Polio 3 } & 68 & 89 & 71 & 64 \\ \text { Measles } & 73 & 87 & 75 & 55\end{array}$

Women

$\begin{array}{lllll}\text { TT } 2 \text { doses } & 65 & 73 & 75 & 55\end{array}$

Source: UNHCR 1990.

Refugee women in Pakistan have significantly more access to immunization than their counterparts in Kabul or rural areas. This immunization access of Pakistan refugees is reflected in differentials in mortality rates. Comparable information is not available for refugees in Iran.

Awareness of the importance of immunization and demand for immunization appears to be strong and growing. EPI coverage surveys among Pakistan refugees (1990) and in Kabul (1990) explored reasons for immunization failure. Findings suggest a moderate level of knowledge about immunization and of motivation in both locations. Lack of knowledge about the need for second and third doses was a key problem identified with respect to lack of knowledge, suggesting an opportunity for refocussing health education. This is reflected in the high drop 
out rates after the first dose, a problem most serious in the cross-border operations. Chief obstacles to immunization were "mother too busy" (Kabul) or "medical technician did not arrive" (Pakistan refugees).

Implementation issues in the immunization programmes for Afghans derive from their fragmented development and structuring. Originally, separate efforts for immunization campaigns started from Kabul and from Pakistan. From the Kabul Government side, more than $80 \%$ of vaccinations are given at $\mathrm{MCH}$ clinics; most are from fixed sites. Government staff morale is low and outreach activities limited. In Pakistan, a large number of autonomous agencies have been involved in launching cross-border immunization. This meant a variety of strategies and a lack of a sharp focus, particularly from Pakistan, on the priority targets of children 0-1 and women of childbearing age. Despite the complexities of working through different civil and military authorities, in urban areas, cross-border and cross-line, significant achievements have been made in establishing and maintaining a cold chain. From the Government side, UNICEF supports fixed EPI units in 116 locations, mostly urban; more than 14 fixed centres are operating with cross-line support through UNICEF. Regional vaccine cold stores have been established in four provinces and EPI warehouses in three provinces to preposition supplies. There are ongoing efforts to integrate approaches and targets used in crossborder, cross-line and Kabul Government programmes. Cross-border immunization efforts were launched in an emergency environment. Drop-out rates between the first and third dose exceed $90 \%$ in the case of some programmes. Though a comprehensive cost-effectiveness analysis has not been done, evidence suggests that current cross-border immunization carries a high cost per fully immunized child or woman and that such efforts are neither the most efficient nor sustainable. The cross-border operations have achieved a break-through by introducing childhood vaccination where it scarcely existed before. The challenge for the future is to coordinate immunization efforts to achieve the most cost effective ways of reaching children and women without destroying the local initiatives.

A key implementation problem remains that of reaching women with two doses of tetanus toxoid. Only among women refugees in Pakistan does the proportion of women with two doses of tetanus toxoid exceed $60 \%$. Coverage surveys among refugees and in Kabul suggest problems of information, lack of motivation and of staff outreach as causes of immunization failure. Closer examination of the dynamics of immunization delivery in Kabul and among refugees may identify the delivery strategies, staff management and motivation factors leading to the better immunization rates of women.

DIARRHOEAL DISEASE PROGRAMMES
Diarrhoea is widespread and severe among Afghan children in all locations. Access to and knowledge about remedies is limited. Constraints on addressing the problem are the low priority assigned to the problem by authorities, poor water and sanitation facilities and practices, and the weakness of health services and outreach in most locations. 
Inside Afghanistan, UNICEF estimates that 3 million packets of ORS would meet rehydration needs. Presently there is capacity for production of 1.75 million packets annually and UNICEF is assisting in expanding production to 3 million packets. In practice, production is constrained by the erratic and inadequate supply of electricity. Distribution problems limit the capacity to use even what is currently produced. UNICEF is supporting distribution of ORS through the Kabul Government, cross-line and cross-border through multiple outlets. Nonetheless, UNICEF estimates, in the absence of surveys and comprehensive field monitoring, that only $15 \%$ of the children of Afghanistan have access to oral rehydration therapy. From the Government side key problems are the lack of resources for operation of the CDD (Control of Diarrhoeal Diseases) Programme in the ministry, and the low level of motivation of health staff. Transport and the security system more generally reduced accessibility to ORS packets and to knowledge about its use.

Among the refugees in Pakistan, a 1989 UNHCR survey found that $21 \%$ of children with diarrhoea were given oral rehydration salts, usually obtained from the basic health unit, and $3 \%$ were given a sugar salt solution. The same survey addressed to mothers and guardians of children under five found that $95 \%$ of respondents had heard of ORS, but only $19 \%$ could describe it and only $13 \%$ could demonstrate its use. Thirteen per cent of households had a packet of ORS. Informal UNICEF interviews at the household level in Kabul City imply a high degree of awareness of ORS as a result of government mass media campaigns. Less is known about ability or willingness in practice to prepare and use home-prepared oral hydration therapies (ORT).

\section{MCH CARE}

The information which exists on maternal health care for Afghans illustrates the degree to which most Afghan women are cut off from access and knowledge. Improvement in morbidity and mortality indicators may be impossible so long as women's access remains low.

Only in Kabul and for other limited urban populations do women have access to ante-natal, postnatal and delivery care. The UNICEF 1990 Immunization Coverage Survey in Kabul City found that $65.9 \%$ of mothers attended an ante-natal clinic, --- though only $37.7 \%$ of these received two doses of tetanus toxoid. Among these Kabul women, the 1990 immunization survey found that $53 \%$ of deliveries took place in a hospital. Of the $47 \%$ of deliveries at home, $59 \%$ were attended by a trained dai or relative, $33.3 \%$ by a trained nurse or midwife. and $6.6 \%$ by a physician. Earlier (1989) Pigot had estimated a lower number of attended births suggesting that $25 \%$ of births are hospital or clinic based and therefore attended by health personnel. He also indicated that the remaining deliveries are home based; the percentage of home deliveries in Kabul attended by trained dais is about $15 \%$. Both findings suggest an important role for trained dais who could be assumed to be serving the least well-off Kabul residents. Among Iranian refugees, Rezai indicates that all births were home based, of which $99.5 \%$ were attended by family members and the remaining $0.5 \%$ by untrained dais. 
The experience of refugee and rural women suggests far less access to trained medical support during delivery, though refugee women in Pakistan have access to ante-natal care and relatively high levels of tetanus toxoid immunization. A Save the Children (UK) survey in Pakistan camps in $1987-88$ found that only $6.6 \%$ of deliveries were with a trained attendant in a health facility; $93 \%$ of deliveries were reported as being at home with an untrained person or no person in assistance. In a 1990 household survey in Wardak province, MSH found that $66 \%$ of births reported were assisted by a dai (probably untrained). More than $90 \%$ of deliveries were at home. Mother-in-law and mother were the other principal sources of delivery assistance. Most of these women received no ante-natal care and only $12 \%$ received care from a basic health worker or doctor. Cultural constraints on use of male health workers and the paucity of female health workers sustains the isolation of women at a critical event in the life cycle.

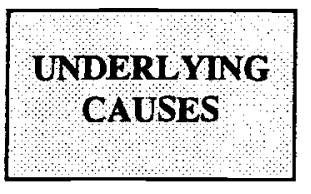

The chief causes of high mortality and morbidity among Afghans are largely preventable. To recapitulate, diarrhoea, acute respiratory infections (including pneumonia and tuberculosis), measles, neonatal tetanus and malnutrition are the chief causes of morbidity. Polio, malaria, whooping cough and meningitis are among the other severe causes of morbidity and sometimes mortality. Parasites, skin infections, eye infections, leishmaniasis and nutritional disorders such as goitre, anemia and vitamin-A deficiency are widespread and contribute to debility and the severity of other diseases.

With the partial exception of malnutrition, most of these causes of high morbidity and mortality can be substantially reduced or prevented through simple technologies or simple improvements in health and hygiene practices. Where morbidity occurs, its severity and duration can be reduced through simple, often home-based care. Hand-washing, oral rehydration therapy, immunization and improved weaning practices would all have direct and visible impacts on the levels of morbidity and mortality.

The one partial exception is malnutrition. Where absolute shortage of food and of essential nutrients exist, health interventions and changed nutritional practices are insufficient. This problem is discussed in greater detail in Chapter 6 on nutrition.

To understand the continuing prevalence of easily preventable or treated causes of morbidity and mortality, it is useful to look at the nature of health decision-making at the household and the government levels, at the health environment and at the health knowledge, attitudes and practices of the population.

CULTURE \& HEALTH

to the honour of the family and the family is bound to avenge threats to this honour. In the Pashtunwali or code which governs the behavior of Pashtuns, this is called namus or defense of limit women's access and that of their children to the health services which exist. The tendency to seclusion of Afghan women stems from tribal traditions related to patrilineal inheritance of property and the consequent importance of assuring the paternity of children. The honour of the woman becomes bound

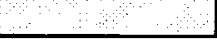

Attitudes about women are deep-seated in Afghan culture and they continue to of the population. 
the honour of women. All traditional and rural groups, even non-Pashtuns, seek to shield women from contact with outsiders to guard against dishonour or even gossip which would threaten the family and call for violence or revenge. (cf. Dupree 1973). It is because the appearance of honour to the community is so important that individual efforts to expand the access of women are difficult. There are regional, class and educational variations on the Pashtun pattern and in the access of women to services. Even where the code of seclusion for women is strong, there is often a tradition of women's rights and of independent and powerful women in the private sphere. Nonetheless, confined to the private sphere, women's access to new knowledge of family health is even more limited than that of men and their capacity to contribute positively to household decisions related to health is static.

Outside agencies, through whom the principal resources for child health and development are funneled, have been sensitive about the dangers of pressing for women's health and education programmes. There are examples of threats and even violence against individuals and groups attempting to work with women. The danger of over-sensitivity is that of generalizing the resistance of some Afghans to all Afghans and of missing opportunities. Privately some NGOs working cross-border and in refugee camps note qualitative changes in attitudes toward women's participation. In particular, they suggest a widening gap between the Afghan leadership in Peshawar and resistance leaders inside Afghanistan, with the some of the latter accepting or supporting health, education, veterinary and other programmes involving participation of women.

KNOWLEDGE,

ATTITUDES \&

PRACTICE

Afghanistan is poor at the household level and at the government level. Nonetheless Afghans, like most other peoples, are prepared to invest their own resources in health care. They lack an understanding of the causes and mode of transmission of diseases, and of improved health behaviors that would reduce risk of infection and make their own health care investments more efficient.

A frequently cited pre-war study (MSH 1977) indicated that Afghans are willing to spend income on modern or traditional medicine. A recent MSH follow-up to this study in Wardak Province indicates that, in addition to free care from clinics, rural people continue to spend on health care from hospitals, private doctors, pharmacies and shops (medicines), mullahs and others. Afghans have a little developed comprehension of bacteria, viruses and patterns of disease transmission. Traditionally they had a strong belief in jinns and spirits as the cause of disease. To some extent, Afghans may turn to modern cures, injections and antibiotics as new supernatural forces which conquer disease and suffering. Health workers in Afghanistan and among refugees in Pakistan complain of abuse of drugs and of a magical belief in injections. Misconceptions about medicine and health may be shared and reinforced by Afghan leaders who have used their leadership role to give priority to curative measures and to ignore the importance of prevention. The low levels of health knowledge and practice continue because of the low level of literacy, particularly among women. 
Lack of knowledge of both men and women about sound health practices and women's lack of control over access to health services and education perpetuates practices that threaten health. For example, field research reveals a preference among Afghans for drinking jui or canal water that is thought to have a better taste than water from protected sources. Also traditional is the belief that any flowing water is clean. There is a limited anthropological literature describing predominant rural health behaviors, both negative and positive (see bibliography). Critical practices include treatment of the umbilical cord following delivery, delayed introduction of breast-feeding, beliefs on introduction of weaning foods and taboos on foods during fever, illness, and pregnancy.

HEALTH, WATER, SANTTATION \& HOUSING

The environment in which Afghans live explains much about the transmission of diseases and high morbidity and mortality. On a practical level, access to safe water and sanitation is virtually negligible. Sewage and garbage collect in the streets of many urban areas, and the potential for disease transmission has increased with swelling of population in principal urban centres. Traditional mud and mud brick housing has been an design suitable for individual household construction patterns. Overcrowding in urban areas has become a problem with internal dislocation of population. Considerable but unquantified amount of rural housing has been destroyed by bombing.

WHO reports that in $198519 \%$ of the national population had access to safe water and $2 \%$ to sanitation. It is true that there are piped water systems in principal urban areas. In Kabul, 40\% of the population are said to be served by piped water systems. In Mazar-i-Sharif, $10 \%$ and in Herat $60 \%$ are served by piped water. In practical terms little of this water can be expected to be clean. Power cuts in all areas interrupt water availability in all systems, allowing contamination to be pulled into the system when the water pressure dissipates. Those without access to piped systems rely on unprotected wells, pools and water carriers.

Little current information is available on rural water supplies, though they would be expected to be less than in pre-war times. In a 1978 survey for UNICEF of available data on water supply in Afghanistan, Feacham found that only 3\% of the rural population had access to protected piped or handpump water sources, while the remainder relied on jui (irrigation canal), howz (open tanks), karez (underground tunnel) river, spring or unprotected well water. For the protected systems, a UNICEF survey found that $50 \%$ of handpumps and $60 \%$ of power pumps were not functioning. The MSH 1990 household survey in Wardak Province confirms the lack of access to protected sources. They found the principal sources were river water, wells, karez and springs. UNHCR reports that $45 \%$ of refugees in NWFP and Balouchistan have access to safe water.

The relationship between the lack of safe sanitation systems and disease transmission can be suggested by illustrations. Urban sanitation may be a night soil latrine where the waste is periodically cleaned from the chamber and carried out of the city on donkey (as in Herat) or a drainage system depositing waste in the street or in juis. Overcrowding and the breakdown of municipal services has increased stress on these systems and allowed considerable night soil to 
remain in streets and channels, open to flies and other agents of transmission. Overcrowding in rural areas is less of a problem. In some areas there is virtually complete reliance on the fields. In others, there are unimproved and vaulted latrines in the compound, but maintenance and use varied. Children might use a corner of the compound. Survey data from the 1970s show that only $33 \%$ of schools in the country had latrines and that many of these were illmaintained and little used. Many basic health centres at that time lacked water and sanitation.

The critical issue with regard to housing is the overcrowding that results from war and population dislocation. As noted before, the population of Kabul may be as much as 2 million, over two times its 1978 size of 730,000 . The density in the Old City is 700 persons per hectare (Habitat). Mazar-i-Sharif has experienced relative security during the war. The population there grew from 103,000 in 1979 to $250-300,000$ in 1990. There is overcrowding and deterioration of housing in the central area with three families to a household in some cases. Kunduz had 100,000 people in the pre-war period and has now grown to at least 250,000 . It has experienced bombing and destruction of housing stock. Tashqurgan was heavily damaged during the war with an estimated 2000 houses destroyed, but its population has swollen in recent years. Towns like Pul-i-Khumri have grown with refugees returned from Pakistan. The movement of people to urban areas puts stress on primitive urban facilities at a time no money exists for maintenance or construction. A positive feature of the urban growth has been the capacity of households to build their own mud and mud-brick houses. Habitat noted that $80 \%$ of the new building in Kabul during the period of the war was self-built housing; only $20 \%$ resulted from the official construction, largely pre-fabricated multi-story housing which produced about 1200 units annually.

\section{MANAGEMENT AND HEALTH}

The low morale of Kabul Government health workers has already been noted. In part this reflects the low pay of government staff and the degree to which staff may be distracted by second jobs or other efforts to obtain income. There are more fundamental management problems which pre-date the current conflict and which would hamper any effort to improve child and female health. First, the management culture in Afghanistan is not oriented toward performance but toward maintenance. Some have described this approach as a storekeeper mentality, with the priority given to accounting for inputs rather than to achieving an impact. Observers have noted the indifference of health staff on a tea break while children and mothers wait in long lines for service or the willingness of a vaccinator to use outdated vaccine rather than destroy it. Second, personal health service is not a high status activity.

\section{MCH CLINIC IN MAZAR-I-SHARIF}

"A Pashtun woman in black comes into the clinic with a child of about one year who is extremely malnourished. The female doctor talks to her quickly in Farsi--non-stop and with no exchange-Take this prescription to the pharmacy and give the baby this dosage, and feed the baby beans and is waiting in the doorway interrupts and translates-The woman speaks no Farsi and the doctor hadn't figured that out. She seemed unconcerned about reaching the woman."

Pamela Hunte

UNICEF Consultant 1991 potatoes and meat...' Finally the grandfather who 
Lack of status discourages doctors and other health staff from serving in rural areas and from working directly with patients who may come from a different ethnic group. Difficulties in recruiting Afghan doctors for rural service was present in pre-1978 Afghanistan and is found in cross-border operations today. 


\section{CHAPTER 6 \\ NUTRITIONAL STATUS}

\subsection{OVERVIEW}

Starvation only occasionally marks the faces of Afghan children. Their faces are more likely to mask chronically poor nourishment. Under nutrition, or continuing moderate malnutrition, contributes to stunting, poor child development and susceptibility to disease. It results from food insecurity and poor food consumption practices. This chapter and the next explore nutritional status and the impact of food security.

From the information available, the following generalizations can be made about nutrition:

There is no accurate data on the extent of severe malnutrition. It does exist and it is most likely to occur among poor urban households and poor rural families in food deficit areas and lacking access to cash income;

- Moderate malnutrition is a long-term and continuing problem for a substantial portion (say $20-30 \%$ ) of all children. There is evidence of stunting, indicating long-term undernutrition.

- Incidence of malnutrition is greatest among weaning-age children. Poor food consumption practices contribute to inadequate nutritional status.

Other nutritional problems include anemia in children and women of child-bearing age, iodine deficiency diseases and vitamin- $\mathrm{A}$ and possibly vitamin- $\mathrm{C}$ deficiency.

- The variables influencing nutritional status and food availability include factors of location, occurrence of natural disasters, class and gender;

Food production has decreased substantially since 1978/79. In 1990 wheat production was perhaps $60 \%$ of the pre-war total. Population in the country has decreased. Some observers estimate that present rural production may in general terms be sufficient to meet the needs of present rural population.

- Warfare and destruction of transportation routes interfere with food distribution and contribute to rapid inflation of food prices.

Poverty reduces purchasing power. This is particularly acute in the case of dislocated persons in urban areas, widows, orphans and other at-risk groups, as well as for rural populations in areas temporarily or permanently food deficit where opportunities for cash income are limited or non-existent. 
- Gender may be a variable in food distribution within the family, resulting in poor nutritional status of pregnant and lactating women and to a high rate of low birth weight in infants. Gender limits women's access to literacy, knowledge of improved nutrition practices and services.

- Poor nutrition interacts with diarrhoeal diseases and communicable diseases (particularly measles) to increase morbidity and mortality.

- Food consumption practices, not only weaning food practices but also food taboos and intra-household food distribution patterns, influence nutritional status.

There is little systematic or reliable data on the nutritional status of Afghan children and women. The nutritional information available is derived from limited samples whose selection may be determined as much by opportunity as by design. Measurements are often acknowledged to be carried out in less than ideal circumstances. There are discrepancies among the results. The information presented here does not represent a baseline, but only an indication of the nature, severity and magnitude of the nutrition problems of Afghans.

Considerable effort is being invested by several agencies in the development of estimates on food production, imports and prices. Different views exist on the nature of food insecurity. Actual food availability and utilization are also determined by distribution problems, by the low purchasing power of at-risk groups and by food practices at the household level.

\subsection{WOMEN AND NUTRITION}

Systematic data on the nutritional status of women is nearly non-existent. A 1970s study from the Institute of Public Health is one of the few indicators of the low nutritional status of women. It found that of mothers surveyed in Kabul, only 7\% reached the normal standard body weight for pregnant mothers. Incidence of low birth-birth-weight babies, estimated at just under $20 \%$ for the country, is an indicator of poor maternal nutrition status. UNFPA analysis of Malalai Hospital (Kabul maternity) records shows a much lower rate (4-5\%) of low birthweight babies in hospital births among a predominantly urban clientele. The current political situation and cultural constraints limiting access to women do not allow collection of current data on female nutrition. The little information that is available is presented below in relation to specific nutritional deficiencies. A particular need in Afghanistan are statistical approaches which make visible the nature and extent of nutritional deficiencies affecting women, and the impact of those problems on child health and development.

\subsection{PROTEIN ENERGY MALNUTRITION}

Protein energy malnutrition is not a new problem in Afghanistan. Surveys noted the existence of PEM in urban and rural locations during the 1970s. More recently surveys as well as rapid assessments available to UNICEF suggest significant levels of moderate malnutrition and evidence of stunting among particular groups. A chart in Annex III attempts to bring together 
information from a selection of surveys or rapid assessments carried out over the past twenty years. The purpose of that chart is to show continuity in the identification of an overall problem. The surveys and assessments are neither comprehensive not comparable in methodology or results. Few claim to be properly designed sample surveys. They provide the only present basis for establishing priorities and identifying opportunities for action. The information suggests that some severe malnutrition exists but that moderate malnutrition is more widespread. It indicates that malnutrition is most serious for children age one to two and it identifies some of the particular localities and groups that may be at-risk.

URBAN AREAS

The current nutritional status of children under five in urban areas, particularly Kabul, is a controversial issue. The assessments which have been done provided support for arguments for and against food aid for Kabul City. The estimates of ICRC $(1988,1989$, and 1990) are at variance with those of UNICEF (Pigot 1989) and Saboor 1990. ICRC concluded (January 1991) that the nutritional situation of children under five was essentially stable. Its December 1990 assessment of 976 children at 10 Afghan Red Crescent Society Clinics found $77.7 \%$ of children normally nourished, $21.9 \%$ moderately malnourished and $0.4 \%$ severely malnourished. These results represented no significant change from their findings in December of 1989 and December of 1988. The ICRC 1990 results show no statistically significant differences in nutritional status among ethnic groups or between boys and girls. ICRC has concluded that nutritional problems are the consequence of socio-cultural factors rather than food supply issues and argued that external food assistance programmes would risk disturbing "traditional existing support systems to weaker groups of the population".

The results of the UNICEF/Pigot and the Saboor assessments suggest a rather different picture of the nutrition situation in Kabul. Pigot's results from September/October 1989 suggested that $11 \%$ of the under-five population in Kabul was seriously malnourished and $29 \%$ moderately malnourished. Pigot's data, like that of ICRC, is clinic based and susceptible to the bias inherent in a clinic based survey. Pigot used chiefly weight-for-age measurements. Saboor undertook a survey for UNICEF of 3069 children 0-5 in Kabul in August 1990. His sample was drawn from 12 randomly selected clusters of houses in the eleven districts of Kabul. His results correspond to those of Pigot rather than those of ICRC. Using weight-for-height measurements, Saboor found $11.6 \%$ of children below two standard deviations of the norm and $25.9 \%$ between minus one and two standard deviations. Saboor also found evidence of stunting, which grew in severity up through 36 months of age. Both Pigot and Saboor indicate that malnutrition in Kabul is most severe in winter, following the diarrhoea season and during the period when basic food prices are highest.

Reconciling the differences among these estimates is not easy. All of the available information is methodologically weak simply because of the difficulties, socio-cultural, political and security of carrying out reliable survey work. Detailed discussion here of the methodological problems of the available information is probably not very useful. UNICEF as a key advocate and fund for children needs to make assumptions about nutritional status as a basis for planning. Without knowing the precise severity and magnitude of the nutrition problem in Kabul, UNICEF has solid basis for assuming that: 
- There are pockets of severe malnutrition in the Kabul under-five population, perhaps ranging from 1 to $11 \%$ among some groups. Visible starvation is not a feature of the Kabul landscape.

- Moderate malnutrition is the serious concern among under-fives in Kabul. Probably $30 \%$ of under fives are moderately malnourished and at-risk because of food insecurity and disease.

Undernutrition is a problem extending beyond the $30 \%$ who may be moderately malnourished. There is evidence of stunting, which implies undernutrition over a long period, and of a qualitatively poor diet.

A longer term perspective gives credence to assumptions of some severe malnutrition, of significant moderate malnutrition and of persistent undernutrition. Before estimates of nutritional status acquired the controversy they currently carry, nutrition was widely recognized as a problem in Kabul as well as in rural areas (World Bank 1977; MOPH 1976). Recent assessments have largely been based on clinic populations. The poorest and weakest in the city (the dislocated, orphans, widows, disabled) have less access to clinic services. This would tend to deflate estimates of malnutrition. While there is disagreement over the reality of food availability in Kabul, it is certain that internal dislocation and heavy in-migration to Kabul have altered the demographic and cultural characteristics of the city. There is general agreement that there is an increase in number of vulnerable groups, or those living in especially difficult circumstances. Assumptions about severe and moderate malnutrition provide the basis for UNICEF emergency feeding interventions. The risk of intervening without a reliable estimate of nutritionally at risk under fives is that UNICEF food supplements would be in excess of need. The risk of not intervening in the case of unrecognized malnutrition is that of increased mortality. The argument for assuming the higher levels of malnutrition goes beyond the risk of failure to meet the needs of under-fives. By engaging in winter emergency feeding programmes, UNICEF in Kabul has gained valuable experience. It has used integration of EPI and health screening with food distribution to lay the basis for future child development work. UNICEF has developed new modalities of working with semi-official and community-based leadership. These modalities may provide a basis for a future participatory health system which has few precedents in Afghanistan.

Less information is available on nutritional status in other urban centers. There is little evidence of widespread severe malnutrition. Rates of severe malnutrition may be around $3 \%$. Moderate malnutrition may be as high as $20 \%+$ in some urban locations. Survey reports relate malnutrition to poverty and food practices.

RURAL AREAS

Estimates of nutritional status outside of Kabul also provide a mixed picture. A 1989 survey in Badakhshan by Medicins Sans Frontiere (MSF) suggested that $37.3 \%$ of children surveyed were moderately to severely malnourished. An AfghanAid Survey conducted in 1990 screened (MUAC) 10,145 children in 202 villages of non-government held areas of Badakhshan, Jawzjan and Faryab. It found 26\% 
of children 1-5 moderately malnourished and $24 \%$ severely malnourished. In Badakhshan alone the survey found $33 \%$ of children severely malnourished and $26 \%$ moderately malnourished. In three districts of Badakhshan, only $35 \%$ of children surveyed were found to be normally nourished. Severe malnutrition in isolated areas of Badakhshan is consonant with the observations of anthropologists in the pre-war period (L. Dupree).

The AfghanAid survey was conducted in the wake of a severe locust and sunn-pest infestation which reduced basic cereal production particularly in Jawzjan and Faryab. This survey, like others, has been criticized on methodological grounds. The report acknowledges survey inability to interview mothers and to use female investigators, as well as under-representation of girls among children surveyed. Nonetheless, survey results indicate that malnutrition is most serious for children 0-1 and that girls surveyed suffer slightly greater malnutrition than boys.

UNICEF Kabul fielded nutritional teams in several rural areas in 1990 and 1991 to undertake rapid nutritional assessments, sometimes in combination with supplementary feeding efforts. Areas covered by these assessments are by no means comprehensive. They suggest wide variation by location in the severity of malnutrition and a tendency for more severe malnutrition during the weaning period. Measurement techniques were generally MUAC for children 1-5, and weight for age for under ones. In Shamali, north of Kabul, 21-35\% of children surveyed were severely and moderately malnourished. In three rural locations in Faryab, which in 1990 was still experiencing the effects of sunn-pest and locust infestation, assessors found $6 \%$ severe malnutrition and $56 \%$ moderate malnutrition. This survey shows far fewer severely malnourished children than the AfghanAid survey conducted the same year. It does indicate widespread moderate malnutrition. In two rural locations in Herat Province, survey teams found $3-6 \%$ severe malnutrition and $24-27 \%$ moderate malnutrition.

Several survey teams noted that status of nomad children appeared to be worse than that of settled population. Little data is available since the 1970 s on the nutritional status of nomads.

Only anecdotal evidence on nutritional status is available from other regions of the country. Stories of households subsisting on grasses or on linseed oil cake are brought back by crossborder missions, along with stories of adequate food supply in other areas. Looking at pre-war information on rural nutrition provides some depth to UNICEF assumptions about current patterns. Nutrition was widely believed to be a serious problem in rural Afghanistan (World Bank 1978). An MSH three province survey in 1976 showed high levels of moderate and severe malnutrition. This situation existed despite good harvests in the mid and late 1970s and the fact that two of the provinces were surplus food areas. This suggests that the pre-war nutritional base was not good and that nutritional problems were related to distribution issues and to food practices. Therefore, whatever the food supply in a given area, nutritional problems would be expected to remain in the absence of changes in distribution and food habits. Chronic or temporary food deficits as well as bombing and insecurity contribute to the severity and extent of malnutrition by location. 
In summary, it would appear that severe malnutrition is present in some rural locations and most likely to occur in food deficit areas like Badakhshan and the Hazarajat. There is considerable undernutrition, ranging from a fifth to more than one half the under-fives, in other areas. The extent of undernutrition may be exacerbated by natural events such as insect infestations or floods. Finally nutritional status is dynamic, related to food supply and potential changes in population due to refugee return.

REFUGEES

Refugee populations in Pakistan, with access to food aid, are not at-risk for severe malnutrition. Undernutrition, evidenced as stunting, is present. A survey of childhood mortality and nutritional status carried out in 1990 among Afghan refugees in the North West Frontier (NWFP) and Balouchistan Provinces (Centres for Disease Control/UNHCR) found only $1.8 \%$ of children in NWFP and $3.1 \%$ in Balouchistan to be severely malnourished or below two standard deviations of the median weight for height for the reference population. In addition, $2.8 \%$ of children in NWFP and $7.4 \%$ in Balouchistan were between 1.5 and 2 standard deviations below normal and were considered to be at risk for acute malnutrition. The study also found evidence of stunting; $57.9 \%$ of children 1-4 in NWFP and $67.4 \%$ in Balouchistan fell below two standard deviations of the reference height for age. This latter may reflect delayed introduction of weaning foods and what CDC calls a "qualitatively poor diet". Overall data may make invisible small groups of the refugee population who are at risk because of lack of access to refugee rations. UNRISD survey data in Pakistan (1988) found that nearly one in five households was not registered and therefore receive neither food nor cash rations. These households may also be the ones least likely to be represented in health service based nutrition surveys.

There is little information on the nutritional status of Afghan refugees in Iran. A survey conducted in 1988 by UNHCR in collaboration with the Ministry of Health and Medical Education in Iran found the nutritional status of children age six months to five years to be satisfactory in most of the settlements surveyed. 


\subsection{OTHER NUTRITIONAL PROBLEMS}

Other nutritional deficiencies exist for children and women, particularly anemia, iodine deficiency and vitamin A deficiency, and possibly vitamin C deficiency. Information is fragmentary, but all deficiencies appear to be widespread and some have severe impact.

\section{ANEMIA}

Pigot reports a survey at the Malalai Maternity Hospital indicating $47.7 \%$ of pregnant women as anemic, though only $15 \%$ had a haemoglobin rate lower than $7 \mathrm{gm} / 100 \mathrm{ml}$. The 1989 survey among under-fives at Kabul MCH clinics showed $6.5 \%$ of the children had severe cases of anemia while $23.9 \%$ had suspected cases. Saboor in 1990 found a prevalence rate of $30 \%$ among women in his community based sample. Survey teams in rural areas and in other urban areas have also noted signs of anemia. Various studies in the 1970s (PHI, CINAM, MSH) suggested the wide prevalence of anemia among Afghan women. The literature relates anemia to low birth weights, and high neonatal and maternal mortality. Malaria (thought to be increasing in Helmand and other provinces, and among refugees in Pakistan) and hookworm (common in only some areas) exacerbate iron deficiency anemia. UNICEF has provided iron folate tablets in Government and nongovernment controlled areas.

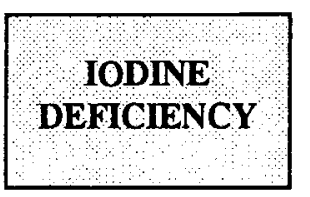

Iodine deficiency diseases (IDD), most visibly manifested as goitre, are endemic in the northern and mountain regions of Afghanistan, including Kabul. IDD results from a lack of iodine in the rock salt normally used as the source for the diet. In addition to being widespread and a source of discomfort when found in pregnant women, it has severe consequences in terms of congenital deafness and cretinism.

A UNICEF study in schools and MCH Clinics (Lopes-Pardinas 1988) found the following rates of iodine deficiency in Kabul:

$\begin{array}{lr}\text { women } & 25 \% \\ \text { pregnant women } & 16 \% \\ \text { children } 7-14 & 11 \% \\ \text { children } 0-6 & 8 \%\end{array}$

Saboor in 1990 reported that $34.3 \%$ of 1000 pregnant women surveyed in Kabul had goitres. A Medicins Sans Frontières survey of 2800 females of all ages in Jurm and Teshkan valleys in Badakhshan found that $48 \%$ of the women had goitres (UNICEF Peshawar 1989).

While the problem of goitre has been recognized by Government in Kabul, conditions have not permitted a salt iodization or other comprehensive approach. UNICEF Kabul and Peshawar have been supporting distribution of iodized oil capsules as an intermediary approach. Because of the visible results of supplementation on an uncomfortable condition, supplementation may be a useful tool in establishing the legitimacy of health interventions. 
VITAMN DEFICIENCIES

There is lack of agreement on the nature of vitamin- A deficiency among Afghans. One view holds that vitamin A deficiency is rare and that reports of deficiency blindness result from confusion with trachoma (Friesen as reported in UNICEF Peshawar 1989). Other evidence suggests increasing vitamin-A deficiency particularly in Kabul and Herat. Pigot in Kabul found conjunctival signs of xerophthalmia in $2.4 \%$ of children aged 5-14. Increase in vitamin-A deficiency may be related to food shortages, increasing prices and contracting purchasing power in urban areas as well as to nutritional practices.

Survey teams have noted clinical signs of vitamin-C deficiency in both urban and rural locations. As there is little previous information for comparison, the evidence of the deficiency serves only as an indicator of food habits and access to food.

There is no direct data available on calcium deficiency, but the incidence of osteomalacia noted above in relation to maternal mortality suggests a problem.

\subsection{UNDERLYING CAUSES - MALNUTRITION}

Food security and consumption practices together explain much of the malnutrition in Afghanistan. Food security is the supply side of the nutrition problem. It is not simply a question of how much food is available. Entitlement and purchasing power limit access to available food. Consumption practices, involving knowledge and attitudes, shape demand, or what households will decide to consume, as well as how they will distribute food, given available entitlement and purchasing power. Consumption practices are discussed below. Food security is explored in the next chapter.

Information on consumption practices is fragmented. Breast-feeding is common and long term, but nutrition problems emerge with weaning and post-weaning practices and with food taboos (cf. MSH 1977). Understanding local practice and attitudes concerning consumption and decision-making on distribution need to be part of initiating health and nutrition activities at the community level.

BREAST-FEEDING

mean duration of breast-feeding was 18.4 months. A 1983 household survey in Kabul found that $73 \%$ of mothers breast-feed at least 12 months and $33.6 \%$ more than 18 months (Pigot). In Kabul (and by extension other urban areas) breastmilk is often supplemented with over-diluted powdered milk. Practice on initiating breast-feeding varies. Among some groups initiation of breast-feeding is delayed for up to seven days after the birth. Sugar water is offered instead. Both practices are harmful, eliminating or reducing infant intake of colostrum while giving opportunity to introduce infection. 
WEANING

PRACTICES

The weaning period is generally acknowledged to be the most critical in Afghan child development after the first year of life. Weaning practices which increase the vulnerability of the one to two year old include the late introduction of weaning foods, the poor nutritional quality of weaning foods and the abrupt ending of breast-feeding. The MSH survey in three provinces in 1976 noted the late introduction of weaning foods, with tea and nan being introduced at a mean age of 11.6 months; fruits and vegetables at 18 months; and meat and eggs not until 20 and 26 months each. In Kabul, Pigot (1989) suggests that $60 \%$ of mothers do not give supplementary food until the child is two years old. Saboor, however, found in his sample in Kabul (1990) that over 50\% of mothers introduced supplementary food by the age of six months. Weaning food introduced is of poor quality. An MCH study in Kabul found that powdered milk constituted $23.4 \%$ of weaning food; bread and biscuits, $25 \%$; and family food not adapted to the child's needs, $20 \%$. At an earlier period, the MOPH/WHO study found that solid food was introduced at an earlier age (average age 7.4 months) than soft foods (average age 9 months). Weaning sometimes occurs abruptly, as when a new pregnancy begins.

FAMILY DIET

Gender, age, income levels, knowledge and distribution of food influence the nature of the family diet and the individual family member's access to that diet. The quantity and quality of the family diet has been limited in most households by the consequences of war.

Following weaning, children will share the family diet, though in a traditional setting food may have been reserved first for men of the household and secondarily for children and women. The impact of low priority given to the diets of women and children is not well documented in relation to the high rates of malnutrition for those groups. A CARE nutrition survey in 1970 found most mothers reporting that they never had enough to eat during pregnancy. This corresponds to the Institute of Public Health results that only 7\% of mothers reached standard weights for pregnant women. The relationships among food shortages, intra-family food distribution and malnutrition need to be made visible.

Food has been an important part of Afghan culture and of the Afghan family budget. A Household Expenditure Survey in Lashkar Gah (Helmand Province) conducted by the Ministry of Planning in 1968/69 estimated that rural families spent $65.6 \%$ of earnings on food; an urban family spent $60.7 \%$. The UNICEF-funded CINAM study in the north of Afghanistan (1973) produced evidence suggesting family interest in a varied diet. They found a high income elasticity among low-income families for meat, fruit and vegetables, and for milk products and eggs at higher income levels. Survey and observational data in the Hazarajat suggest an absence of vegetables and a lack of knowledge about the role of vegetables in the diet.

In the 1970s the typical diet of a laborer or small- farmer household was described as including nan (flat bread which serves as the staple), soup or sauce and yogurt with tea. Milk was rare. On special occasions meals might include rice pilaus, meat and sweets. Fruits and vegetables might be available in season (World Bank 1978). 
In 1989, the diet in an ordinary Kabul home was described as suffering from the decrease in purchasing power and consisting of nan, tea without sugar and sometimes a soup containing some vegetables and potatoes. Families may have a protein supplement (meat, egg or milk) only two or three times a week. Vegetables and fruit are expensive in the market (Pigot 1989).

Among refugees the aid ration has included wheat, sugar, milk, tea, edible oil and sometimes beans, which may be supplemented by purchases from the market depending on income. Tea, sugar and milk have recently been eliminated from the ration and the amount of wheat reduced from 12 to $10 \mathrm{~kg}$. per person per month.

FOOD TABOOS

There are a number of food practices or taboos in Afghanistan, not well documented by type or area of practice, which have a deleterious effect on the nutrition and health of children. The taboos affect breast-feeding and weaning practices as well as diet during illness, pregnancy, postpartum and lactating periods. Theories about 'hot' and 'cold' foods govern practice in some areas. For example, treatment of diarrhoea among some groups includes the withholding of all liquids. In other cases eggs, even when plentiful, are forbidden to young children. The existence of harmful food practices or remedies will remain an obstacle to introduction of improved nutritional habits.

KNOWLEDGE ATTITUDES \& PRACTICES

Though male literacy and access to outside information is greater than that of females, neither men nor women have a clear idea of the role of diet in individual and family well-being. For the poorest and nutritionally most atrisk nutritional questions may seem a luxury when food is costly and in short supply. UNICEF missions have noted cases where nutritionally at-risk households did not maintain kitchen gardens even where land was available. Kitchen gardens seemed limited to better off households. Within the context of expanding food security, the important nutrition messages for children and women related to the specific nutrition problems identified above include:

- improved weaning foods and practices to reduce the vulnerability of children at the weaning stage; this would include timely introduction of appropriate local foods;

- $\quad$ encouragement of current breast-feeding practices but discouragement of powdered milk supplementation;

- $\quad$ promotion of breast-feeding following birth to take advantage of colostrum;

- identification and popularization of appropriate diets for pregnant and lactating mothers;

- promotion of vitamin-A-rich local vegetables;

- $\quad$ popularization of iodine supplements, as well as vitamin-A and iron supplements; 
- $\quad$ encouragement and facilitation of kitchen garden production where appropriate.

Attitudes influence whether knowledge is applied. Given ingrained food practices in Afghanistan, along with patriarchical patterns in the society, targeting fathers, school boys and leadership with information and advocacy may be necessary to influence change. In 1978 the World Bank, in noting that part of the nutrition problem is educational, called for "making fathers aware of the special nutritional needs of expectant and nursing mothers". 


\section{CHAPTER 7 \\ FOOD SECURITY}

\subsection{OVERVIEW}

Food security in Afghanistan is the product of several variables:

$$
\begin{aligned}
& \text { Availability = production }+ \text { imports } \\
& \text { Distribution }=\text { infrastructure }+ \text { security }+ \text { policy } \\
& \text { Access = purchasing power }+ \text { subsistence production }+ \text { entitlement }
\end{aligned}
$$

In Afghanistan, these variables operate to create a situation of food insecurity for specific population groups:

- Urban disadvantaged people, particularly in Kabul, including female-headed or maintained households or widows, the disabled and others lacking entitlement to government rations;

- Subsistence farming population in the traditionally food-deficit areas of Afghanistan, including Badakhshan and the Hazarajat;

- Subsistence farming population in provinces hard hit by the direct effects of war and by natural events such as flooding, earthquake, and sunn-pest and locust infestations.

The first two groups represent long-term, structural food insecurity. The third group experiences temporary food insecurity. The discussion below singles out these three groups as particularly at risk because of food insecurity. In fact food security is a problem affecting the productivity of much of the population. Even for those with minimum purchasing power and entitlement to government rations, procurement of food occupies considerable energy, and supply of government rations is intermittent. For Afghans who are refugees in Pakistan, the security of the food aid basket is decreasing. The monthly wheat ration for refugees was reduced from $15 \mathrm{~kg}$ to $12 \mathrm{~kg}$. per head per month in January 1991, and pulses, sugar and other items have been reduced or eliminated.

\subsection{FOOD AVAILABILITY}

Food availability is the sum of production and imports and it needs to be seen on an international, national and a local level. Making sense of the food security situation for Afghanistan is not easy. Using wheat as a proxy indicator of overall food availability, the following generalizations are offered as a framework for thinking about food availability in the context of planning children and women in Afghanistan: 
- Wheat production by 1990 has returned to approximately $60 \%$ of its pre-war level. Several sources suggest that this means overall a capacity to meet the minimum cereal needs of more than 8 million people or perhaps all the people presently living in rural areas. Production in 1991, despite floods and an earthquake, is thought to have exceeded that of 1990.

- Imports of wheat into Afghanistan, which were at a level of 250,000 metric tons during the 1970s, have continued to the present. Because imports come from a variety of sources, official and unofficial, it is difficult to make a good estimate of total wheat imports. Government relies on wheat imports to feed the urban population. The decrease in Soviet wheat to Afghanistan for the winter of 1991-91 appears to have been balanced by purchases of wheat from Europe by the private sector in Kabul.

To explain these generalizations and the difficulty of understanding the food availability situation in Afghanistan, the following paragraphs review some of the available information.

Wheat production has declined from 1978 levels because of the direct and indirect effects of war and the flight of population. The table below reproduces Government data on wheat production along with estimates on the basis of data from extensive rural surveys carried out by the Swedish Committee for Afghanistan (SCA). It is interesting to note that these estimates begin to converge in 19.90 .

TABLE 17: ESTIMATES OF WHEAT PRODUCTION IN AFGHANISTAN

\begin{tabular}{|c|c|c|c|c|c|}
\hline \multicolumn{6}{|c|}{ METRIC TONS } \\
\hline & $1977 / 78$ & $1983 / 84$ & 1988 & 1989 & 1990 \\
\hline $\begin{array}{l}\text { Government of } \\
\text { Afghanistan }\end{array}$ & 2,652 & 2,927 & - & 2,200 & 1,650 \\
\hline $\begin{array}{l}\text { Estimates based on } \\
\text { SCA Data }\end{array}$ & & & $1,406^{*}$ & - & $1,591^{*}$ \\
\hline
\end{tabular}

In pre-1978 Afghanistan, aggregate data suggested that in normal years overall food production was adequate for consumption requirements or a per capita calorie intake per day of $2250,7.5 \%$ below the FAO standard (World Bank 1978). There were, however, wide fluctuations in production of staple crops, particularly wheat, due to rainfall conditions. The annual variation in production was estimated at $\pm 500,000$ metric tons or half the total amount entering the domestic market. The variation resulted in fluctuations of market prices for consumers. Small- 
scale wheat producers usually failed to benefit in years of good production as stocks were sold at low prices in the post-harvest glut period (Street 1977).

Warfare throughout much of Afghanistan has disrupted even normal production, and destroyed productive capacity. The 1987 Agricultural Survey of Afghanistan carried out by the Swedish Committee for Afghanistan showed a decline in yields for irrigated wheat of $33 \%$ and for dry land wheat of $50 \%$ between 1978 and 1986 . This suggests that total agricultural production in 1986 had fallen to about $45 \%$ of its 1978 levels. Data from the survey show high levels of bombing of villages, destruction of irrigation systems and grain stores, and livestock lost to bombing, shooting or mines. The SCA data, along with provincial profiles being prepared by UNIDATA and UNHCR and information from UNOCA and UNDP, provide considerable information on agricultural infrastructure.

As the intensity of fighting and bombing has reduced in some areas of the country, both the number of jeribs cultivated and yield has increased. SCA survey data in 1988, 1989 and 1990 show gradual increases in production. In 1990 it was estimated at $60 \%$ of pre-war totals. Sunnpest and locust infestations in 1988-1990 and flooding and earthquakes in 1991 reduced potential production in specific areas in a year which overall saw a good harvest.

What do these food production estimates mean for food availability? How much food is available on a per capita basis? FAO reports that total food cereal production (wheat, maize and rice) in 1990 amounted to 2.413 million metric tons. This is sufficient to provide 513 grams per day of cereal to the estimated $12,870,000$ population in country (UNIDATA), or above the FAO estimated minimum consumption level of 500 grams per day. Separately, SCA estimated informally that wheat production inside Afghanistan in 1988 was sufficient to provide 8 million people with $10-12 \mathrm{~kg}$. per month or a minimum requirement. This estimate suggests that current production levels are lower than the FAO estimate but sufficient to meet two thirds of the requirement of the population inside.

Whatever the precise production levels, there is clear evidence that Afghanistan has had and continues to have a need for substantial imports of cereals and other food. Estimates of annual cereal imports in the 1980 s range between 200,000 and 1.5 million metric tons. Accurate estimates are impossible as cereal imports come as commodity assistance from various donors, purchases by government and private traders and as unofficial imports from Pakistan. The Soviet Union has been a principal source of cereal imports to Afghanistan in the 1980s. In 1990 , The Soviet Union is reported to have provided a total of 250,000 metric tons. Unofficial wheat imports from Pakistan to Afghanistan have been estimated at 225,000 to 1.0 million metric tons per year (cf. R.R. Nathan Associates 1989). Within Afghanistan, observers note considerable but unquantified amounts of cereal and food exchange in both directions between government and non-government-controlled areas.

The short-term prospect for food supply is not promising. Though the 1991 harvest overall is estimated to be better than previous years, there are shortfalls in several provinces and questions about the capacity of Government to acquire enough wheat to meet urban needs. FAO is 
estimating wheat import needs for 1991-92 at 460,000 metric tons, relating the requirement more to distribution problems than to overall availability. The Soviet Union is not expected to supply wheat at the same levels as in the past. About 50,000 metric tons from Kazakhstan (under a barter arrangement where India supplies tea to Kazakhstan) are expected for the 1991/92 winter. WFP food assistance for 1992 is expected to be 50,000 metric tons. Government reportedly has arranged for 200,000 metric tons to be imported through a local trading company and is negotiating for an additional 125,000 metric tons. Additionally there is the possibility of informal trade in wheat from Pakistan, or from wheat surplus in rural areas to government-held urban areas. This kind of trade has been price driven. The rapid rise of prices in Kabul has made cross-border sales attractive. Currently it is believed that the Pakistan Government is discouraging accumulation of wheat in its border provinces in order to reduce unofficial wheat flows to Kabul during the coming winter season.

In Kabul, Government appears to have fewer reserves of wheat in storage this year than it did at the same period last year. In early September 1991, the Government had 10,000 metric tons in the silo, while WFP had 3,600 metric tons in storage in Kabul. This represented a 10-14 day supply. Approximately 8,000 metric tons of WFP wheat were in storage in Mazar-i-Sharif and Herat, while the Government had a total of 10,800 metric tons in the two cities. While supplies continue to enter the city, the low level of reserves offer little protection against closure of the Salang Highway or other entry routes.

\subsection{DISTRIBUTION}

Production of wheat, the main staple, and other principal foods has always been unevenly distributed over the country. Presently distribution of food from surplus to deficit areas is hampered by a limited road transport system which has been damaged by war, the interruption of traditional trading patterns and insecurity. In addition to transiting government and mujahiddin posts, trucks may have to pass militia posts which also claim a tax for passage. Shipments may be lost. These factors add to the end cost of food in food-deficit areas.

As noted above, intra-family distribution choices particularly in situations of scarcity may leave women and girl children with less food.

\subsection{ACCESS}

Household access to adequate food supply is determined by purchasing power, entitlements and subsistence production. Overall purchasing power of the household appears to have declined because of an escalation of prices in the past twelve years and a much slower growth in income. The section on the economy in Chapter 3 of this analysis describes the overall deterioration in the Afghan economy. This section discusses changes in relation to the household.

Food and other consumer prices have escalated in Kabul and throughout Afghanistan. Information available for Kabul shows a 30-fold increase in the price of cereals between 1978/79 and 1990/1991. Wheat has gone from 8 Afs. per kg in September of 1978 to 245 Afs per kg 
in September 1991. UNIDATA estimates that the price change between 1978 and 1988 in Kabul was at an average of $25.8 \%$ a year. After that it has increased at a faster rate:

\section{Trend of Wheat Prices in Kabul}

$\begin{array}{lcc}1988 & 35 \mathrm{Afs} / \mathrm{kg} & \text { Average } \\ 1989 & 108 \mathrm{Afs} / \mathrm{kg} & " \\ 1990 & 119 \mathrm{Afs} / \mathrm{kg} & " \\ 1991 & 245 \mathrm{Afs} / \mathrm{kg} & 16 \text { September (FAO) }\end{array}$

Prices changes were most rapid between 1988 and 1989, and apparently in 1991. UNIDATA price estimates for other food items in both Kabul and Afghanistan show similar trends (see Chapter 3). UNIDATA has estimated that the average household food basket in Afghanistan cost three and a half times as much in 1990 as it did in 1987. For Kabul, UNIDATA estimates a slightly higher increase.

DAI, a USAID contractor, has been tracking prices by province from the Pakistan side of the border. At the end of 1990, they calculated a country-wide wheat price of $838 \mathrm{Afs} / \mathrm{seer}$, or about 105.4 Afs $/ \mathrm{kg}$. DAI found the highest prices in Faryab, Badghis, Ghor, Nangarhar and Badakhshan. All had wheat prices in 1990 over $1000 \mathrm{Afs} / \mathrm{seer}$ (143 Afs $/ \mathrm{kg}$ ). Faryab, Badghis and Ghor all suffered sunn-pest and locust infestation, Nangarhar was the scene of heavy fighting; and Badakhshan (as well as Ghor) is a food deficit area. Samangan, Bamyan, Kabul, Jawzjan and Kapisa had the next highest average wheat prices (See table in Annex III).

Prices are one side of the purchasing power equation. Income is the other side. Good, comparable data is not available but some information and examples may indicate the nature of the decline in purchasing power. Describing what has happened to household income in relation to price trends is not easy. At a macro-economic level per capita income levels in real terms remain virtually stagnant. Salaried incomes remain low: teachers earn 2500-3000 Afs per month; soldiers 2000-5000 Afs.; ministers 18,000 Afs (ICRC). UN and NGO mission reports note a decline in small-scale production and services which would have provided cash income to rural and urban families. At the same time, mission reports note that markets in Kabul, other urban areas and rural bazaars have ample food. If price mechanisms operate in the relatively free markets of Afghanistan, the supply of food at high prices implies some level of demand. Observers note the evidence of income in Afghanistan from unofficial economies (drug production and trade, smuggling); it is not evident that this income is widely distributed.

In attempting to explain how Kabul households survive in the face of high prices, ICRC (1990) refers to food coupons (see below) and to the phenomenon of "parallel incomes" and "parallel supply systems" that they describe as being widespread in Kabul, but difficult to assess. Second jobs, 'baksheesh' or corruption, drug trade, smuggling and subsistence production are different forms of parallel income. Additionally Kabul residents may have links into mujahiddincontrolled areas where they can obtain food at lower prices. ICRC maintains that the Kabul population has developed a special capacity to adapt to the food shortages. The population 
would appear to make that adaptation at the cost of considerable investment of time and energy. For households at risk, that adaptation may not be possible.

In rural areas, the contraction of the economy limits cash availability to subsistence households. Traditionally a household might meet its needs for cash, not only through sale of surplus (if it existed), but through the cash earnings of a family member in a nearby town.

\section{ENTITLEMENTS}

A new feature on the Afghan scene in the post-1978 period is the widespread introduction of food coupons or rations, chiefly affecting urban areas. Civil servants, party members, security and military forces and war widows are eligible. The coupon system was said to reach 252,000 households in Kabul in 1990, which would represent nearly $80 \%$ of total Kabul households (ICRC). UNDP estimates that there were 450,000 coupon holders overall in 1990.

The coupons have considerable potential value. ICRC estimates that in 1990 their value was $15,000 \mathrm{Afs}$ per month for $56 \mathrm{~kg}$ of flour and $722 \mathrm{~kg}$. of ghee distributed free, plus $9000 \mathrm{Afs}$. per month for the tea, dried skim milk, sugar, rice and salt sold at a subsidized price. Government has used this ration system to stabilize the food situation in Kabul. In late 1990, they distributed four monthly rations at one time to forestall hoarding and to build confidence. In 1991, as a result of reductions in Soviet food aid, distribution from Government shops is reported to be less frequent and in reduced quantities.

Another form of entitlement for urban residents is the government subsidy of bakeries through provision of free flour and subsidized fuel, in return for which fixed bread prices are maintained. Since 1990, the subsidies have been reduced, the size of bread (nan) has decreased, and price has increased.

Refugees in camps have also had entitlements to food rations and cash. An estimated $20 \%$ of refugees in camps in Pakistan, plus a portion of residents in towns are not registered (UNRISD) and thus have no access to rations. Registration is linked to mujahiddin political party membership. 


\section{CHAPTER 8 \\ EDUCATING CHILDREN AND WOMEN}

\subsection{OVERVIEW}

The educational status of Afghans ranks among the lowest in the world. Access to formal and informal educational opportunities has always been limited and the quality of education available frequently poor. Civil war has further reduced the quality and quantity of educational opportunities.

Analyzing the present situation of education for Afghans is more complex than sifting through the incomplete and sometimes conflicting and unverifiable information from the Kabul Government and organizations working cross-border and cross-line on rural education, as well as from schools for refugees. Underlying the current situation is a continuing lack of a shared national vision of the purposes and nature of education. It was the female literacy programmes of the new Government in 1978 that ignited the mujahiddin resistance and made school buildings a priority target during the war. The nation is still divided on the purposes of education and particularly on the question of education for girls; however, time may have begun to moderate the extremes of ideological vision. To focus only on the political tensions surrounding formal and informal education is to obscure the real issues of illiteracy, limited access and wastage and to inhibit assessment of the diverse educational efforts spawned by a fragmented education system.

This chapter attempts to describe the current state of education in the context of recent historical experience and of opportunities for expanding education. Policy and management patterns should set the framework for education implementation. For Afghans today, policy and structure are fragmented. Literacy and the percentage of school age children, by gender, enrolled are key indicators of the status of education now and over time. Analysis focusses on access to basic primary education, including enrolment, wastage, quality and factors limiting access. It also describes post-primary education, non-formal education and emerging issues.

Out of the analysis several generalizations are possible:

- Literacy levels (24\% for those 15 or above) are nearly half the level for the rest of South Asia. Literacy of rural women is only $1-2 \%$ and has not increased significantly in recent years.

- The coverage and quality of basic primary education in Afghanistan have always been low and remain low today. Enrolment ratios have increased in Kabul since 1978, but have probably decreased in the rest of the country. 
- Girls are largely excluded from basic education. Either no schools exist for girls, or girl students are a fraction of the number of boys. Only in Kabul and at the secondary and post-secondary levels do female enrolment rates approach those of males.

- Despite the destruction of schools, the loss of qualified teachers and politicization of education, demand for education exists among Afghans, and is reviving in rural areas.

- A nationally directed and funded education system, however, inadequate, has been disrupted. Locally based schools and proto-systems have emerged in rural areas, supported largely through external aid.

Mosque schools and madrassa continue to operate throughout the country, offering primarily religious education.

There is little information available on education for refugees in Iran. In principle Afghan children in Iran have access to the Iranian school system. For the most part, this analysis does not include refugees in Iran.

\subsection{EDUCATION, POLICY AND MANAGEMENT}

Officially Afghanistan has a national education policy and strategy but it is a policy and strategy applicable only in those areas ( $20 \%$ of the total) controlled by the Government. Political differences over education policies and separately administered educational systems have divided the Afghans living in Kabul Government areas and Afghans in rural areas and as refugees. Differences remain among Afghans as to education for what and education for whom. At some level there is a common interest among Afghans in basic primary education, whether it is in response to the requirements of religious education, the demand for skilled manpower to carry on the war or the demand for skills for economic survival.

In its National Strategy for Education for All in the Republic of Afghanistan (1991) the Government committed itself to the following objectives:

- equality for all citizens in the sphere of education;

- free and compulsory primary education for all;

- education in the mother tongue;

- eradication of illiteracy up to the age of 55;

- provision of further opportunities for secondary and higher education for all youths.

There is no equivalent statement for all the cross-border primary education efforts. By their actions military commanders and shura on the inside and political leadership of the Pakistanbased political parties seem to be endorsing some level of basic primary education, though in the context of supporting Islamic values and Afghan culture. Their commitment to the goals are demonstrated by their increasing requests for schools and by their willingness to support school operations with in-kind contributions. 
Afghans are exposed to two separate and diverging systems of school management. Kabul government schools are centrally directed and financed. Presently, formal education is structured into six years of primary education, leading to three years of middle school and three years of lycee. Post-lycee educational choices are university or higher teacher training institutions. An alternative course is to move from primary or middle school education into technical or vocational training (See structure in Annex I).

The structure of education supported by the NGOs and for refugees is simpler. For those who have access, education consists mainly of primary classes, sometimes only up to the third or fourth grade. In a small number of cases secondary schools have been set up. Opportunities for tertiary level education are rare.

Cross-border education is managed in a decentralized fashion. Nine NGOs provide most of the external funding and the organization. The education programmes operate on the authority of the local military commander and/or the shura, and often in conjunction with a Pakistan-based political party. The Swedish Committee, to use an example, is one of the three major NGOs involved in cross-border education. In 1990 SCA worked with 78 different military commanders or village shura or councils in 20 provinces to support 473 primary schools. The other two major NGOs involved in cross-border work are Muslim Aid and the Education Centre of the Alliance/University of Nebraska (ECA/UNO). In recent years there has been growing collaboration among these Pakistan- based NGOs on monitoring of school functioning, eliminating double funding of schools, standardizing teachers' salaries and production of textbooks, and strengthening of curriculum and training. NGO supported schools are dependent on outside funding for operation as local capacity for funding has so far been limited. AND VALUES
ATTITUDES

Attitudes about education in general and for women in particular are a constraint to the development of education. For rural Afghans, the primary reason for sending children to school has traditionally been for religious education. The economic potential of education was not valued; instead the demand for child labor might be stronger than the wish to educate the children. Education generally is less valued for girls than for boys. Limitations on girls' mobility, requirements for all-girl schools in conservative areas and household demand for the labor of girls all inhibit girls' participation. Demand for education is higher among non-Pashtun groups of Afghans. Statistics for the pre-war period suggested higher demand for education in the north and northeast where Tajik groups predominate. Among the urban middle classes demand for education has always been high, including for girls and especially for secondary and higher education.

Government policies, though not necessarily expenditures, have long made the link between education and development. This was true of the objectives of the Seven Year Plan (1976-1982) of the Daoud Government as well as of the Peoples' Democratic Party of Afghanistan (PDPA) Government in 1978 that began aggressively to use education as an instrument of rapid economic and social modernization. Neither Government, for different reasons, invested significantly in education. The PDPA initial efforts in literacy and education politicized education and galvanized opposition so that government resources were increasingly funneled into the war. 
The education policies of the PDPA Government in 1978 appeared to polarized Afghans between the pro-active Government approach and the fundamentalist mujahiddin perception of schools as symbols of a godless, communist regime. A simple, dichotomized picture of Afghan education attitudes and values is less accurate over time. The Kabul Government has softened or eliminated the political content of curriculum and re-introduced elements of Islamic education. The mujahiddin, responding to the prolonged disruption of education patterns and the unmet demand for education among their supporters, are increasingly asking outside support for schools. Some observers suggest that, working with increasingly sophisticated weapons and equipment during their military campaigns, mujahiddin have come to value secular and technical education (cf. L. Carter 1989).

\subsection{LITERACY}

The capacity to read and write is not an end in itself, but an avenue to a wider range of ideas and information. Research has demonstrated a significant link between the educational level of the mother and the survival and development of the child. The continuing low literacy rates (Table 18) among Afghans, particularly females, corresponds to the continuing high infant and child mortality rates. Estimates of literacy rates vary by source but together they suggest a serious deficiency that is improving only among Kabul residents. No estimates are available for the

TABLE 18: ESTIMATED AFGHAN LITERACY RATES

\begin{tabular}{|c|c|c|c|c|}
\hline \multirow{3}{*}{$1977(1)$} & \multirow{2}{*}{\multicolumn{2}{|c|}{$\begin{array}{c}\text { Male } \\
\text { Urban Rural }\end{array}$}} & \multirow{2}{*}{\multicolumn{2}{|c|}{$\begin{array}{l}\text { Female } \\
\text { Urban Rural }\end{array}$}} \\
\hline & & & & \\
\hline & $36 \%$ & $16 \%$ & $15 \%$ & $1 \%$ \\
\hline $1978(2)$ & $20 \%$ & $10 \%$ & $10 \%$ & $1 \%$ \\
\hline $\begin{array}{l}1988 \text { (3) } \\
\text { (Kabul Govt. }\end{array}$ & reas) & $25-30 \%$ & -- & \\
\hline $1989(4)$ & -- & $23.7 \%$ & -- & $--11.1 \%--$ \\
\hline Sources: & $\begin{array}{l}\text { (1) } \mathrm{Na} \\
\text { (2) } \mathrm{Ge} \\
\text { (3) } \mathrm{Ba}\end{array}$ & $\begin{array}{l}\text { eal Dire } \\
\text { al Agen } \\
\text { 1989; }\end{array}$ & of Adult & $\begin{array}{l}\text { Education; } \\
\text { Campaign; } \\
1989 .\end{array}$ \\
\hline
\end{tabular}
present on literacy among rural women but there is no evidence to suggest a change.

The Government in Kabul has placed high priority on literacy, particularly for women. In 1991, for example, the Government reports a total of 269,089 students enrolled in adult literacy classes, $28 \%$ of whom are women. This total is skewed toward male enrolment because it includes 118,683 students from the military who are all male. According to government figures, $70 \%$ of literacy students in Kabul City and $29 \%$ of those in the provinces are female.

Programmes for literacy, particularly those involving females, have been politically divisive. It was the promotion of literacy classes for women, sometimes by coercive means, in 1978 and 1979 that helped to spark the mujahiddin rebellion. While some outside observes believe that the increases in literacy may not be permanent, others observers note the widespread participation of women in literacy classes and the involvement of women's organizations in 
promoting literacy and in mobilizing women (Basu 1989 and Moghadam 1989). Though Connor (1989) in a skills inventory of Afghan women refugees found that $19 \%$ of female health workers and traditional birth attendants reported being literate, there is little information on the literacy levels of the whole female refugee population. The evidence on school attendance (see below) suggests a decline in literacy rates for females.

Literacy can to some degree be used as a proxy for measuring the access women have to new ideas and to means of influencing change. To understand the capacity of rural Afghan women to receive and use new information for the welfare of their families, it is useful to go beyond literacy as the ability to read and write, and to look at the access and exposure to new forms of communication. While Afghan women may remain illiterate, the nature of that illiteracy may be changing. Traditionally Afghan women might spend their entire lives in a single valley, without interchange with strangers. Connor, reporting on Afghan women refugees, notes the very narrow perspectives of formerly rural women whose isolation prior to flight limited them from access to varied sources of information (radio, films, markets) beyond their own and related households. Village life was not porous to new ideas.

The refugee experience, and to some extent the experience of dislocation inside Afghanistan, has had differing and sometimes contradictory effects. Within refugee camps, households have sometimes been thrown in with unrelated groups from different locations and tribal affiliations. Among strangers, refugee women have been secluded to a greater extent than they would have been in their ancestral village. Relief agencies have encountered resistance to their access to refugee women. Nevertheless, the refugee experience has pierced the isolation of these formerly rural women. The significant drop in infant mortality among refugees in Pakistan is one indication of the increased access of women and children to health care. Moreover, women have become directly exposed to the power of health technologies, particularly immunizations, to reduce mortality. Other forms of outside communication, radio and television, may have become more accessible to refugee women. Widespread widowhood, the breakdown of traditional social support systems, along with other forms of economic need, have forced some women to seek employment or income-generating opportunities. Self-settled refugees in Peshawar and elsewhere may have wider experience than in rural Afghanistan. Ten years of exile may have begun to alter the world view and expectations of Afghan women refugees. To some extent the same contradictory pressures can be said to be working on rural women dislocated from rural homes to urban areas inside Afghanistan.

\subsection{ACCESS TO PRIMARY EDUCATION}

Describing current access to basic primary education and assessing trends since the 1970s is difficult because there is currently no reliable national data on students, schools and teachers. The information prepared by the Government includes estimates on areas not under government control and may not reflect the many schools operated with cross-border support from Pakistan. 
The indicators of access to primary education presented in Table 19 are not comparable because of differences in the way statistics were prepared. The data for 1977/78 was collected when a statistical system, established with UNESCO support, was operating adequately. Both the Government and the UNIDATA figures from 1989 and 1990 include numbers of schools and

TABLE 19: COMPARATIVE INDICATORS OF ACCESS TO PRIMARY EDUCATION 1978-1991

\begin{tabular}{|c|c|c|c|c|c|}
\hline & \multirow{2}{*}{$\begin{array}{l}\text { No. of } \\
\text { Primary } \\
\text { Schools }\end{array}$} & \multicolumn{2}{|c|}{ Enrollment } & \multirow{2}{*}{$\begin{array}{l}\text { Participation } \\
\text { Rate }\end{array}$} & \multirow{2}{*}{$\begin{array}{c}\% \text { age } \\
\text { Enrollmen } \\
\text { Female }\end{array}$} \\
\hline & & Male & Female & & \\
\hline $\begin{array}{l}\frac{1978}{\text { Ministry of }} \\
\text { Education* }\end{array}$ & 3,371 & 737,732 & 134,590 & $30 \%$ & $8.4 \%$ \\
\hline $\begin{array}{l}\frac{1990}{\text { Ministry of }} \\
\text { Education }\end{array}$ & $563^{* *}$ & 416,722 & 210,778 & - & $33.6 \%$ \\
\hline $\begin{array}{l}\frac{1989}{\text { UNIDATA }} \\
\text { Estimates }\end{array}$ & 1,008 & 511.072 & 238,942 & - & $31.8 \%$ \\
\hline $\begin{array}{l}1990 / 91 \\
\text { Rural } \\
\text { Afghanistan } \\
\text { Cross-border }\end{array}$ & 2,044 & 200,000 & (1988 est.) & - & \\
\hline
\end{tabular}

${ }^{*}$ Includes village and primary schools.

** Is an understatement of total number of primary units. Ministry data does not include the middle schools and lycees which also offer primary education.

Sources: $\quad$ UNICEF 1978; UNICEF Peshawaar 1989; Carter 1988; UNIDATA; UNESCO

students for all provinces, including those where Government exercises little or no control. Given the security problems, there are limits to the accuracy of the numbers. UNIDATA has had access to information in non-government controlled areas through their own survey missions and from NGOs in Pakistan operating cross-border.

Information on cross-border supported schools was supplied by the NGOs themselves. There is concern about the existence of some of these reported schools as well as their enrolment and quality. The NGOs have been attempting to monitor them more carefully. A good number of schools have been verified by outside monitors. In a three-day mission to Parwan Province in 
August 1991 UNICEF staff identified 24 primary schools serving an estimated 6000 children. This is one quarter of the total number of primary schools in Parwan reported by NGOs.

\section{PARTICIPATION RATES}

In $197837.8 \%$ of boys and $8.4 \%$ of girls of primary age were enrolled in primary school. Urban boys had the greatest access while rural girls had little opportunity to attend schools. The rate of participation for boys in Kabul was $66.9 \%$. Nearly half of Kabul girls of primary age were enrolled. In rural provinces, participation of girls fell to nearly $0 \%(0.6 \%$ in Wardak, $0.7 \%$ in Oruzgan, $0.8 \%$ in Paktya, and $1.0 \%$ in Zabul).

The quality of data does not permit reliable estimation of present rates of participation in primary school in all Afghanistan. Participation rates can be judged to have declined from 1978. Present population inside Afghanistan is $92.9 \%$ of the 1979 population of 13.8 million. The Government and UNIDATA figures on primary enrolment in 1990 (1989) are $71.9 \%$ and $85.9 \%$ respectively of the 1978 enrolment figures. The Ministry of Education (1990) has estimated that $37 \%$ of urban children and $3 \%$ of rural children are enrolled in formal general education schools. This implies a participation rate less than the 1978 level of $30 \%$.

Information on number of schools and of primary school students supported cross-border by NGOs is fragmented. Carter in 1988 collected data for UNICEF on NGO cross-border education activities. She found then 1347 schools with 179,789 students staffed by 2896 teachers. Since then the number of schools and students is thought to have increased substantially. In 1991, the Swedish Committee for Afghanistan (SCA) reported operating 474 schools inside Afghanistan serving 90,000 students with nearly 3,000 teachers. In 1990 SCA supported 26 female schools, three separate girls' classes in boys' schools and 21 mixed schools which served a total of 2629 girl students. During that year SCA monitoring teams visited 426 schools. Fifty schools were eliminated because of lack of evidence of adequate operation. The Education Centre of the Alliance/University of Nebraska (ECA/UNO) programme reported supporting 1199 schools with 161,000 students and a reported 7000 teachers in 1991. Muslim Aid is the third NGO playing a major role in cross-border primary education. No information is available on the current size of operations. In 1988 they operated 252 schools, the largest number of which were in Logar, Wardak, Ghazni and Kandahar. An independent and current assessment of rural schools operated cross-border needs to be undertaken as a basis for future planning.

UNHCR estimates that there are 118,000 refugee children enrolled in schools in Pakistan, 6.7\% of whom are female. This represents an estimated 15-20\% participation rate (UNHCR 1989). Schools for refugees are run by the Pakistan Commissionerate for Education and by the Afghan resistance parties (tanzeem schools).

Gender; location, security and tribal affiliation appear to influence access to primary education. A series of examples show evidence of the influence of these factors. Tables in Annex I on schools and enrolment by province and gender over time also reflect the variations which are due to the influence of these factors. 
The interesting feature of government system enrolment patterns is the shift in enrolment to urban areas and the increase in enrolment of girls. Preliminary government figures for $1991^{1}$ show that of a total enrolment of 700,646 primary students(grades $1-6$ ), 336,551 or $48 \%$ were in Kabul City. By contrast, in 1978 only 109,607 or $14 \%$ of students were based in Kabul.

Concurrent with the growing bias toward Kabul in primary enrolment has been the increase in female enrolment in both absolute and relative terms. On a national level female enrolment (MOE) as noted above was 210,778 in 1990 or $33.6 \%$ of the total as compared to 134,590 and $15.4 \%$ of the total enrolment in 1978 . The preliminary figures from 1991 suggest that the increase in female enrolment occurs primarily in Kabul and other urban centres. Female primary enrolment in Kabul represented $40 \%$ of total national female enrolment in the 1991 preliminary figures. Prior to the war female enrolment in Kabul was also high (39\%). The data available, however, does not permit direct comparison of percentages of primary age females enrolled in primary school.

Differences by province in female enrolment appear to correspond to difference in tribal affiliation. Female enrolment (Ministry of Education) in 1991 in Badakhshan was 33\% of the total and even higher in some of the other northern, Tajik provinces. This relatively greater support for female education in the north and northeast is corroborated by evidence from 1978 and from reports of NGOs supporting schools cross-border. In 1978, the only provinces outside of Kabul with more than $10 \%$ of primary age girls enrolled were three provinces in the north, Badakhshan, Balkh and Faryab, and Herat, an urban and Persian cultural centre. Today NGOs supporting schools cross-border note greater receptivity to female education in the northeast.

The eight provinces bordering Pakistan appear to have experienced the greatest decline in access to primary education due to insecurity and political issues. Government figures for 1991 show lower enrolment for 1991 than was the case in 1978. NGO supported schools are also significantly fewer in border provinces, with the exception of Nangarhar, than in other provinces. (See tables in Annex I). NGOs are supporting only two schools in Nimroz; Government reports 1964 students grades 1-6 in the whole province. Government controls only a small area around the capital, while mujahiddin factions are fragmented and split by HazaraPashtun conflicts, creating an unstable environment. Tribal rivalries and conflicts among mujahiddin groups extend the length of the border. Many areas have experienced heavy bombing and destruction. By contrast, Wardak which has been relatively peaceful and politically stable, has the second largest number of NGO supported schools (223).

\subsection{QUALITY ISSUES IN PRIMARY EDUCATION}

Wastage and drop-out rates are quantitative indicators of the quality of education. The capacity of teachers, curriculum, school facilities and textbooks, reading materials and teaching aids are important determinants of quality. In the Afghan situation, the development of two systems of

\footnotetext{
'1991 preliminary figures are used here because they are disaggregated by province. 1990 data from the Ministry of Education are used when aggregate figures only are required.
} 
education -- a Kabul-based centralized system and a decentralized rural system supported from Pakistan --.- is a factor which will impinge on quality if careful efforts are not made to integrate the two systems in the event of a political settlement.

WASTAGE

Afghan schools have always been inefficient. Nystrom, in a 1977 UNESCO study using 1973 data, found such a high rate of drop-outs and grade repeaters that for every male sixth grade graduate, the system provided 15.2 years of education. For girls the school had to provide 18 years of education, or three times the minimum, for each primary school graduate. Because of the high rate of drop-outs and repeaters, educational investment was wasted on individuals who dropped out before becoming literate. These wastage rates are indicative of the quality of education in the 1970s.

The data available today do not track cohorts through primary education and cannot provide comparable wastage rates. Moreover, there have been changes in promotion and examination policies. The information that is available indicates that wastage remains a serious problem. A UNICEF consultant in 1989 (Shrestha) analyzed information from student registers in Kabul suburban schools and found a drop-out rate of $50 \%$ in grade one and 15 to $25 \%$ in other grades.

In the NGO-supported schools crossborder, the majority of students are enrolled primarily in the first three grades, with roughly half the number attending in first grade still attending by grade four. It is not clear whether the first three years provide sustainable literacy. Drop-out rates are also high in the Commissionerate Schools for Afghan refugees in Pakistan. In NWFP, half the first grade boys do not go on to second grade. Only one quarter of the original first graders are in school by the fourth grade. (Carter 1988).

High wastage and drop-out rates reflect the quality and relevance of teaching and learning, the condition of facilities, the degree to which Afghans value the education being offered and problems in the larger political and economic environment. Wastage is costly anywhere but particularly where resources for education are limited.

TEACHER QUALITY

Afghanistan entered its period of civil war with a shortage of qualified teachers. War itself has killed an estimated 2000 teachers and led others to abandon teaching or to flee their jobs to urban areas or as refugees outside. In all schools operated for Afghans today there is a shortage of teachers and, except for schools 
in Kabul City and some other urban areas, a shortage of qualified women teachers. Observers note a lack of mastery of the content of the subject matter, of child-centered teaching and learning skills and of classroom management skills.

In schools operated by the Kabul Government, there is a clear movement of teachers into Kabul City and away from the provinces and a $41 \%$ drop in the total number of teachers as indicated in Table 20. This is greater than the $20 \%$ drop in primary enrolment between 1978 and 1991 .

Equally significant is the increase in absolute and relative numbers of female teachers at the primary level. In 1978 there were 3593 female teachers in primary and village schools. They represented $15 \%$ of total teachers (UNICEF 1978). In 1991, female teachers in primary schools numbered 9291 , or $66.6 \%$ of the total number. Of the 9291 female teachers in 1991, 88.8\% are based in Kabul City (Ministry of Education, preliminary 1991).

\section{TABLE 20: PRIMARY SCHOOL TEACHERS}

\begin{tabular}{lcc} 
& 1978 & 1991 \\
\hline Kabul City & 3,320 & 9,957 \\
Provinces & 20,251 & 3,988 \\
\hline Total & 23,571 & 13,945 \\
$\begin{array}{l}\text { Sources: } \\
\text { Education } \\
\text { only) }\end{array}$ & 1991. & (Government \\
\end{tabular}

The Ministry of Education estimates that only one third of present teachers are regarded as academically qualified and trained. The total number of graduates in 1990 from two- and fouryear teacher-training programmes amounted to 1022 , nearly two thirds of whom were from Kabul based institutions.

Comprehensive figures on the number of teachers working at the more than 2000 schools supported by NGOs inside Afghanistan are not available. In 1988, 2896 teachers were reported as working at schools supported by seven NGOs. In 1991 the number of teachers has increased but no total is available. The Educational Centre of the Alliance supported by the University of Nebraska (ECA/UNO) indicates it funds 7000 teachers in 1991 and the Swedish Committee for Afghanistan (SCA) supports 3000 teachers; most of these are inside Afghanistan. The best supply of qualified teachers is thought to be in the northern provinces not heavily damaged during the war and where education has traditionally been valued. There are few female teachers in rural schools supported cross-border. SCA, for example, has 20 female teachers. In other cases, female students are taught by male teachers. In general, teachers are presumed to be unqualified and teacher training represents a large part of NGO strategy to improve the quality of education in schools they support.

Information collected by ECA/UNO on their teachers suggested that one third have less than a secondary education. The Swedish Committee estimates similar preparation among its teachers. Most NGOs are putting increased effort into upgrading teacher skills and knowledge. SCA, for example, had 26 teacher trainers working in mobile teams inside Afghanistan to train and monitor 2500 teachers in 1990, and they plan to establish two teacher-training centres inside 
Afghanistan. Other NGOs have embarked on similar training activities and there has been some collaboration among them on training materials and sessions.

Teachers in the various schools operated for refugees in Pakistan are predominantly underqualified. Agencies involved in training teachers have noted difficulties of trainees in reading Pashtu (their native tongue) or in carrying out basic arithmetic functions. Of the $\mathbf{3 0 1 4}$ Commissionerate teachers (1988) about two thirds were Afghan. The Commissionerate employs about 100 Pakistani women teachers. In the tanzeem (party) schools, $90 \%$ of teachers are firsttime teachers and lacking basic classroom management skills as well a knowledge of methods of teaching beginning reading and arithmetic. The shortage of female teachers is most severe. In 1988 there were no female teachers in Balouchistan, and only 80 female teachers in the Peshawar area, plus a smaller number in the camps; of these $30 \%$ were teachers before the war. (Carter 1988)

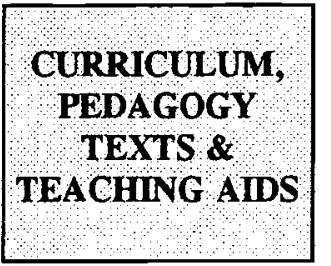

as a vehicle for political content.

Following the 1978 revolution in Afghanistan the new Government revised the school curriculum to include socialist and secular content that was offensive to portions of the Afghan population. In 1989, the Ministry of Education began revision of primary school curriculum to be more relevant to the conditions of Afghanistan and less politicized. Curriculum for the first grade includes each week the following hours of instruction:

$\begin{array}{lc}\text { Holy Koran } & 2 \\ \text { Religious Education } & 1 \\ \text { Mother Tongue } & 10 \\ \text { Math } & 6 \\ \text { Work Education } & 2 \\ \text { Physical Education } & 1 \\ \text { Calligraphy } & 1 \\ \text { Drawing } & 1 \\ \text { Culture and Civil Defence } & 2\end{array}$

New textbooks are available in some of the schools but the Ministry identifies severe resource constraints to the full implementation of the new curriculum and in-service training of teachers. 
Because of Kabul Government scarcity of paper and other materials for printing, text production is less than three fifths of current needs and declining. Government supply of teaching aids, from chalk to primary school kits which include manipulable materials and charts has almost ceased. UNICEF is the only source of assistance for teaching materials for the schools. Instructional hours are limited because of school closures and the need to use school buildings for two to three shifts.

There appear to be a variety of curricula developed for the schools operated cross-border. In fact, there is a certain commonality about the curricula originally developed. Because of the political sensitivity of outside involvement in curriculum, all models were developed either directly with representatives of the Afghan Interim Government or in consultation with them. In the first grade curriculum of four major NGO projects, between 39 to $48 \%$ of time is devoted to religious studies. The increase in religious studies is balanced by fewer hours devoted to mother tongue and math instruction than in Kabul government schools.

In most cases the curricula are not written out as a guide to teachers but must be derived from the textbooks. From a qualitative view, the textbooks available may not provide enough information for teachers who lack mastery of the substance; other rely on examples or pictures foreign to the users' experience; and sometimes the quality of print is poor. (Carter 1988) Another aspect of the textbooks has been their political message, inculcating support of the jihad or holy war against the Kabul Government and glamourizing war.

The legacy of deeply felt resistance to the Kabul government curriculum introduced after 1978 keeps curriculum development a sensitive issue. The involvement of foreigners in curriculum development has been seen as threatening its acceptability. Nonetheless as NGOs have come increasingly to focus on improving the quality of education they are working through their Afghan staff to prepare a comprehensive curriculum and accompanying teaching guides, to revise textbooks, to develop examinations useful for assessment and to develop and distribute teaching aids. The Swedish Committee, for example, views its girls schools in Pakistan as an opportunity to test techniques which are most likely to be effective with girl students. NGOs are increasingly experimenting with child-centered primary materials and appropriate visual aids and cooperating with each other in the effort. Curriculum and teaching aid development proceed independently in Kabul and in Pakistan, in isolation from each other.

There is a severe shortage of reading materials available for Afghans anywhere. The shortage constrains the capacity to sustain literacy once achieved. It may also reduce the perceived importance of literacy skills.

SCHOOL FACILITIES that $70 \%$ of schools lacked proper buildings and facilities. A UNICEF analysis
of 1974 survey data found that only $5.4 \%$ of schools had access to safe water and $33 \%$ had Ministry of Education reports that 1860 school buildings with equipment were destroyed by war for a loss of US $\$ 360$ million. The base from which pre-war schools operated was inadequate. The Seven Year Plan 1976-1982 estimated that $70 \%$ of schools lacked proper buildings and facilities. A UNICEF analysis
data found that only $5.4 \%$ of schools had access to safe water and $33 \%$ had

War has been devastating to the school infrastructure in Afghanistan. The 
latrines, few of which were of sanitary design or well-maintained. In 1991, the Ministry of Education indicated that $44 \%$ of schools lacked buildings and that $19 \%$ were in rented facilities.

In rural areas of Afghanistan UN missions report substantial damage to school structures. Heaviest damage occurs in areas of intense bombing, including Kandahar, Herat, Laghman, Nangarhar and Konar. In other cases school buildings were seen as symbolic of the policies of the Kabul Government and so destroyed by the mujahiddin. NGOs working inside Afghanistan now report an increasing demand for school construction in areas with reasonable security.

\subsection{ALTERNATIVE FORMS OF BASIC EDUCATION}

International development agencies frequently envision education as a responsibility of central governments. This perspective may tend to make invisible autonomous community-based education in developing countries, as well as to obscure the essentially private and community origins of public education systems in the now developed countries.

Among Afghans there is a long standing tradition of local, privately financed, religiously oriented basic education. Mosque schools and madrassa operate throughout Afghanistan and among refugees in Pakistan. Little information has been collected about these schools. Mosques offer religious education. Some will provide classes for girls. Madrassa traditionally serve only boys. In addition to religious subjects, they offer limited instruction in other primary levelsubject matter. UNIDATA survey teams in Samangan, Wardak and Bamyan counted large numbers of mosque schools and madrassa, suggesting something about the extent of traditional private education initiatives (Table 21). Roy (1986) points out that madrassa are not evenly distributed throughout the country and that some areas are without them.

With the war there was a disruption of the madrassa. Many mullah (religious leaders) fled to Pakistan and established madrassa there, preparing mullahs to return inside Afghanistan. Roy reports that madrassa in the north continue to be strong, but that most of those in the south have closed.

There has long been a system of Governmentsupported madrassa. In the past government madrassa trained some of the leading Islamists in the country who are now associated with the resistance (Roy 1986). Government in 19901991 supported 12 madrassa in Kabul City and eight provinces serving 3622 students in grades 7-12. There were 216 graduates in 1990 . One of the madrassa in Kabul is for girls and has an enrolment of 151. Government also supports 10 Darul-Hefaz in Kabul and eight provinces that offer education grades $1-8$ to 5,897 students (wrote recitation for the blind).
TABLE 21: SCHOOLS AND MADRASSA IN THREE PROVINCES

\begin{tabular}{lcc} 
& $\begin{array}{c}\text { Mosque } \\
\text { Schools }\end{array}$ & Madrassa \\
\hline Samangan & 526 & 46 \\
Wardak & 2,540 & 55 \\
Bamyan & 1,295 & 75 \\
\hline
\end{tabular}

Source: UNIDATA 


\subsection{POST-PRIMARY EDUCATION}

Political and social division along with the consequences of war have markedly changed the orientation of and access to post-primary education. With the exception of secondary and tertiary schools operated in Kabul, opportunities for post-primary education have diminished for Afghans. For women, access has increased in urban areas controlled by the Kabul Government at the same time as it has been curtailed in non-government areas and among refugees.

There has been an increase in the number of middle schools and lycees operated by the Kabul Government between 1978 and 1991 and an increase in the total number of students served, despite the reduction of the area of effective government control.

Table 22 illustrates the increase in schools and enrolment at the post-secondary level. The total number of schools and postsecondary students has more than doubled in this period. There is also a nearly doubling of the proportion of the students who are female. In $197817.9 \%$ of post secondary students were female; in 1991, $33.5 \%$ are female. In $1978,40.8 \%$ of the post-secondary students were in Kabul; in 1991, $44.8 \%$ were in Kabul. In 1990, 7800 Afghan students were studying in the Soviet Union, some for post-primary education.

Secondary education in rural Afghanistan has largely broken down due to the war. Where secondary schoois operate, it is with damaged facilities and usually for male students. One of the exceptions is a secondary school in Badakhshan for 1000 girls. Among refugees in Pakistan, secondary education is also limited. Efforts to establish secondary schools for girls have sometimes encountered opposition. Limited opportunities for study overseas have been made available to refugees by donors. Selection is usually through the political parties.
TABLE 22: TRENDS IN POST PRIMARY EDUCATION TOTAL SCHOOLS

$1978 \quad 1991$

\begin{tabular}{lll}
\hline Middle Schoois & 134 & 480 \\
Lycees & 199 & 344 \\
Total Post-Primary & 333 & 824 \\
\hline \multicolumn{3}{c}{ TOTAL STUDENTS } \\
& 1978 & 1991 \\
\hline Middle Schoois & $10,477^{*}$ & 150,274 \\
Lycees & $92,563^{*}$ & $58,321^{*}$ \\
Total Post-Primary & 103,030 & 208,595
\end{tabular}

*Some 1978 Lycee students include Middle School students. 1991 Lycee student numbers include only 10 and 11 grades. The new 10-12 structure has not been implemented.

Sources: UNICEF 1978 and preliminary 1991 data from the Ministry of Education. 


\subsection{NON-FORMAL EDUCATION}

Non-formal education has followed different strategies in areas controlled by the Kabul Government and among refugees and cross-border programmes. Initially the Kabul Government used non-formal education as a primary tool to promote literacy and the values of the Peoples' Democratic Party of Afghanistan (PDPA). They relied on mass organizations, including the army and women's and youth organizations, as vehicles for mobilization and training. In recent years the political content of training has diminished and some of the mass organizations have begun to establish positions autonomous of Government and more oriented to a service role. Mass organizations, such as the All Afghan Women's Council, are dependent upon government and limited international agency funding for their activities.

Even with a lower profile to non-formal education, literacy training remains important. Government reports that there are 50 literacy schools ( 35 in the provinces), 45 workers' literacy schools (22 in the provinces), 4 skills training literacy schools and 9 out of school children's literacy centres. In 1991, enrolment in literacy courses was 269,089. Women represent more than two thirds of the students in Kabul City literacy courses and $29 \%$ of those in rural areas. The All Afghan Women's Council also operates 28 literacy centres in Kabul City and Province. In the rural areas training in literacy and numeracy is combined with skills training, often in agriculture or cattle breeding. Twelve community training centres in Kabul and the provinces combine skills training (carpet weaving, tailoring, home economics, family planning) with literacy training. UNICEF has been working with counterparts from Kabul on training and support to income generating activities for widows. Additionally, the All Afghan Women's Council has offered legal advice and support to women and seeks to raise women's consciousness of their rights and opportunities (Moghadam 1989).

Among Afghans in non-government areas and refugees in Pakistan, most non-formal training has been in support of health and education programmes, implemented for Afghans and dependent on Afghan participation, or to create income-generating skills. Teacher training and refresher training as well as training of mid-level and community health wprkers (including traditional birth attendants or dais) has been offered in Pakistan and increasingly inside Afghanistan through the use of mobile teams and fixed training centres. Income generating skill training initially focused on handicrafts production, in some cases relying heavily on NGOs for materials, marketing and quality control. Recently there have been cross-border initiatives in training and support to traditional women's productive activities such as poultry hatching and production. There has also been experimentation with alternative methods to making education accessible to girls. The International Rescue Committee has been organizing classes for girls in private homes. Literacy training courses are small in number, but NGOs are exploring suitable approaches. For example, Save the Children (USA) initiated a youth literacy programme for children 10-14. 


\subsection{EMERGING ISSUES}

Looking beyond conflict in Afghanistan, Afghan leadership needs to look for a broad framework to accommodate a diversity of educational goals and values, and to enable all children to have access to basic education. UNICEF, other international agencies and NGOs can assist Afghans in this process, beginning with rehabilitation and development assistance. Political sensitivity is a major constraint to harmonization, but steps can be taken to lay the groundwork. Approaching harmonization can begin by assessing the experiences in education since 1978 as a basis for organizing and managing basic education in the future; for financing education given expected financial and human resource constraints; and for enabling girls and women to have access to basic education.

MODELS

FOR THE

FUTURE

In looking ahead, it may first be useful to look backwards. Reviewing the successes and failures of the many educational experiments may be the starting point to identifying acceptable models for a future Afghan education system. Several UNICEF consultants have suggested a re-examination of the goals of education for Afghanistan and have questioned the usefulness of the formal primary education model to the Afghan situation. Carter (1988) notes that there has been little questioning among refugees and cross-border education groups of "the usefulness of traditional primary education to peasant communities". From observations on the Kabul side, Shrestha suggests that the Government has given little consideration to non-formal methods as a way of increasing equitable access to education for Afghan children." The traditional formal education system is costly. Wastage and drop-out data suggest that the formal education system is both inefficient and ineffective in producing permanent literacy.

In looking for models that work, Afghans and outsiders may find it useful to evaluate the outcomes and impacts of the various educational activities carried out by Government and crossborder. What has the considerable literacy programme in Kabul achieved in terms of permanent literacy? What successful techniques should be expanded? Which discarded? How many graduates are still literate? What was the cost per individual of enabling permanent literacy? What do graduates do with their literacy. How effective are the cross-border schools in achieving permanent literacy among their students. How cost effective are they? What can be learned from the NGO experience with primary education for female Afghan refugee children? Are there techniques that can be transferred? What can be learned from the decentralized management of cross-border schools and the close collaboration with local commanders and/or shura? Are there benefits from decentralization that can be transferred to a national system? Are there hazards to be avoided? To the extent possible, this is an assessment that needs to be done by education professionals operating on both sides of a bifurcated sector.

FINANCING EDUCATION:
Resources for education are limited. Current data on government operating and capital expenditure for education are not available for this report nor are comprehensive data on the levels of investment through NGOs in cross-border education. Outside funding for rehabilitation and development, as noted before, is likely to shrink over time because of changed political priorities on 
the part of some donors as well as because of constraints on development assistance generally. Whatever political settlement emerges or fails to emerge, Afghan leadership will have to explore sustainable sources of financing basic education.

The place to look for models may again be in past experience. Afghans have a long tradition of local or community support for mosque schools and for non-government madrassa. More recently, military commanders and shura in some areas have invested management time, in-kind assistance and even cash in community schools. Local financing, shaped by the recovery of the economy, is a sustainable source of basic educational support. The various kinds of existing local support to education need to be assessed in selected areas by a specialist in community financing in order to determine what is possible in the Afghan context.

\section{EDUCATION FOR THE GIRL CHILD}

As a public issue, education of girls will continue to be sensitive with many groups.' Concern about education for girls is both real and politically symbolic. On a less public or confrontational level many observers believe there are opportunities. Some note the existence of several, not necessarily united, groups of women and their families in Kabul and in Pakistan that increasingly articulate a demand for education for women (Carter, Dupree, and Moghadam). There are strong women's groups in Kabul with the potential to serve as advocates with their families, communities and male leadership for the education of girls. In Peshawar a multi-party organization of women's leaders has emerged and meets periodically on issues of women's participation. Afghan women leaders argue that women themselves in the community, if given the opportunity, can often negotiate solutions with men to enable access to education or other services.

Women's groups may be a channel for women's advocacy with decision-makers on education for girls and women. Women's organizations have always been a part of modern Afghan life, though their outreach to rural areas has usually been limited. Women's traditional networks have long existed in most villages. The challenge may be finding ways to empower these potential avenues of advocacy. 


\section{CHAPTER 9 \\ CHILDREN AND WOMEN IN ESPECIALLY DIFFICULT CIRCUMSTANCES}

\subsection{OVERVIEW}

The physical, psychological and social consequences of war exacerbate the situation of at-risk groups of children and women in Afghanistan. War has created new classes of people in Afghanistan. These include the disabled (and particularly the children and women among them), orphans, and widows whose numbers overwhelm the traditional social security systems and the very limited services for the handicapped. Also at risk are the internally displaced families without access to entitlements, and rural communities in areas of already marginal subsistence production where insecurity, contraction of purchasing power and political powerlessness deny access to available food and entitlements. The experience of UN and NGO agencies working from the Kabul Government side, cross-line and cross-border confirms that the disabled, orphans, widows, the dislocated and the disempowered confront especially difficult circumstances. There are, however, little hard data on the magnitude of the groups or on the severity of the problems they face. Examples can illustrate the nature and dynamics of the difficult circumstances and indicate localities of concentration.

\subsection{DISABILITIES}

There are no statistical data on the extent or severity of disabilities among Afghans, let alone an analysis by age and gender. A commonly voiced estimate is that $20 \%$ of Afghans suffer disability. Disability is not defined. War-related injuries have visibly increased the incidence of physical disabilities. Physical disability resulting from immunizable diseases or from nutritional deficiencies are also believed to have increased as a consequence of war. Psychological disability resulting from the trauma of war is observerable among women and children in refugee camps, and in schools inside Afghanistan. There are few resources to address even the physical disabilities. As non-combatants and as females, children and women have less access to the limited treatment and rehabilitation facilities that do exist.

PATTERNS

Reports on disability patterns note both a high incidence of war-related disabilities and an increase in polio and other disabling diseases. Children and women do not suffer war related injuries at the same rate as males but their access to treatment is more limited than that of adult males. Some observers suggest that the real level of war-related disabilities in Afghanistan may be masked by the low level of medical treatment available and the resulting high mortality. Many war-injured children and women may simply not survive to join the ranks of the disabled (Mendis 1989). Disability needs to be recognized as a double problem for Afghan women. It is a problem of women as disabled and of women as principal caregivers for the disabled in a society that offers women limited access to the resources for coping. 
A UNOCA disabilities specialist travelling cross-border to Takhar Province in the north-east (Kristiansson 1991) described the difficulties collecting baseline data on disabilities. When asked about the numbers of disabled in the area, the Afghan informants would give the standard reply "too many". Disability was linked in the minds of most to war-related injuries. Kristiansson found that more specific questioning was required to elicit information on other disabilities. In Takhar, his informants suggested that blindness was a larger problem than polio.

Reports from the Kabul side also give emphasis to the impact of war-related injuries, particularly anti-personnel mines and rockets, on children. Hospitals in Kabul providing civil care are filled with war-injury victims, particularly children, who have lost limbs and eyes to mine explosions. Pigot (1989) on a review of Kabul hospital information suggested that disabilities to children were primarily upper body disabilities resulting from the 'butterfly' devices scattered around the countryside. An ILO community-based rehabilitation project in Kabul, intended to enable people to return to productive functioning in the community, also serves children. Principal disabilities are movement impairment. The Afghan Women's Council information collection suggests that $13 \%$ of women in Kabul suffer some degree of impairment.

On the basis of information gathered in Pakistan, Mendis in 1989 found that the most frequent type of disability was that of movement, resulting from war wounds, mine injury amputations, paraplegias and burns. Polio (among children and adults) as well as cerebral palsy were other important causes of disability. Mendis also found visual impairment, mental retardation, mental illness, hearing and speech problems resulting from the war or inadequate health services.

Handicap International, which works with the disabled in Pakistan and in rural Afghanistan (Helmand, Ghazni, Kandahar and Herat), estimates that the incidence of disabilities has nearly doubled among children living in areas of armed conflict. Handicap International links the increase in physical disabilities to the increased incidence of polio and of nutritional deficiencies (One in Ten, Vol. 10, 2-3 1991). During the first six months of 1991 at the Handicap International Rehabilitation Centre for Afghan Refugees in Balouchistan, the most common cause of disability for children and female patients was polio. Of new patients under five, $24 \%$ had disabilities resulting from polio; $18.7 \%$ of women patients were disabled due to polio.

Psychological disability is hard to measure. There are countless individually poignant stories of the traumatic experiences of child survivors of brutal village battles. Little is known of the emotional costs of loss of family and home, of disruption, and of continuing insecurity. The Psychiatry Centre for Afghan Refugees in Peshawar reports a large increase in mental illness as compared to their pre-war experience in Afghanistan. They link mental illness to the multiple traumatic stresses of war, bombing, family deaths, injuries and flight. Mental illness appears to be higher among women refugees (Habibi 1989), probably aggravated by the isolation and heightened seclusion they experience in refugee camps. Mendis has suggested that the extent of depression, personality disorders and other forms of mental disability resulting from the trauma of war will only gradually be revealed as children grow up. 
From the limited information it is difficult to make anything but the broadest of generalizations. Physical disability is perceived as a serious problem. Polio and other preventable causes may be as much at the root of disability as the more obvious war and mine injuries. Polio may be the greatest risk in rural areas where the absence of immunization and the dislocation of populations have placed children and adults at risk. Psychological disability exists but little is known about its short and long-term impacts on children. Good data on causes, prevalence and severity of disability among children and women are needed. Data can serve both planning and advocacy functions for the future. Advocacy needs to be grounded in knowledge of the costs children pay both directly because of land mines and other instruments of war and indirectly because of reduced access to normal preventive health care.

\section{CONTINUING RISKS}

Battle-related injuries, rockets and mines represent a continuing threat to the population inside Afghanistan. Mines will remain long after fighting ceases. Estimates of the number of mines seeded in Afghanistan during the more than twelve years of conflict vary from 3 to 30 million; a UNOCA demining official suggests a realistic estimate may be 8 million. UN missions collected samples of more than 25 different types. The 'butterfly' poses the greatest risk. Made of plastic, it is difficult to detect and has been scattered in large quantities from the air. Its intent is to maim rather than kill. UNOCA is supporting cross-border and cross-line demining and mine awareness efforts. The goal is not to remove all mines. De-mining is a timeconsuming and dangerous process. The intent is to remove mines from areas used by people for production, and to demarcate other areas still seeded with mines.

\section{TREATMENT \& REHABILTTATION}

As suggested above, medical care for war-injured children and women is limited. Among the Resistance the first priority of medical care has been to treat the direct participants in the war. The same priority is seen in Kabul where the curative health system is focused on the war injured among the military. Hospitals for treatment, rehabilitation programmes, and centres for production of protheses exist in Kabul, Pakistan and to some extent in resistance-held areas of Afghanistan. There is only fragmented information on numbers of patients served by these facilities and programmes; capacity is far below actual and potential demand. One indicator of this gap comes from Handicap International. They note with respect to Pakistan that there is a waiting period of at least one year for prosthetic devices for Afghan victims of land mines. Children, of course, may have to be fitted with more than one device during their years of growing. Capacity to work with the mentally ill and with community health problems is even more limited. The Handicap International Rehabilitation Centre in Balouchistan served 831 new patients (26\% of them female) in the first six months of 1991. Handicap International supports community rehabilitation services in four provinces inside Afghanistan. In Kabul, the ICRC and ILO, with support from UNICEF, provided treatment and/or rehabilitation services to the war-injured. ILO community rehabilitation services are aimed at workers but reach some children. Capacity to work with the mentally ill and with community health problems are extremely limited. 
The experience of programmes to date confirms the more limited access of women to prevention and rehabilitation programmes. It also suggests an Afghan preference for services that are delivered in the community and which enable the disabled to function within the family. Mendis in Pakistan found some reluctance of Afghan refugee parents to have their disabled children take part in physiotherapy and educational programmes. Only a third of those recommended for physiotherapy actually turned up for the service. A disabled Afghan journalist has recently founded the National Association of Disabled Afghans. Oriented to adult males, the organization's advocacy efforts have the potential for positive influence on treatment and rehabilitation for children and women.

\subsection{VULNERABLE GROUPS}

ORPHANS \& WIDOWS

There are no data, only estimates, on the number of orphans, fatherless children and widows in the Afghan population. Between 500,000 and 1.0 million Afghan children may be orphaned or fatherless. The number of widows may number 3-400,000. Several estimates of the proportion of orphans (fatherless ${ }^{2}$ ) and widows in the Afghan population hover around $20 \%$. Sliwinski in 1988, extrapolating from Gallup poll data on a representative sample of Afghan refugees in Pakistan, estimated that $19 \%$ of children among refugees in Pakistan were orphans. Sliwinski and a UNICEF Skills Inventory of Afghan refugee women also estimated that as many as 18 to $20 \%$ of refugee women were widowed. The Afghan Women's Council information indicates that $21 \%$ of women in Kabul are widowed. On a simple arithmetic basis this would imply as many as 1.5 million orphans or fatherless children and about 700,000 widows among the 17.4 million Afghans inside Afghanistan and living as refugees in Pakistan and Iran. In fact, projections based on the Pakistan refugee population are biased. Actual numbers are likely less than a simple, arithmetic calculation. Refugees in Pakistan have come disproportionately from border provinces. They became refugees because of prolonged fighting and bombing and because their communities experienced heavy fatalities. The proportion of widows and orphans in the Pakistan refugee population could therefore be expected to be higher than that from areas experiencing less warfare. Indeed, as the demographic discussion above notes, women and children predominate in the Pakistan refugee population. This linkage between incidence of orphans, fatherless and widows and areas of high intensity bombing and fighting lead one to conclude that there would also be a high proportion of orphans and widows among the dislocated who fled to Kabul and other government controlled cities for security.

The fatherless, orphans and widows were traditionally absorbed into the traditional family system in Afghanistan. Public institutions for public wards were a rarity. That the Government in Kabul and local communities in rural Afghanistan are expanding the limited pre-war institutions,

${ }^{2}$ Among many, but not all, Afghan groups a fatherless child is regarded as an orphan. When people speak of orphans, it is not always clear whether they refer to a child who has lost the male or both parents. Use of the term fatherless along with that of orphan may also serve to draw attention to the possible remaining parent, the mother. 
and creating new public institutions for orphans is an indicator of a problem so severe that Afghans themselves acknowledge the inadequacy of traditional systems. UN missions travelling in rural areas have found examples of local commanders or shura supporting schools or institutions for orphans.

OTHER

GROUPS

Other vulnerable groups are also difficult to categorize and to count. Among them would be households where the male head has been disabled; families dislocated to Kabul and other relatively secure areas in Afghanistan and who lack entitlement to government or other food, access to cash income or skills for urban employment; and poor households in chronically or temporarily-food deficit areas.

There is no estimate of number of households headed by a disabled male, or less likely, a disabled female. The category is important to distinguish because of the double burden placed on the female(s) of the household for both household maintenance and care of the disabled.

The total number of internally displaced people in Afghanistan is estimated at around 2 million. Various UN reports note doubling or tripling of the population in Kabul, Mazar-i-Sharif and Kunduz, and significant increases in smaller cities and towns like Tashqurgan and Faizabad. This suggests that most of the dislocated have been absorbed into urban areas. UNOCA interviews with recent (1991) migrants from Paktya to Kabul reveal a precarious existence for many of those dislocated. Households are dependent on day labor for basic survival income. Their margin of survival is determined by the demand for day labor and the price of food and basic necessities relative to the daily wage. Small changes in the economy can push these households over the margin. These households, to the extent that they are predominantly urban, can be readily identified through government, and local community leaders.

Access to at risk households in chronically or temporarily food deficit areas may be more problematic. Some areas of Afghanistan, particularly Badakhshan and the Hazarajat, have been chronically short of food. These areas have also lacked access or entitlement to surplus resources. During the famine of the early 1970s, poor households of the Hazarajat failed to get adequate access to the food aid intended for them. In post-harvest 1991, households whose crop production was reduced by rust were found leaving the Hazarajat for Pakistan where minimum food was assured as aid.

It is difficult to estimate the numbers of households at risk because of temporary or chronic food shortage. Survey data collected by the Swedish Committee for Afghanistan suggests the outlines of the problem. SCA conducted a food deficit survey in 1990 in the nine northern provinces which had been affected by sunn-pest and locust infestations. All of these provinces, with the exception of Badakhshan, have traditionally been food-surplus areas. SCA found that on average $67 \%$ of the population surveyed lacked sufficient wheat to feed themselves for the year. The situation was worst in Badakhshan and Jawzjan where $81 \%$ of farmers said they had to buy wheat to survive and $90 \%$ said they were below subsistence level. The survey also found that 99\% of wheat sales in Badakhshan are made immediately after the harvest, reflecting the chronically marginal position of that province. In four other provinces, more than $70 \%$ of the farmers reported having to purchase wheat. Overall, SCA estimated that perhaps 1.2 million people in the northern provinces suffered food shortage in 1990. 
Several factors are present in the Afghan environment which create especially difficult circumstances for children and women. The disabled, caregivers for the disabled, orphans, fatherless and widows are groups at risk. The fragility of agricultural production can put further numbers of children at risk because of insufficient food. 


\section{CHAPTER 10 \\ PROBLEMS, CONSTRAINTS AND OPPORTUNITIES}

\subsection{LOOKING TO THE FUTURE}

Forecasting is a hazardous enterprise. In the case of Afghanistan, this is even more true. Yet whatever results from negotiations on ending the civil war and forming a new Government for all Afghans, life goes on for those children and women of Afghanistan who survive despite high mortality rates. The needs continue even if political solution of conflict eludes the leadership. International programmes of support for rehabilitation and development will continue to be essential, whether to a country united under one government or in some variation of the present pattern of assistance direct to the Kabul Government and cross-border and cross-line to people in resistance held areas.

The preceding analysis does suggest an enduring basis for planning programmes of rehabilitation and development. The critical problems of children and women, the basic constraints on action in the Afghan environment and opportunities for action are going to remain the same at least for the medium term. This final chapter is an attempt to summarize those factors important to planning.

\subsection{PROBLEMS: A REPRISE}

Survival is the critical problem for the one out of six newborns who do not survive to age one; for the one out of nearly three Afghans born who do not survive to age five; or for the 69 out of 1000 women who succumb to maternal mortality. Chief causes of mortality suggest areas for action. Most sources identify diarrhoea, communicable diseases and acute respiratory infections, all complicated by malnutrition, as the key causes of mortality. Tetanus is a key cause of neonatal mortality. High maternal mortality is linked to complications of childbirth.

Severe malnutrition exists but is not common. The key problem for Afghanistan is the "hidden malnutrition" of children and women. Between 20-30\% of children may be moderately malnourished, and another $30 \%$ may be chronically under-nourished. Women, including those pregnant and lactating, are thought to be undernourished.

Low levels of literacy --- perhaps $1 \%$ for rural women --- and limited access to basic education relevant to the daily lives of Afghans persist. Both contribute to low levels of knowledge about health and hygiene and indirectly to high mortality. They also limit the development of children who are the future capital of the community and the country.

\subsection{PRIORITY TARGET GROUPS}

Principal target groups can be classified by class or income, location, gender, the impact of war, disabilities and family status. 
- The poorest children and women, whatever their location, are most likely to be in female headed or maintained households or in families that have been dislocated by war or that have a disabled family member. As individuals, orphans, widows and the disabled are at risk. At-risk households and the individuals in them are also least likely to have entitlement to government coupons in Kabul Government areas. Landless families and families without access to alternative sources of income or employment are also at risk.

The most at-risk locations are the perennially food-deficit areas (Badakhshan, Hazarajat); areas subject to temporary natural disaster such as pests, floods or earthquakes; urban slums with high density population and low provision of basic sewage and water services; and areas subjected to protracted or severe fighting and insecurity.

\subsection{CONSTRAINTS, OPPORTUNITIES AND MODALITIES}

In identifying the constraints, there are also possibilities of identifying opportunities for action and modalities of intervention that will maximize the opportunities. Constraints on planning and action include:

The capacity to provide basic health and education services was never great. War has destroyed this limited infrastructure for health and education services and dispersed much of the trained manpower of the country. Health services are historically and presently institution based and oriented to curative care. Management of government health services is vertically organized, with limited capacity for delivery and integration at the community level. Government outreach is largely limited to urban areas.

- Poverty will continue to limit capacity at central government and community level to implement programmes for children and women. The per capita income of Afghanistan is one of the lowest in the world. On a macro-economic level Afghanistan lacks the resources to expand rapidly its economic base, to create employment and selfemployment opportunities and to raise income available at the national or local level. Afghanistan is thought to have a strong alternative economy that includes drug trade and smuggling. The considerable income being generated from this side is not believed to be available for development purposes.

- Should refugees begin to return to Afghanistan in large numbers, land issues will become important for two reasons. First, land tenure or ownership questions have the potential in some areas to create disputes and contribute to insecurity. Second, there is a question of the capacity of available arable land to accommodate refugees should a substantial portion return to agricultural occupations. The best agricultural land, free of mines, is presently being cultivated. Returnees will move onto increasingly marginal land.

- The socio-cultural environment constrains access to women who are the principal caregivers for children. Traditionally society has sought to shield women from contact with outsiders. The question of access to women to involve them in improved health care 
practices and in basic education has become a political issue because of government programmes during the $1980 \mathrm{~s}$. Recognizing the sensitivity of approaches to women, some outside donors are inhibited from addressing women's basic needs in providing for child health and development.

The physical environment in which Afghan families make their homes contributes to the rapid transmission of disease. Access to safe drinking water is negligible in rural areas and most urban areas. Even in Kabul only $40 \%$ of the population has access to piped water, which because of water pressure cannot be considered safe. Sanitation and solid waste disposal systems are nearly non-existent.

Afghanistan has a traditional administrative system which is more oriented to controlling inputs than it is to managing development and change. The implication is that there is little capacity for devolution of authority and responsibility to the level of service delivery. There is little notion of accountability for performance against targeted improvements in the situation of children and women. The tendency toward centralized planning and control is at odds with the long-standing tension between central government authority and local autonomy.

- There is potential for rapid, even explosive, population growth in Afghanistan. Present estimates of population growth rate are depressed due to high war related mortality. The estimated total fertility rate remains one of the highest in Asia. The possibility of a posthostilities baby boom, along with the potential for reduction of the high infant and child mortality, suggests a return to pre-war or higher population growth rates. This brings the corresponding challenges of escalating demand for social services, of land shortages and of unemployment -.- all of which affect capacity to assure child health and development.

Opportunities and modalities include:

Managing Community Based Interventions. The fragmentation of Afghan society and the weakness of central Government offer opportunities as well as constraints. Central Government was never and is not likely to be able to address directly the needs of children and women described above. The experience of UNICEF programmes in Kabul (Winter Emergency) as well as cross-border and cross-line immunization, primary health care and other initiatives pioneered new approaches for UNICEF. Increasingly UNICEF has worked more directly than before with leaders at the community level. Development thinking and experience over the past twenty years or more argue that the communitybased approach is the only way to achieve sustainable change. The challenge for UNICEF is that of exploiting and expanding a community-based approach that works while supporting a transformation of a central government capacity able to service the requirements of immunization, other primary health care and basic education at the community level. This approach has implications for UNICEF's own mode of operation. 
Involving Women. UNICEF global experience establishes the centrality of women's status, and particularly education, to the health and development of the child. On one level, the issue of programming for women and girls is politicized and sensitive. On another, changes have been occurring in different parts of Afghan society which offer new opportunities. Changes in the status and expectations of women in Kabul have occurred which cannot be eliminated. There is evidence throughout Afghanistan of women being forced into more public and economic roles because of poverty. In Pakistan, programmes directed to Afghan women have started and expanded despite threats and violence. NGOs in Peshawar and some cross-line missions are reporting cases of commanders requesting immunization and health care for women and children, and even schools for girls. There are opportunities for UNICEF advocacy with male leadership on the importance of health and education for children and females for the development of the local community and the country. There are opportunities to build, with community leadership, the kinds of services which will achieve mutually desired improvements in the welfare of children, women and the family. 


\section{ANNEX I - ACCESS TO BASIC EDUCATION}

1. Female Enrolment in Primary Schools by Province (\%) 1977/78, 1991.

2. NGO Supported Cross-Border Schools.

3. Structure of Education, Kabul Government Schools, 1991.

The information in the two tables that follow is presented in order to raise questions, not provide answers, about access to primary education.

It is not possible to make comparisons across time abut access to basic education. Data are not comparable and there are anomalies in the data themselves.

Nonetheless, the information enrolment along with percentage in the following tables describe some possibilites that raise questions for future investigation:

In the Kabul Government schools there are more female primary students proportionately (and also in real terms) than in $1977 / 78$.

Only seven provinces appear to have fewer female students today than in $1977 / 78$.

The increase in female enrolment appears to have been at the expense of male enrolment. In only two places, Balkh Province and Kabul City, is the real number of male primary students greater in 1991 than it was in 1977/78. In some provinces, the reduction of male primary students in this period has been by a factor of ten or more (Wardak, Ghazni, Paktia, Oruzgan).

- In Kabul City, the number of females as a percentage of total enrolment appears to have decreased between 1977/78 and 1991 .

Though enrolment figures are not available, data on the number of NGO supported schools in a few provinces suggests the possibility of increased access to primary education. Numbers give little information about the kind and quality of education.

- Information on female enrolment in NGOs supported by province is lacking. 


\section{PROPORTION OF MORTALITY DUE TO \\ FOUR MAJOR CAUSES}

Location

\% of deaths due to respiratory

Source infections: diarrhoea, malnutrition, and measles (age range)

\begin{tabular}{|cc|}
\hline Kabul* & $51 \%(0-1)$ \\
Kabul* & $84 \%(1-4)$ \\
Hazarajat* & $68 \%(0-14)$ \\
Baghian, & $57 \%(0-5)$ \\
Ghazni \& Helmand & $40 \%($ all ages) \\
Jawzjan & $36 \%(0-5)$ \\
Parwan, Kapisa & $54 \%(0-20)$ \\
Provinces & $68 \%($ all ages) \\
& $73 \%(0-5)$ \\
Kabul* & $68 \%(0-5)$
\end{tabular}




\section{$1977778^{*}$}

Female Enrolment as $\%$ of Total
Female Net

Enrolment Ratio**
$1991^{* * *}$

Female Enrolment as \% of Total

\begin{tabular}{|c|c|c|c|}
\hline Kabul (Province) & $18.7 \%$ & 13.8 & 33.2 \\
\hline Kapisa & $14.3 \%$ & 4.4 & 35.3 \\
\hline Parwan & $12.3 \%$ & 7.8 & 33.9 \\
\hline Wardak & $1.5 \%$ & 6.6 & 33.3 \\
\hline Logar & $10.6 \%$ & 5.6 & 33.3 \\
\hline Ghazni & 8.0\% & 2.9 & 30.5 \\
\hline Paktia & $2.0 \%$ & 0.8 & $33: 2$ \\
\hline Nangarhar & $8.7 \%$ & 3.9 & 33.3 \\
\hline Laghman & $10.2 \%$ & 7.1 & 33.3 \\
\hline Konar & $12.9 \%$ & 7.6 & 33.7 \\
\hline Badakashan & $13.4 \%$ & 12.4 & 33.0 \\
\hline Takhar & $10.1 \%$ & 4.6 & 33.7 \\
\hline Baghian & $13.9 \%$ & 6.8 & 35.6 \\
\hline Kunduz & $13.6 \%$ & 9.5 & $34: 4$ \\
\hline Samangah & $15.3 \%$ & 5.2 & 34.4 \\
\hline Balkh & $19.0 \%$ & 14.2 & 34.3 \\
\hline Jawzjan & $11.8 \%$ & 7.2 & 34.8 \\
\hline Faryab & $22.4 \%$ & 16.8 & 33.7 \\
\hline Badghis & $7.0 \%$ & 2.0 & 33.9 \\
\hline Herat & $18.3 \%$ & 10.9 & 33.9 \\
\hline Farah & $9.7 \%$ & 5.1 & 31.0 \\
\hline Nimroz & $14.1 \%$ & 9.4 & 33.7 \\
\hline Helmand & $5.9 \%$ & 4.1 & 33.6 \\
\hline Kandahar & $16.2 \%$ & 4.7 & 33.8 \\
\hline Zabul & $3.7 \%$ & 1.0 & 30.0 \\
\hline Oruzgan & $1.7 \%$ & 0.7 & 30.3 \\
\hline Ghor & $5.2 \%$ & 2.4 & 51.4 \\
\hline Bamyan & $7.8 \%$ & 3.4 & 33.9 \\
\hline Pakteka & -2 & - & 34.1 \\
\hline Sar-1-Pul & - & -1 & 33.9 \\
\hline Khost & - & - & 35.1 \\
\hline TOTAL PROVINCES & $12.0 \%$ & 6.1 & 33.6 \\
\hline KABUL CITY & $39.0 \%$ & 49.4 & 33.6 \\
\hline TOTAL & $15.4 \%$ & 8.4 & 33.6 \\
\hline
\end{tabular}

Includes villoge and Primary Schools

- Net ennolment ratio (female) is the total female enrolment who are of primary age divided by the total number of females (of primary age) in the population. This is a better indicator of true access than the percentage of cotal enrolment that is female. Net enrolment rattos are not avallable for the present.

**+Preliminary estimated figures.

Source. 
ECA/UNO 1991

\begin{tabular}{|c|c|c|c|c|c|}
\hline$\therefore$ & $\begin{array}{l}\text { Active } \\
\text { Salaried }\end{array}$ & $\begin{array}{c}\text { Active } \\
\text { Non-Salaried }\end{array}$ & SCA 1988 & Aid & Others 1988 \\
\hline Kabul & 23 & 2 & & 2 & - \\
\hline Kapisa & 49 & 13 & & - & 2 \\
\hline Parwan & 60 & 12 & 27 & - & 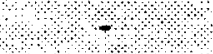 \\
\hline Wardak & 105 & 10 & 55 & 32 & 21 \\
\hline Logar & 78 & 27 & 20 & 38 & 25 \\
\hline Ghazni & 98 \% & 26 & 25 & 27 & 53 \\
\hline Paktia & 36 & 1 & ? & 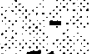 & $5 \%$ \\
\hline Nangarhar & 44 & 4 & 8 & 51 & 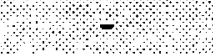 \\
\hline Laghman & 33 & 6 & 4 & 10 & 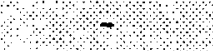 \\
\hline Konar & 20 & 5 & $12 \%$ & 20 & 1 \\
\hline Badakashan & 41 & 8 & 41 ? & 3 & 89 \\
\hline Takhar & 21 & 4 & 18 & 3 & - \\
\hline Baghlan & 54 & 9 & 36 & 2 & 2 \\
\hline Kunduz & 52 & 5 & मै. & 1 & 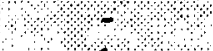 \\
\hline Samangah & 41 & 8 & 5 & - & 1 \\
\hline Balkh & 17 & 10 & 20 & 1 & 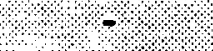 \\
\hline Jawzjan & 26 & 16 & 22 & 7 & + \\
\hline Faryab & 34 & 0 & 12 & 3 & 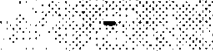 \\
\hline Badghis & 4 & 0 & - & - & $\bullet$ \\
\hline Herat & 21 & 6 & 15 & 4 & 8 \\
\hline Farah & 12 & 2 & 4 & 1 & - \\
\hline Nimroz & 1 & 0 & $\bullet$ & 1 & 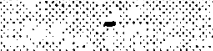 \\
\hline Helmand & 27 & 4 & $=$ & 5 & 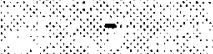 \\
\hline Kandahar & 8 & 0 & 8 & 18 & - \\
\hline Zabul & 16 & 2 & - & 8 & - \\
\hline Oruzgan & 14 & 1 & - & - & - \\
\hline Ghor & 15 & 4 & 7 & 1 & 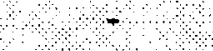 \\
\hline Bamyan & 28 & 1 & 20 & - & - \\
\hline Pakteka & 33 & 4 & 13 & 11 & $=$ \\
\hline Sar-i-Pul & - & & & & \\
\hline TOTAL & 1009 & 190 & 372 & 249 & 207 \\
\hline
\end{tabular}

"Total schools by province combining data collected in 1988 and in 1991. SCA supported 473 schools in 1990; breakdown by provthce, war: not avallable. Totals may include schools double counted and schools not in operation. These estimates are intended, not as a basts for planning, but as an indicator of efforts to establish primary schools working in the cross-bonder.

Sources: $\quad$ ECA/UNO; L. Carter 1988. 
GENERAL EDUCATION

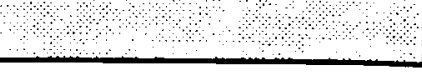

\section{PRIMARY SCHOOLS} CLASSES 1-8
FREE OCCUPATION

\author{
ISLAMIC TEACHING \\ COLLEGES \\ TECHNICAL EDUCATION \\ VOCATIONAL, \\ WORKMANSHIP \\ TECHNICUM \\ HIGHER EDUCATIONAL \\ INSTITUTES, \\ TECHNICAL \& \\ VOCATIONAL \\ INSTITUTES
}

INTERMIEDIATE

CLASSES 7-9
FREE OCCUPATION

TECHNICUM

HIGHER EDUCATIONAL INSTITUTES, TECHNICAL \& VOCATIONAL INSTITUTES
LYCEES

CLASSES 10-12
FREE OCCUPATION

HIGHER TEACHER

TRAINING INSTITUTES

UNIVERSITIES 
Map 1 Population Density By Province

Map 2 Approximate Locations of Internally Displaced Persons

Map 3 Distribution of Major Ethnic Groups by Area

Map 4 Percentage Distribution of Population by Province According to Languages Spoken 
1. Age Structure.

2. Proportion of Mortality Due to Four Major Causes, A Summary of Surveys up to 1978.

3. Summary of Selected Nutritional Surveys in Afghanistan

\section{AGE STRUCTURE POPULATION INSIDE AFGHANISTAN}

(1990)

\begin{tabular}{|c|c|c|c|c|}
\hline & \multicolumn{2}{|c|}{ MALE } & \multicolumn{2}{|c|}{ FEMALE } \\
\hline & $\%$ & No. & $\%$ & No. \\
\hline $0-1$ & 4.19 & 276,909 & 4.20 & 263,001 \\
\hline $1-4$ & 13.14 & 868,397 & 13.22 & 827,826 \\
\hline $5-9$ & 13.59 & 898,137 & 13.64 & 854,126 \\
\hline $10-14$ & 11.70 & 773,230 & 11.72 & 733,897 \\
\hline $15-44$ & 43.41 & $2,868,883$ & 42.80 & $2,680,103$ \\
\hline $45+$ & 13.96 & 922,589 & 14.39 & 901,091 \\
\hline TOTAL & 99.99 & $6,608,806$ & $99: 97$ & $6,261,923$ \\
\hline
\end{tabular}

Difference with totals due to rounding.

- Calculated using South Asian model in the United Nations, Stable Population Age Distribution, (DIESA, 1990); assuming 2.5 growth rate and male life expectancy of 41 years; female life expectancy of 42 years. This model does not account for the higher than normal mortality in males particularly of ages 15-44. 


\section{SUMMARY OF SELECTED NUTRITION ASSESSMENTS IN AFGHANISTAN}

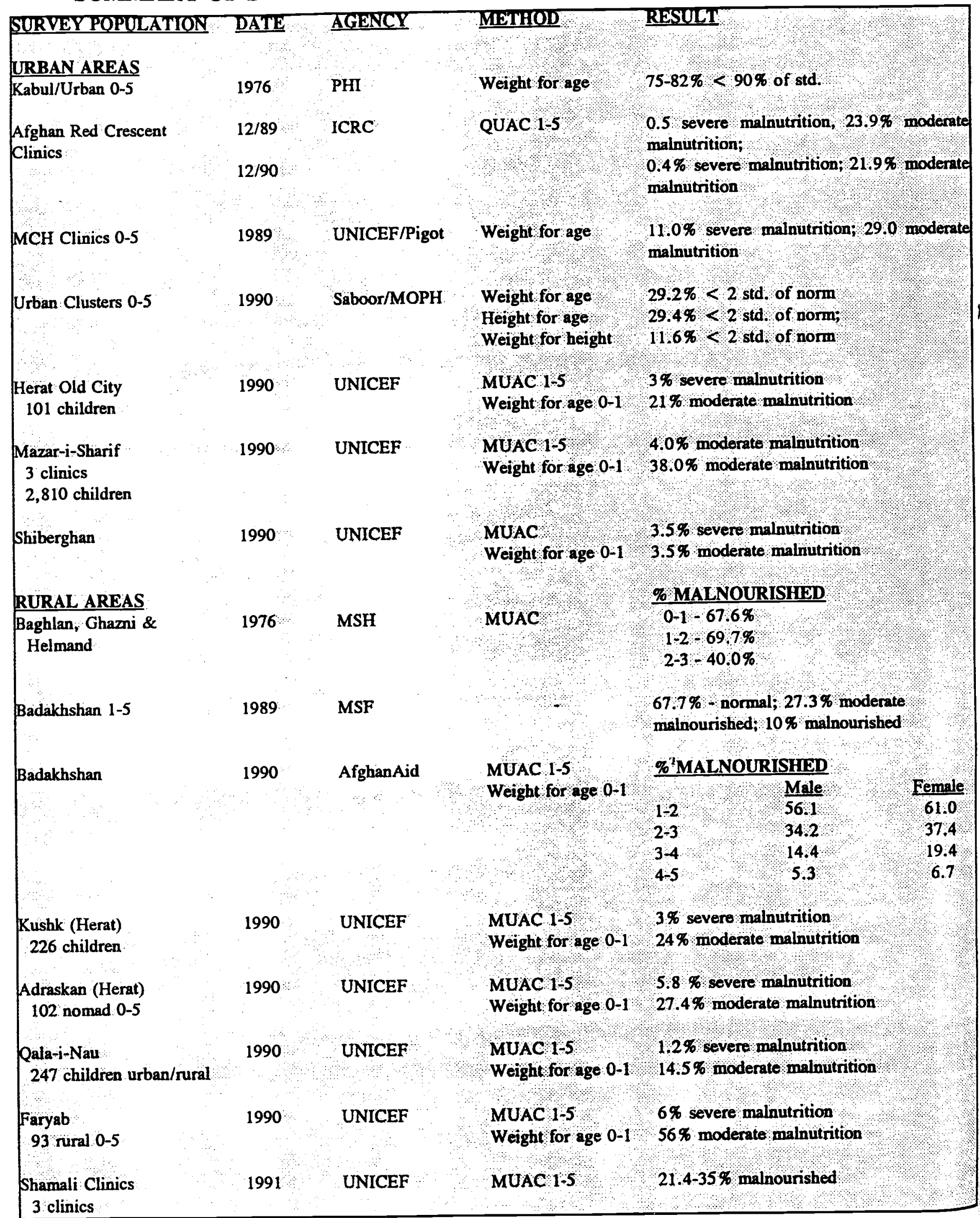




\title{
ANNEX IV
}

NGOs Operating Cross-Border from Pakistan

\begin{abstract}
Budget of ACBAR Members
$1 \cdot$

Breakdown of Member Budgets By Country in Millions of US\$

$2 \cdot$

Refugee and Cross-Border Programmes of ACBAR Members (In Million US\$)

3

ACBAR Members as Employers

A.

ACBAR Directory of Members 1991-92, ACBAR, Peshawar, 1991.

$5^{\mathrm{u}^{\mathrm{urce}}}$
\end{abstract}

1. 


\section{ANNEX V}

Notes on Sources of Population Information

A brief history of modern efforts to count the population of Afghanistan suggests the data problems. The only population census attempted was in 1979 with UNFPA assistance. The results were flawed by circumstances which limited enumeration to an estimated $56 \%$ of the population. Estimation techniques were used to produce the 1979 Government of Afghanistan Census figures. These form a basis of the Ministry of Statistics, UNIDATA, and other projections of current population.

There are several other key attempts to estimate the population of Afghanistan or particular demographic factors. These include or are reported in the following documents:

The Afghan Demographic Survey (ADS) was conducted in 1972-73 with technical support from the State University of New York. Government regarded the ADS overall population figure of 10.2 million settled population as an underestimate. The mortality, growth and other rates were generally incorporated into Government statistics. :

Seven Year Economic and Social Development Plan (1355-1361) presents the population estimates of the Daoud Government just prior to the 1979 Census. It estimated settled population of 14.2 million, plus 2.4 million nomads for a total population of 16.7 million.

Government of Afghanistan, Ministry of Central Statistics, Final Results of the First Population Census of Afghanistan, 1979, is one source of the 1979 Census data.

"Afghanistan: A Demographic Profile", Frank B. Hobbs of the Center for International Research of the U.S. Census Bureau, 1988.

The United Nations High Commission for Refugees (UNHCR) "Refugee Origin Survey" carried out in 1988-89 developed the estimates used in the UNIDATA population projections.

"Afghanistan's Population Inside and Out" by Thomas Eighmy of the Office of the USAID Representative, Afghanistan Affairs, Peshawar, represents an attempt by a participant in the 1973 ADS to estimate current Afghanistan population on the basis of earlier ADS work and on new assumptions about population shifts and change rates.

"Afghanistan: The Decimation of a People", Marek Sliwinski, 1988. Sliwinski analyses and estimates current Afghan population patterns as well as mortality and disability directly due to war related causes. His work is based on previous population data and the results of a 1987 survey in 318 refugee camps in Pakistan. Sliwinski's estimates are expressed as percentages.

- "Estimated Population of Afghanistan 1370 (1991)" published by the Ministry of Statistics in September 1991 is the most recent Government projection. 


\section{BIBLIOGRAPHY}

AfghanAid, "Nutrition Survey Report: Badakhshan, Jawzjan and Faryab", 1990.

Agency Coordinating Body for Afghan Relief (ACBAR), "ACBAR Director of Members 199192", Peshawar 1991.

, ACBAR Task Force for Maternal and Child Health, Final Report, n.d.

Rasil Basu, "Planning and Afghan Women: An Educational Profile of Afghan Women", prepared for the UNIFEM-UNICEF Workshop, 21-23 August 1989.

Inger Boesen, "Afghan Women In Repatriation and Reconstruction", Seminar on the Potential for Recovery in Afghanistan and the Role of International Assistance, UNOCA, Geneva, 5-7 May 1989.

Michael J. Casimir, "Animal Husbandry and Rural Development in Afghanistan". Seminar on the Potential for Recovery in Afghanistan and the Role of International Assistance, UNOCA, Geneva, 5-7 May 1989.

Lynn Carter, "Assessment of Current Activities and Priorities in Primary Education and Teacher Training for Afghans", Consultant to UNICEF, Peshawar, 1988.

Centers for Disease Control (CDC), "Evaluation of Infant Mortality and Childhood Nutritional Status Among Afghan Refugees in Pakistan, 1990", (Rudolf H. Tangermann and Elsie Pamuk), in collaboration with UNHCR and Medicins Sans Frontieres in Islamabad, Peshawar and Quetta.

Christian Science Monitor, Sheila Telft, "Change Challenges Afghan Women", June 28, 1989; Richard Murphy, Afghan Village Begins to Rebuild", August 3, 1989.

Hanne Christiansen, The Reconstruction of Afghanistan: A Chance for Rural Afghan Women, UNRISD, Geneva, 1990.

Hanne Christiansen and Wolf Scott, Survey of the Social and Economic Conditions of Afghan Refugees in Pakistan, UNRISD, Geneva, 1988.

Kathleen Cita, "A Report on Vaccination Progress in Resistance Held Area of Afghanistan as of April 1988", Consultant to UNICEF, April 1988.

Comite International De La Croix Rouge, Rapports de Mission, 19 janvier 1990, 5 janvier 1991.

Conference on Micronutrient Malnutrition, "Ending Hidden Hunger", Montreal, October 1991. 


\section{BIBLIOGRAPHY (continued)}

Kerry M. Connor, "Skill Inventory of Afghan Women Refugees in the North West Frontier and Baluchistan Provinces" UNICEF, Islamabad, December 1988.

The Coordination of Medical Committees (CMC), "Disease in Rural Afghanistan, Green Book Data Analysis, Consolidated Report Data Sets \#1-10" Peshawar, August 1991.

Danish Committee for Aid to Afghan Refugees, "Annual Report", 1989, 1990.

Democratic Republic of Afghanistan, "Afghan Women and Development", First National Seminar, 18-22 April 1987, Reports, in collaboration with UNDP Project AFG/84/016, Kabul 1987.

Development Alternatives, Inc (DAI), computer printout and photocopied material on opium production and prices of agricultural commodities in Afghanistan, Peshawar, September 1991.

Louis Dupree, Afghanistan, Princeton University Press, Princeton, 1978.

Nancy Dupree, "Afghan Women and Agriculture", Briefing Note prepared for the UNIFEMUNICEF Workshop on Planning and Afghan Women, 21-23 August 1989.

"Women in Afghanistan, A Preliminary Needs Assessment", prepared for the United Nations Development Fund for Women (UNIFEM) 1988.

Richard English, "Preliminary Report on Conditions Affecting the Repatriation of Afghan Refugees" prepared for the Operational Unit for Repatriation to Afghanistan, United Nations High Commission for Refugees", June 1988.

Richard G. Feacham, "Environmental Sanitation in Afghanistan; Án Integrated Approach", a report to the Government of Afghanistan and UNICEF, Kabul, 1978.

Food and Agricultural Organization Office, Kabul, Afghanistan; photocopied estimates of cereal production and cereal requirements in Afghanistan.

Government of Afghanistan, Central Statistics Office, Population Census Project, "Estimates of the Population of Afghanistan in 1357 and Projection of the Population for the Years 13581362", Kabul, 1357.

Ministry of Planning, First Seven-year Economic and Social Development Plan, 135 - 1361 (March 1976 - March 1983). 


\section{BIBLIOGRAPHY (continued)}

, Ministry of Public Health and the World Health Organization, "Infant

and Early Childhood Mortality in Relation to Fertility Patterns", Report on an Ad Hoc Survey in Greater Kabul, Afghanistan, 1972-1975, Kabul 1978.

"Gulbadan Habibi, "Disability among Afghan Women - Its Impact on Child Survival and Development and the Quality of Life of the Family", prepared for the UNIFEM - UNICEF Workshop on Planning and Afghan Women, 21-23 August 1989.

Handicap International, Afghanistan Programmes Newsletter, July 1991, August 1991.

Month Report June 1991.

"Rehabilitation Centre for Afghan Refugees in Balouchistan", Six

Cynthia Lawrence Haq, "Status of Women and Children Refugees", Report to the Women's Commission for Refugee Women and Children, International Rescue Committee, March 1989.

Frank B. Hobbs, "Afghanistan: A Demographic Profile" Asia, Europe, North America and Oceania Branch, Center for International Research, Bureau of the Census, U.S. Department of Commerce, Washington, D.C., January 1988.

Susan Holcombe, "Water Supply and Sanitation in Afghan Schools; Analysis of a 1974 Survey", UNICEF, Kabul 1978.

1978.

"Women's Employment Patterns", Briefing Note, UNICEF, Kabul,

Pamela Hunte, "Women and the Development Process in Afghanistan", USAID, AID/NE-C1487 Afghanistan Project:298-035, Kabul 1979.

Anne E. Hurd and Stephen J. Masty, "Opium Poppy Cultivation, Nangarhar Province, Afghanistan, 1990" prepared for The United Nations Fund for Drug Abuse Control, Peshawar, 1990.

Catherine Lidwell, "Baseline Survey on the Female Health Worker Programme in Afghan Refugee Villages, NWFP, Pakistan (1987/1988), Save the Children Fund UK, 1990.

Nancy MacPherson and B.K. Fernando, "Opportunities for Improved Environmental Management in Afghanistan", Consultants to UNOCA, Kabul, 1991.

Management Sciences for Health (MSH), computer printout on immunization results for 1990 Programme of Immunization Cross-border, Peshawar 1991. 


\section{BIBLIOGRAPHY (continued)}

Wardak Province" (Youssef Tawfik), March 1991.

, "Demographic and Health Household Survey in Afghanistan, "Financial Analysis of Health Programs" Kabul, 1977.

Planning of Health Services", "Aabul, 1977.

Padmini Mendis, "Report on CADA Short-term Consultancy to Pakistan", March 1989.

Valentine Moghadam, "Patriarchy, the State and Women in Afghanistan: Problems and Prospects", prepared for the UNIFEM - UNICEF Workshop, 21-23 August 1989.

Robert R. Nathan Associates, Inc, and Louis Berger International, Inc., "Afghanistan MacroEconomic Database Development", submitted to the Office of the AID Representative for Afghanistan Affairs, January 1990.

Dennis Pigot, "Health and Nutrition in Kabul, Herat and Mazar-i-Sharif: A Preliminary Assessment", UNICEF Consultant, 1989.

Rehabilitation International/UNICEF Technical Support Programme to Prevent Childhood Disabilities and to Help Disabled Persons, One in Ten, Vol 19, Issue 2-3, 1991.

Republic of Afghanistan, "Country Presentation to the Second United Nations Conference on the Least Developed Nations" UNCTAD, 1990. Kabul City, 1986, Volume I, Kabul, 1987, (UNIDATA translation).

Afghanistan" n.d.

, Ministry of Education, "Education for All in the Republic of , Education Statistics 1988, 1990; preliminary statistics 1991.

Ministry of Planning, "Socio-Economic Situation and Programme for

the 1990s", July 1989.

(1991) Kabul, September 1991.

Ministry of Statistics, "Estimated Population of Afghanistan 1370" 


\section{BIBLIOGRAPHY (continued)}

Statistical Yearbook 1990-91, Kabul 1991.

P. Rezai, "Health and Nutrition Survey of Afghan Refugees in the Islamic Republic of Iran", Consultant Epidemiologist, UNHCR, 1988.

Olivier Roy, "Afghanistan: The Social Aspects of Recovery in a Fragmented Society", Seminar on the Potential for Recovery in Afghanistan and the Role of International Assistance, Geneva, UNOCA, 5-7 May 1989.

Cambridge, 1988.

Islam and Resistance in Afghanistan, Cambridge University Press,

Richard B. Scott, "Afghan Social Structure and the Development Process: Power and the Rural Scene" mimeo 1975.

Shrestha, "Status of Education in Afghanistan", UNICEF Consultant, Kabul, December 1989.

Marek Sliwinski, "Afghanistan: The Decimation of a People", Orbis, Winter 1989.

Peter Street, "Wheat Price Stabilisation and Strategic Storage Reserve Scheme for Afghanistan" UNDP Consultant, Kabul 1977.

M.C. Swaminathan, "Nutrition in Afghanistan", WHO Consultant, Kabul 1987.

The Swedish Committee for Afghanistan, "Annual Report 1990", Peshawar, 1990.

, "The Agricultural Survey of Afghanistan" First Report, Peshawar 1988.

" 1988 and 1989 Surveys", Sixth Report, Peshawar, 1990.

, "Northern Afghanistan Food Deficit Survey" Ninth Report, Peshawar,

November 1990

, "Livestock", Tenth Report, Peshawar, November 1990.

Linda Tawfiq, "A Proposed Maternal and Child Health Strategy for the Afghanistan Health Sector Support Project", Consultant Report to Management Sciences for Health, Boston, 1988.

United Nations, Department of International Economic and Social Affairs, Stable Population Age Distributions, New York, 1990. 


\section{BIBLIOGRAPHY (continued)}

UNICEF, " Afghanistan: Emergency Winter Relief Project", November 1989, Programme Funding Office, New York, 1989.

Consultant, Kabul, 1990, 1988.

"Immunization Coverage Surveys 1990 and 1988", Aminullah Saboor, , "Project Proposal: Improvement of the Situation of Afghan Women and Children in the Islamic Republic of Iran", Teheran, 1990.

September 1989.

"Situation Assessment of Afghan Women and Children, Peshawar, , State of the World's Children, 1991.

, "Statistical Profile of Children and Mothers in Afghanistan" Kabul 1977.

October 1978. "Statistical Profile of children and Mothers in Afghanistan" Kabul, , "UNICEF Winter Emergency Relief Project Afghanistan 1991/92" First Draft for Discussion, Kabul 1991.

UNICEF and UNIFEM, "Planning and Afghan Women," Report from the Workshop 21-23 August 1989, New York 1989.

UNIDATA, "Afghanistan: Population Estimates By Province, District and Sub-District, a Graphic Presentation", Kabul, April 1991.

"Comparative Analysis of Consumer Prices and Foreign Exchange Rates in Kabul City 1978-1990", Kabul, May 1991.

"Movement of Prices of Major Food and Non-Food Items in Afghanistan, 1988-1990" Kabul, March 1991.

, "Socio-Economic Profiles", Bamyan, Samangan, Wardak, 1991.

United Nations Centre for Human Settlements (Habitat), 'Mission Report - Afghanistan" January to April 1990. 


\section{BIBLIOGRAPHY (continued)}

United Nations Coordinator for Humanitarian and Economic Assistance Programmes Relating to Afghanistan, First and Second Consolidated Reports, Geneva, 1988, 1989, 1990.

Priorities, Geneva, 1988.

Committee on Assistance to Disabled Afghans, Guidelines and , Plan of Action 1990, 1991.

Kristiansson, February-March 1991) Peshawar 1991. , Salam Mission Reports, 1988, 1989,1990,1991.

United Nations Development Programme, "Development Cooperation Report, Afghanistan, 1989", Kabul.

Relief, Rehabilitation and Reconstruction in Afghanistan", 1988.

, "A Programme for Rehabilitation and Reconstruction in Afghanistan" Adbul Maal A. Muhith, Senior Consultant, November 1990.

United Nations Fund for Population Activities, State of the World's Population, 1991.

United Nations High Commission for Refugees, "Diarrhoea Morbidity, Mortality and Treatment Practices" Report of a Survey conducted by UNHCR among Afghan Refugees in North West Frontier Province, Pakistan, 1989, (Dr. Andrew Smith, UNHCR Health Coordinator), Peshawar, 1989.

, "EPI Surveys 1989/90, Consolidated Statistical Results, 1990.

, "Report on the Expanded Programme for Immunization for the Afghan Refugee Health Programme for 1988, Islamabad, April 1989.

Programme for Afghan Refugees, TSS Consultancy Report, Pakistan, 1989.

Mark Urban, War in Afghanistan, Macmillan, London, 1990.

USAID, "Afghanistan: Assessment of Current Harvest and Food Supplies", 1989. 
World Bank, Afghanistan: The Journey to Economic Development, Vols. I and II, 1978. Social Indicators of Development, 1989.

World Food Programme Office, Kabul, Afghanistan: Current data on food aid receipts and distribution in Afghanistan, October 1991.

World Health Organization, Maternal Mortality: A Global Factbook, Geneva, 1991

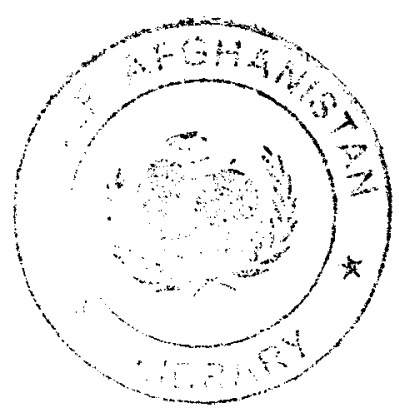

